\title{
ipen
}

Autarquia Associada à Universidade de São Paulo

\section{DETERMINAÇÃO DE ELEMENTOS ESSENCIAIS E TÓXICOS EM COGUMELOS COMESTÍVEIS POR ANÁLISE POR ATIVAÇÃO COM NÊUTRONS}

PATRICIA LANDIM DA COSTA MOURA

Dissertação apresentada como parte dos requisitos para obtenção do Grau de Mestre em Ciências na Área de Tecnologia Nuclear-Aplicações.

Orientadora:

Dra. Vera Akiko Maihara

SÃO PAULO

-2008- 


\section{ton}

Autarquia Associada à Universidade de São Paulo

\section{DETERMINAÇÃO DE ELEMENTOS ESSENCIAIS E TÓXICOS EM COGUMELOS COMESTÍVEIS POR ANÁLISE POR ATIVAÇÃO COM NÊUTRONS}

PATRICIA LANDIM DA COSTA MOURA

Dissertação apresentada como parte dos requisitos para obtenção do Grau de Mestre em Ciências na Área de Tecnologia Nuclear - Aplicações.

Orientadora:

Dra. Vera Akiko Maihara

SÃO PAULO

-2008 - 
À memória de Eugenia 


\section{AGRADECIMENTOS}

À Dra. Vera Akiko Maihara, pela orientação e esclarecimentos no decorrer deste trabalho, pela paciência e amizade.

Ao Laboratório de Analise por Ativação Neutrônica (LAN) do IPEN-CNEN/SP, pela oportunidade concedida para realizar o trabalho experimental.

Às minhas filhas Caroline e Beatriz, meu esposo Cláudio pela compreensão de minha ausência no decorrer desta pesquisa.

Às amigas Lílian e Paola, presentes em muitos momentos nessa jornada, incentivando, apoiando e compartilhando momentos difíceis e agradáveis.

Aos meus pais, pelas orações, pela educação que me deram e incentivo, em todos os momentos de minha vida.

A todos de minha grande família, meus irmãos, irmãs, sobrinhos, sobrinhas, tios, tias, primos, primas, cunhados, cunhadas e em especial a minha sobrinha Luciana pelo auxilio no Inglês e a todos que torceram pela conclusão deste trabalho.

Às amigas Cláudia, Eliane, Edineide, Selma e Roseane pela amizade e convívio.

A Orlando e "Chiquinha”, pelo apoio e incentivo.

Ao Dr Rubens, pelas sugestões, apoio e amizade.

E em especial meu agradecimento a DEUS, por estar sempre presente em minha vida, enchendo-me de forças para concluir este trabalho e continuar lutando em busca de novos conhecimentos. 
“Você não pode provar uma definição.

O que você pode fazer é mostrar que ela faz sentido."

Albert Einstein 


\title{
DETERMINAÇÃO DE ELEMENTOS ESSENCIAIS E TÓXICOS EM COGUMELOS COMESTÍVEIS POR ANÁLISE POR ATIVAÇÃO COM NÊUTRONS
}

\author{
PATRICIA LANDIM DA COSTA MOURA
}

\section{RESUMO}

Neste trabalho foram determinados os elementos $\mathrm{As}, \mathrm{Br}$, Co, Cr, Cs, Fe, K, Na, Rb, Se e Zn presentes em cogumelos comestíveis adquiridos em grandes centros de compra (supermercados), mercados municipais da cidade de São Paulo e diretamente de produtores da região de Mogi das Cruzes, Suzano, Juquitiba e Mirandópolis. A técnica analítica empregada para a determinação dos elementos nos cogumelos comestíveis foi a Análise por Ativação com Nêutrons Instrumental (INAA). Foram adquiridas espécies dos gêneros Agaricus, Lentinus e Pleurotus no período de novembro de 2006 a março de 2007. Cerca de 150 a 200 mg das amostras de cogumelo liofilizado foram irradiadas em fluxo de nêutrons térmicos de $10^{12} \mathrm{~cm}^{-2} \mathrm{~s}^{-1}$ por 8 horas no reator nuclear de pesquisa IEA-R1 do IPEN/CNEN/SP. Para a validação da metodologia com relação à exatidão e à precisão foram analisados quatro materiais de referência: INCT-MPH-2 Mixed Polish Herbs e INCT-TL-1 Tea Leaves, NIST SRM 1577b Bovine Liver e Mushroom da IAEA. Foi verificada uma variação nas concentrações dos elementos determinados entre os diferentes gêneros. Em algumas amostras apresentaram o elemento arsênio, em baixas concentrações, possivelmente de uma contaminação no cultivo pelo uso de pesticidas nos substratos de onde os cogumelos retiram seus nutrientes. Os resultados mostram que as amostras das espécies de cogumelos analisadas podem ser consideradas como boa fonte nutricional, principalmente devido aos baixos teores de Na, sendo também uma boa fonte de K, Fe e Zn. 


\title{
ESSENTIAL AND TOXIC ELEMENT \\ DETERMINATION IN EDIBLE MUSHROOMS BY \\ NEUTRON ACTIVATION ANALYSIS
}

\section{PATRICIA LANDIM DA COSTA MOURA}

\begin{abstract}
In this study concentrations of $\mathrm{As}, \mathrm{Br}, \mathrm{Co}, \mathrm{Cr}$, Cs, Fe, K, Na, Rb, Se and $\mathrm{Zn}$ were determined in edible mushrooms acquired from commercial establishments in the city of São Paulo and directly from Mogi das Cruzes, Suzano, Juquitiba and Mirandópolis producers. The analytical technnique used for determining these elements in edible mushrooms was Instrumental Neutron Activation Analysis (INAA). Species of the Agaricus, Lentinus and Pleurotus genera were acquired during the period from November, 2006 to March, 2007. About 150 to $200 \mathrm{mg}$ of freeze-dried mushrooms were irradiated in a neutron flux of $10^{12} \mathrm{~cm}^{-2} \mathrm{~s}^{-1}$ for 8 hours in the IEA-R1 nuclear research reactor at IPENCNEN/SP. In order to evaluate the precision and accuracy of the methodology, four reference materials: INCT-MPH-2 Mixed Polish Herbs and INCT-TL-1 Tea Leaves, NIST SRM 1577b Bovine Liver, and the material Mushroom from IAEA were analyzed. Results showed some variation in the element concentrations among the different genera. In some samples, arsenic was found but in low concentrations. Arsenic is probably derived from the contamination from pesticides used in the cultivation, in their the substrates where mushrooms uptake their nutrients. Although there are element concentration variations, mushrooms can still be considered a very rich nutritional source, mainly because of their low concentratios of $\mathrm{Na}$, and due to the good source of K, Fe and $\mathrm{Zn}$.
\end{abstract}




\section{SUMÁRIO}

Página

CAPÍTULO 1

1.INTRODUÇÃ

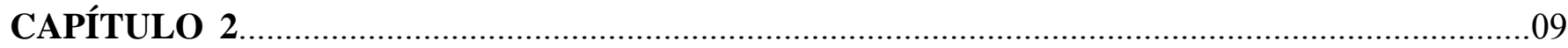

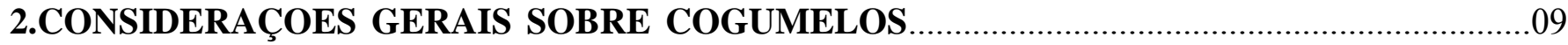

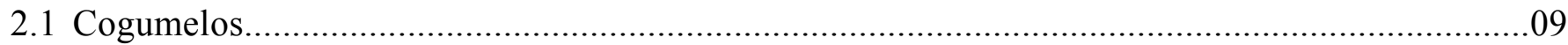

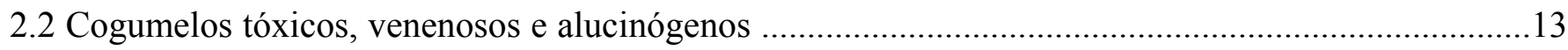

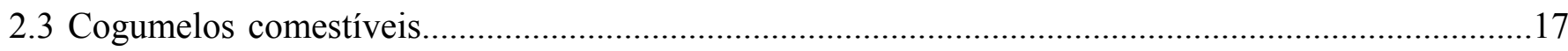

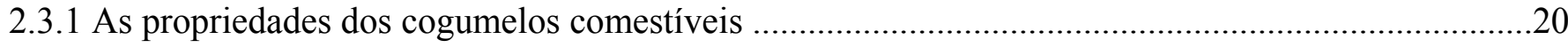

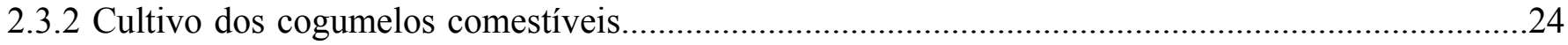

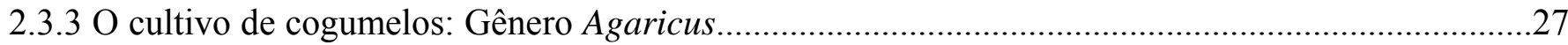

2.3.4 O cultivo de cogumelos: Gênero Pleurotus............................................................................

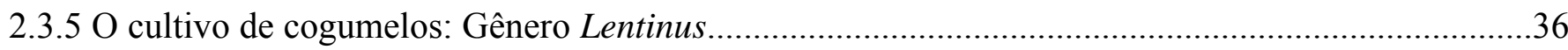

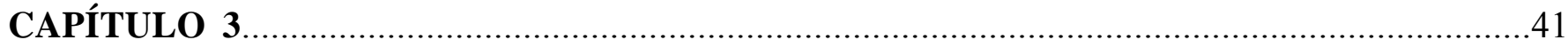

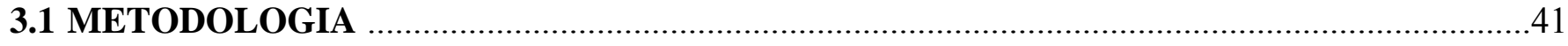

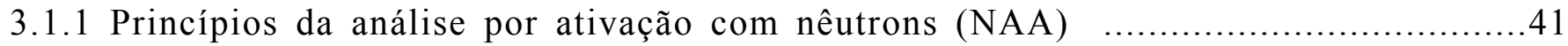

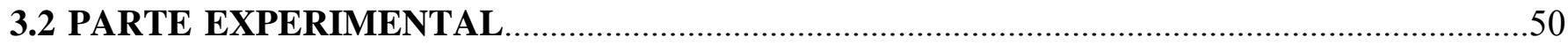

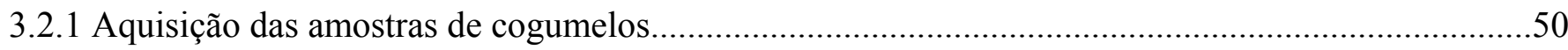

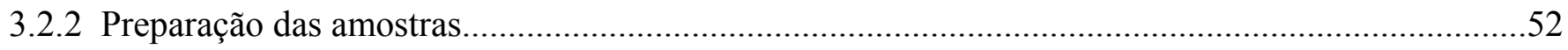

3.2.3 Preparação das amostras para irradiação..................................................................................55

3.2.4 Preparação dos padrões sintéticos dos elementos....................................................................55 
3.2.5 Preparação dos materiais de referência para análise

3.2.6 Irradiação das amostras e dos padrões sintéticos...............................................................57

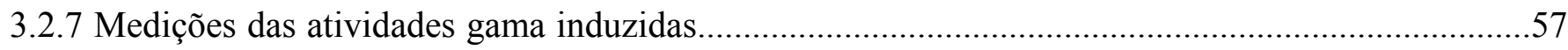

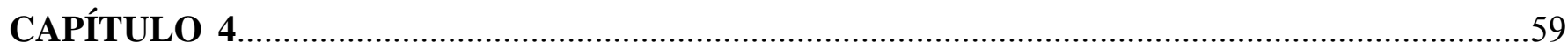

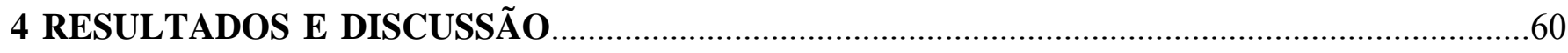

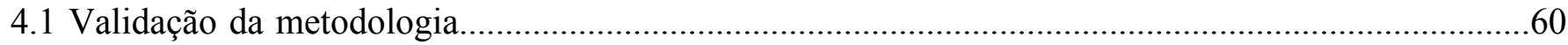

4.2 Determinação dos valores dos limites de detecção.....................................................................64

4.3 Determinação dos elementos presentes nos cogumelos comestíveis............................................66

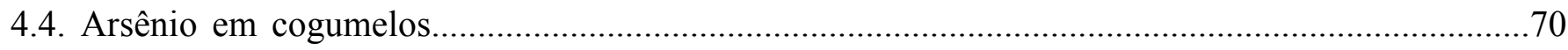

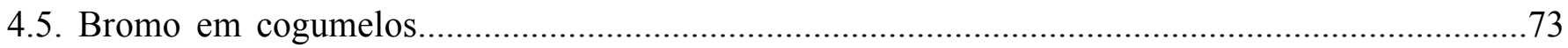

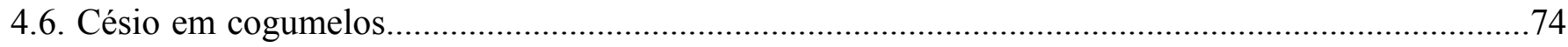

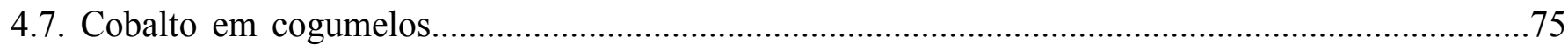

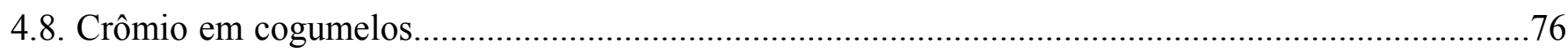

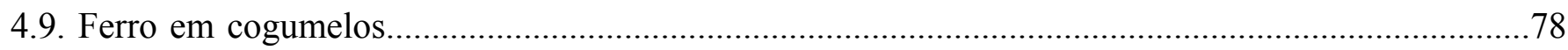

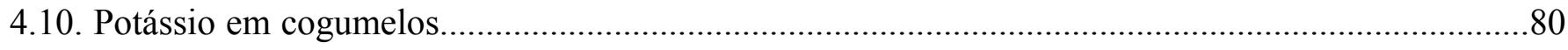

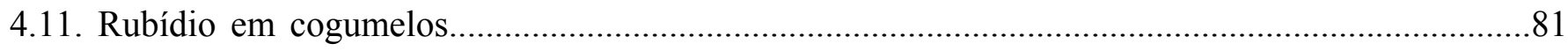

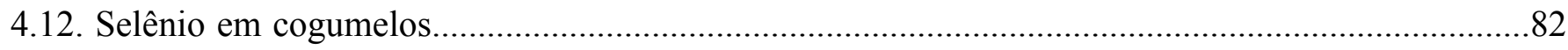

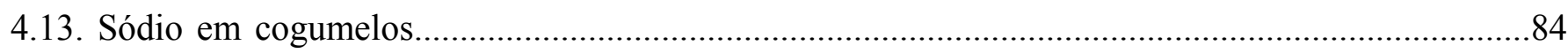

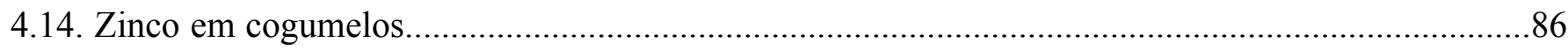

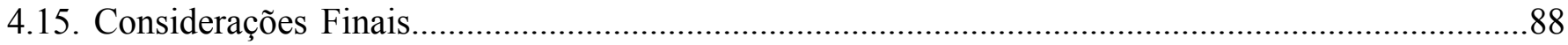

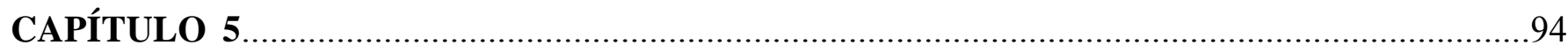

CONCLUSÃO

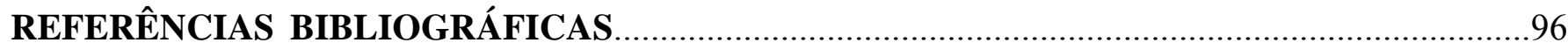




\section{LISTA DE FIGURAS}

Figura

Página

2.1 Classificação do Reino Fungi

2.2 Partes do cogumelo.

2.3 Diferentes tipos de píleo 12

2.4 Diferentes tipos de estipe 12

2.5 Espécie de cogumelo P. cubensis 16

2.6 Espécie de cogumelo Amanita muscaria 16

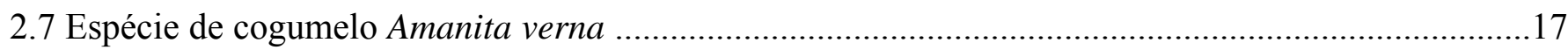

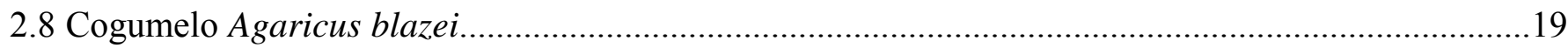

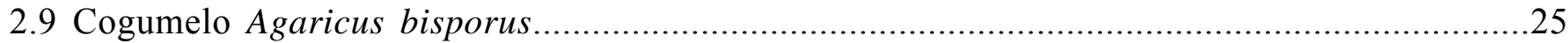

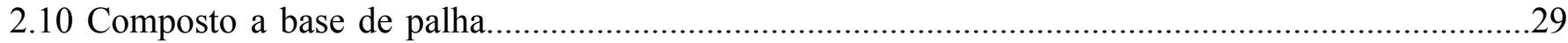

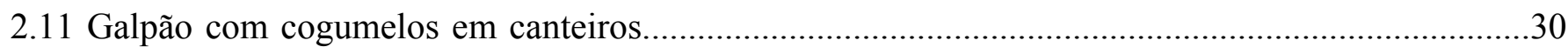

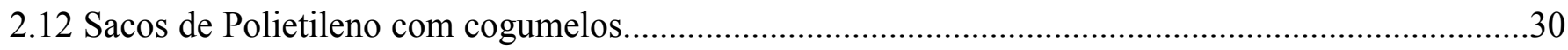

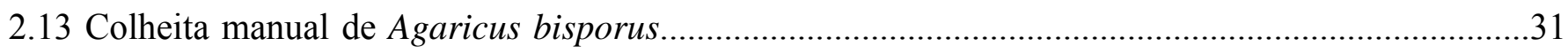

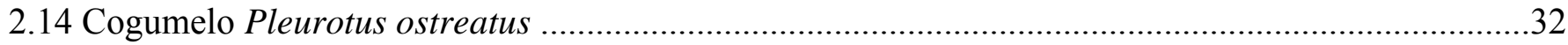

2.15 Troncos colocados sob florestas para o cultivo de cogumelos Pleurotus.......................................35

2.16 Cogumelos Lentinus edodes em troncos de árvores..................................................................36

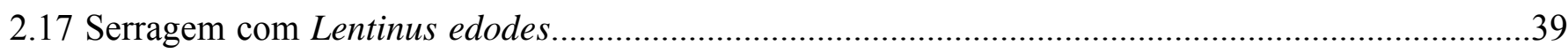

3.1 Seqüência de eventos do mecanismo da reação nuclear do tipo $(n, \gamma)$..........................................43

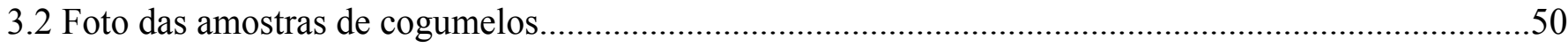

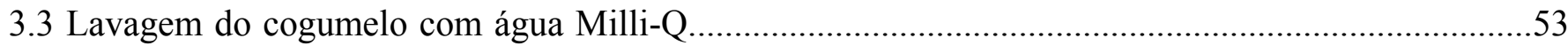




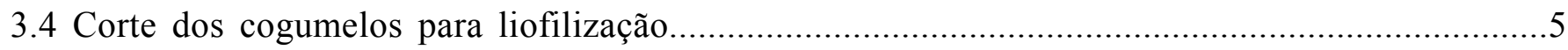

3.5 Cogumelos nas placas de Petri para liofilização......................................................................

3.6 Liofilizador Modulyo D-115..................................................................................................54

3.7 Liquidificador para homogeneização dos cogumelos................................................................................

3.8 Sistema de Espectrometria gama com detector de Ge hiperpuro.......................................................58

4.1 Valores de $\mathrm{E}_{\mathrm{n}}$ - score para os elementos determinados nos materiais de referência Mushroom, Mixed Polish Herb(MPH), Tea Leaves (TL) e Bovine Liver (BL).....................................................................64

4.2 Distribuição dos teores de arsênio nas diferentes espécies de cogumelos..............................................71

4.3 Distribuição dos teores de bromo nas diferentes espécies de cogumelos...............................................73

4.4 Distribuição dos teores de césio nas diferentes espécies de cogumelos................................................74

4.5 Distribuição dos teores de cobalto nas diferentes espécies de cogumelos.........................................75

4.6 Distribuição dos teores de crômio nas diferentes espécies de cogumelos..........................................77

4.7 Distribuição dos teores de ferro nas diferentes espécies de cogumelos...........................................78

4.8 Distribuição dos teores de potássio nas diferentes espécies de cogumelos.....................................80

4.9 Distribuição dos teores de rubídio nas diferentes espécies de cogumelos......................................81

4.10 Distribuição dos teores de selênio nas diferentes espécies de cogumelos......................................83

4.11 Distribuição dos teores de sódio nas diferentes espécies de cogumelos......................................85

4.12 Distribuição dos teores de zinco nas diferentes espécies de cogumelos..............................................86

4.13 Concentração de As, Br, Co, Cs, Cr e Fe para diferentes gêneros de cogumelos................................90

4.14 Concentrações de K, Na, Rb, Se e Zn para diferentes gêneros de cogumelos.......................................91 


\section{LISTA DE TABELAS}

Tabela

Página

1. Composição química dos cogumelos em relação a outros alimentos (\% peso fresco).........................20

2. Composição química de algumas espécies de cogumelos (\% de matéria seca)....................................22

3 Nomenclaturas científicas, comerciais, procedências e características das amostras de cogumelos comestíveis .51

4- Concentração dos elementos nas soluções estoque dos padrões e massa dos elementos irradiados ...56

5 Meia-vida e energia da radiação gama dos radioisótopos (IAEA, 1990)

4.1 Concentração dos elementos obtidos no material de referência Mixed Herb Polish (INCT-MPH-2)..61

4.2 Concentração dos elementos obtidos no material de referência Tea Leaves (INCT-TL-1).................62

4.3 Concentração dos elementos obtidos no material de referência IAEA Mushroom.............................62

4.4 Concentração dos elementos obtidos no material de referência Bovine Liver NIST SRM 1577b.......63

4.5 Valores de Limite de Detecção para amostra de cogumelo.........................................................65

4.6 Concentrações dos elementos presentes nos cogumelos do gênero Pleurotus por INAA (em peso seco) .67

4.7 Concentrações dos elementos presentes nos cogumelos do gênero Agaricus por INAA (em peso seco) .68

4.8 Concentrações dos elementos presentes nos cogumelos do gênero Lentinus por INAA (em peso seco)

4.9 Média e Desvio Padrão dos elementos determinados nos 3 gêneros de cogumelos comestíveis. . .89 


\section{CAPÍTULO 1}

\section{INTRODUÇÃO}

Os fungos são organismos eucariontes, heterotróficos, não podendo fabricar matéria orgânica a partir de carbono inorgânico, pois não apresentam pigmentos fotossintéticos. O estudo dos fungos é chamado de Micologia (LAURENCE, 2005).

Segundo GUERREIRO (2003), durante muitos anos, os fungos foram considerados como vegetais. Porém, a partir de 1969, passaram a ser classificados em um reino à parte. Por apresentarem características próprias, tais como, não sintetizarem clorofila, não possuírem celulose na sua parede celular (exceto alguns fungos aquáticos) e não armazenarem amido como substância de reserva, os fungos foram diferenciados das plantas.

Os fungos constituem um grupo de organismos com enorme variedade de formas, cores e tamanhos. A coloração dos fungos é bem diversificada, variando do branco ao negro, passando por tons de amarelo, laranja e marrom; sendo mais raros, porém belíssimos, os fungos azulados, rosados e esverdeados. Como todos os seres vivos, os fungos são constituídos de células, podendo ser unicelulares, quando formados por células isoladas, e pluricelulares, quando as células são agrupadas em filamentos. Os filamentos dos fungos pluricelulares são denominados hifas (BONONI e col., 1999).

O conjunto de hifas entrelaçadas forma o micélio. O micélio que se desenvolve no interior do substrato, funcionando também como elemento de sustentação e de absorção de nutrientes, é chamado de micélio vegetativo. O que se projeta na superfície e cresce 
acima do meio de cultivo é o micélio aéreo e este, quando se diferencia para sustentar seus órgãos de disseminação (corpos de frutificação ou propágulos), constitui o micélio reprodutivo.

Para obter alimento, os fungos dependem de matéria orgânica pronta que é absorvida pelas hifas. As substâncias assimiladas são distribuídas através de uma corrente citoplasmática que percorre todas as células do fungo. Conforme os tipos de alimentos que utilizam, os fungos são classificados em saprobióticos, parasitas e simbióticos (HERREIRA, 2001).

Os fungos saprobióticos alimentam-se de matéria orgânica em decomposição; portanto decompõem as estruturas orgânicas complexas, que restam de plantas e animais, podendo se desenvolver em folhas caídas, excrementos de animais, em tocos de madeira morta entre outros. Os cogumelos, devido à sua forma de obterem nutrientes, encontram-se neste grupo.

Fungos parasitas colonizam matéria orgânica viva, isto é, vivem sobre ou dentro do hospedeiro, que pode ser o homem, animais ou vegetais, tendo como representantes os fungos causadores de micoses.

Os fungos simbióticos são aqueles que vivem associados a outros seres vivos, como os formadores de liquens, ou associam-se à parte de organismos, como os encontrados nas raízes de algumas espécies de plantas superiores, formando as micorrizas.

Algumas espécies de fungos que formam associações micorrízicas são comestíveis, por exemplo, o Suillus edulis, conhecido como "funghi secchi” dos italianos. No Brasil, este fungo vive associado ao pinheiro e ao cedrinho, sendo comum em áreas de reflorestamento principalmente no outono e primavera. (BONONI e col.., 1999). 
Cerca de 200.000 espécies diferentes de fungos estão distribuídas na natureza, classificadas em vários grupos de acordo com uma série de características, principalmente em relação a estruturas de reprodução (BONONI e col., 1999).

À primeira vista, os fungos são pouco interessantes. Mas eles contribuem de forma decisiva para a preservação da diversidade biológica do nosso planeta e estão presentes, de inúmeras formas, no nosso cotidiano. O pão que comemos necessita de um fungo, que age como fermento biológico. Essa levedura é o Saccharomyces cerevisae, fungo unicelular, base para muitas indústrias, além da panificação.

A cerveja e todas as bebidas alcoólicas feitas a partir da fermentação também são produtos fúngicos. Um dos importantes usos dos fungos é a produção de medicamentos. A primeira e a mais famosa de todas as substâncias medicamentosas extraída dos fungos foi a penicilina, descoberta em 1929 por Alexandre Fleming. A penicilina foi o primeiro antibiótico a ser produzido industrialmente.

Os cogumelos comestíveis fazem parte de dois grandes grupos de fungos: ascomicetos e basidiomicetos. Os ascomicetos são as trufas subterrâneas, como o Morchella, um cogumelo utilizado como aromático, porém, não existe cultivo deste grupo no Brasil. Os cogumelos do grupo dos basidiomicetos são mais conhecidos por nomes populares como: champignon e orelhas - de - pau.

Os cogumelos têm sido parte da diversidade dos fungos há aproximadamente 300 milhões de anos. Na pré-história, os humanos já utilizavam os cogumelos selvagens coletados em florestas como alimento. As primeiras civilizações gregas, egípcias, romanas, chinesas e mexicanas, apreciavam os cogumelos como um manjar dos deuses; eles tinham conhecimento sobre suas propriedades terapêuticas e freqüentemente utilizavam cogumelos em cerimônias religiosas (CHANG e MILES, 2004). 
Existem aproximadamente 45 mil espécies de cogumelos descritas na literatura. Destas, cerca de duas mil são conhecidas como comestíveis, mas somente pouco mais de 25 espécies são cultivadas e aceitas como alimento e somente 10 espécies têm se tornado produto de larga comercialização (URBEN e SIQUEIRA, 2003).

Inúmeras pesquisas relatam que, em geral, os cogumelos comestíveis são alimentos de alto valor nutricional, com baixo teor de carboidratos e de gordura, além de possuírem significativas quantidades de proteínas e vitaminas (SESLI e TUZEN, 2006).

De acordo com URBEN e SIQUEIRA (2003), os cogumelos apresentam elevados teores de proteínas, vitaminas (complexo B, C e D), riboflavina, niacina e biotina.

FURLANI e GODOY (2007) determinaram que os cogumelos do tipo champignon, shitake e shimeji, devido à sua composição química, constituem um alimento com excelente valor nutritivo, pois apresentam altos teores de proteínas e fibras alimentares e uma quantidade considerável de fósforo.

O cultivo de algumas espécies de cogumelos vem crescendo significativamente, devido ao bom retorno econômico, pois podem ser cultivados em pequenas áreas e com baixo investimento inicial.

A forma de cultivo dos cogumelos depende do tipo de nutrição de cada espécie e de suas exigências climáticas, que podem ser ligeiramente diferentes em função da região do globo terrestre, de onde tenham evoluído, ou de melhoramentos genéticos que tenham sido submetidos (EKANEN e UBENGAMA, 2002).

Alguns cogumelos são cultivados em substratos, genericamente chamados de compostos. Para cada espécie existe um tipo de composto mais adequado, como por exemplo, palha de cana, bagaço de cana, folha de bananeira, serragem, troncos de árvores, etc. O cogumelo é inoculado nesses substratos, portanto, economicamente constitui uma 
cultura que permite a reciclagem de diversos resíduos agrícolas e agroindustriais (FURLANI e GODOY, 2005).

A influência do substrato na composição química do cogumelo é bastante significativa, pois esses organismos retiram seus nutrientes por meio das hifas que ficam em contato direto com esse material. Dessa forma, absorvem elementos essenciais, mas juntamente com estes podem vir acumular metais tóxicos como: chumbo, mercúrio, cádmio, arsênio e outros (RANDA e KUCERA, 2003).

Algumas espécies de cogumelos têm sido utilizadas como bioindicadores de poluição ambiental. Uma vez que a composição química dos cogumelos pode estar relacionada ao substrato, uma região poluída apresentará cogumelos com altos níveis de metais, como já foi observado por KALAC e SYOBODA (1999) que analisaram diferentes espécies de cogumelos e determinaram que a espécie Agaricus silvaticus acumula altos níveis de cádmio e a espécie Lepista nuda pode conter grande quantidade de mercúrio, quando expostas à poluição.

Atualmente, os cogumelos são considerados pelos pesquisadores como alimentos nutracêuticos ou funcionais fisiológicos, fato que tem estimulado também os atuais produtores brasileiros e novos produtores na busca de técnicas mais produtivas e na introdução de outras espécies (FURLANI, 2004).

Outro fator importante em relação aos cogumelos é a sua utilização como alimentos terapêuticos, pois de acordo com BODEK e GALBAVY (1999) eles podem ser úteis na prevenção de hipertensão e câncer. Os cogumelos da espécie Pleurotus sp (hiratake e shimeji) podem ser classificados como alimentos ou condimentos no realce do sabor para pacientes com hipertensão ou outras doenças cardíacas, onde há restrição de sódio, pois os mesmos apresentam valores muitos baixo deste mineral (STURION e RANZANI, 2000). 
Dados reportados por FURLANI e GODOY (2007) mostram que, em 1993, a produção mundial foi de 1,95 milhões de toneladas, e que saltou para 3,19 milhões de toneladas em 2003, ou seja, mais de 60\% em 10 anos.

O Brasil não possui dados oficiais sobre a produção de cogumelos, seu maior centro produtor encontra-se na região de Mogi das Cruzes em São Paulo (BONONI e col., 1999).

Informação a respeito da composição de alimentos tem se tornado cada vez mais importante para avaliar a sua qualidade. Constituintes como vitaminas, proteínas, lipídeos, fibras e minerais têm se tornado uma importante preocupação para profissionais da área da saúde e de alimentos. O consumidor também tem se interessado por produtos com melhor qualidade e que contenham informações adequadas. Os cogumelos comestíveis têm despertado interesse em seu valor nutricional e especialmente a respeito de diferenças entre espécies cultivadas no Brasil.

Inúmeras técnicas analíticas como a espectrometria de emissão atômica com plasma de argônio acoplado indutivamente (ICP OES), espectrometria de absorção atômica (AAS), análise por ativação com nêutrons instrumental (INAA), têm sido utilizadas para a determinação de minerais, elementos traço e metais em cogumelos.

OUZOUNI e col. (2007) utilizaram a AAS, para determinar os elementos: Al, As, Cd, Co, Cr, Cu, Fe, Mg, Mn, Ni, Pb, Sn, e Zn em cogumelos comestíveis (Boletus edulis, Boletus luridiformis, Suillus granulatus, Amanita rubescens, Macrolepiota procera, Pleurotus ostreatus, Lepista nuda e Volvariella gloiocephala) coletados na região da Grécia. De todos os elementos por eles determinados nas amostras, apenas o Pb e Co não foram determinados em todas as espécies, somente em algumas, demonstrando que a técnica utilizada foi eficaz para a determinação dos elementos de interesse. 
A técnica de ICP OES foi utilizada por YAMAÇ e col. (2007), para a determinação de oito elementos traço (Cd, Cr, Cu, Fe, Mn, Ni, Pb e Zn ) em cogumelos comestíveis de 15 espécies diferentes, tais como:Rhizopogon roseolus, Boletus chrysenteron, Suillus bovinus, Suillus collitinus, Amanita caesarea, Lepista nuda; entre outros coletadas em regiões florestais da Turquia.

RANDA e KUCERA (2003) utilizaram INAA, para a determinação de 24 elementos traço (Ag, Al, As, Au, Br,Cd, Cl, Co, Cr, Cs,Cu, Fe, Hg, I, K, Mg, Mn, Na, Rb, $\mathrm{Sb}, \mathrm{Sc}, \mathrm{Se}, \mathrm{V}$ e Zn,) em cogumelos (Agaricus arvensis, Agaricus xanthodermus Amanita muscaria, Amanita rubescens, Boletus aestivalis, Boletus edulis, Cantharellus cibarius, Cantharellus lutescens, Cantharellus pallens, Langermania gigantea, Leccinum carpini, Lepiota procera, Lepiota rhacodes, Lycoperdon perlatum, Rozites caperata e Russula virescens) coletados em diferentes regiões da República Checa.

A técnica de análise por ativação com nêutrons foi utilizada por MARZANO e col. (2001) na determinação dos elementos: Ba, Ce,Cr, Eu,Fe, Gd, Ho, La, Lu, Nd, Sm, Tb, Tm, Yb, Zn e Zr em cogumelos comestíveis da espécie Boletus sp coletados na Itália.

O método de análise por ativação com nêutrons tem sido muito utilizado para a análise de diferentes matrizes biológicas, uma vez que apresenta alta sensibilidade e exatidão para a maioria dos elementos de interesse nutricional e toxicológico, possuindo uma característica única entre os métodos de análise de elementos traço, que é de não necessitar de um branco analítico, pois a amostra uma vez irradiada com nêutrons produz isótopos radioativos que são distinguidos dos não radioativos, por medições nos espectrômetros de raios gama (PARRY, 2003).

A técnica de análise por ativação, também tem sido utilizada para a certificação da concentração de elementos na faixa de $\mu g \mathrm{~g}^{-1}$ a $n g \mathrm{~g}^{-1}$ em materiais de referência certificados. Esta técnica analítica vem desempenhando um papel importante na 
monitoração de elementos traço em diversos alimentos, dentre eles os cogumelos, e desta forma contribuindo significativamente para estabelecer valores de concentração de muitos elementos essenciais presentes nos alimentos ingeridos pela população.

Apesar da existência de diversos trabalhos realizados em outros países a respeito da composição química dos cogumelos comestíveis, no Brasil há poucos estudos a respeito da qualidade dos cogumelos cultivados e comercializados, especialmente com respeito a seu valor nutricional.

Diante desta perspectiva, torna-se de interesse fazer um estudo sobre o valor nutricional de algumas espécies de cogumelos comestíveis comercializados e consumidos pela população. Portanto, este trabalho teve por objetivo aplicar o método de análise por ativação com nêutrons instrumental (INAA) para a determinação dos elementos essenciais e tóxicos presentes em cogumelos comestíveis adquiridos em mercados da cidade de São Paulo e também diretamente de produtores de diversas cidades do estado de São Paulo. 


\section{CAPÍTULO 2}

\section{CONSIDERAÇÕES GERAIS SOBRE COGUMELOS}

\subsection{Cogumelos}

Segundo BONONI e col. (1999) os fungos são classificados em vários grupos (Figura 2.1) de acordo com uma série de características, principalmente em relação às microestruturas, reprodução sexuada e assexuada, especializações com o modo de vida, enzimas produzidas e outras.

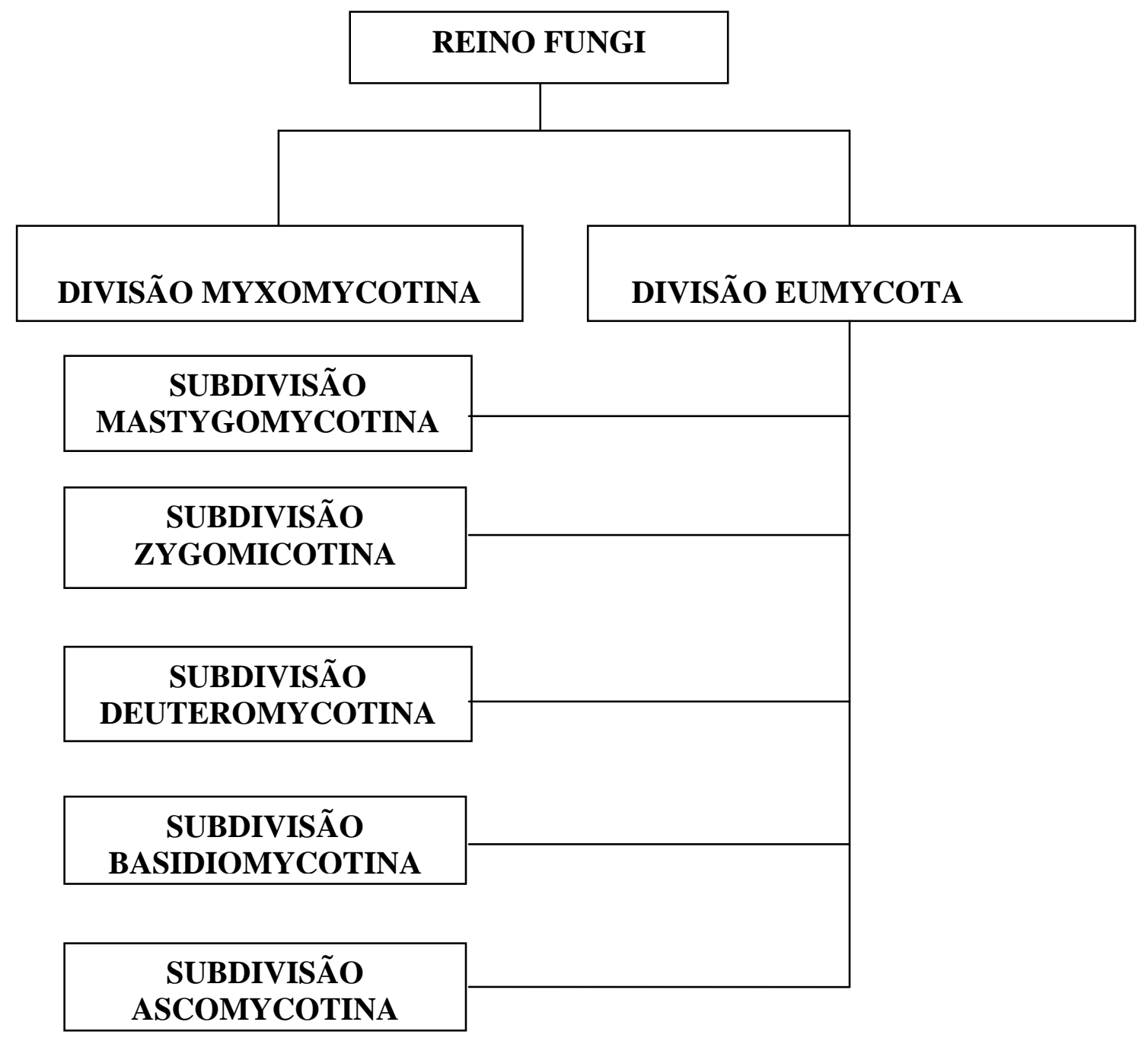

Figura 2.1- Classificação do Reino Fungi 
Os cogumelos são corpos frutificados dos fungos, conhecidos desde a antiguidade, quando o homem já os utilizava com finalidades terapêuticas, alimentar e religiosa (HERRERA, 2001). Os cogumelos comestíveis fazem parte de dois grandes grupos de fungos, conforme citado anteriormente: Ascomycotina (ascomicetos) e Basidiomycotina (basidiomicetos).

O grupo dos ascomicetos apresenta como característica principal, o asco, estrutura em forma de saco ou bolsa, no interior dos quais são produzidos os ascósporos, esporos sexuados, com forma, número e cor variáveis para cada espécie. Estes são usualmente em forma de tigela ou taça, mas alguns possuem estruturas semelhantes às esponjas. Dentro das "taças", cada hifa termina em um asco que produz quatro ou oito esporos.

Os basidiomicetos produzem basidiósporos, esporos sexuados, no interior de uma estrutura denominada basídio. Eles geralmente possuem uma haste, composta basicamente por hifas, e um "chapéu", sendo que embaixo destes há estruturas foliáceas chamadas lamelas. Na superfície de cada lamela há numerosas células-hifas chamadas basídios, com quatro basidiósporos na extremidade externa (exogenamente). Este corpo frutificante multicelular complexo chama-se basidiocarpo, sendo freqüentemente aberto mas, por vezes, pode ser fechado (NOBEL, 1999).

A reprodução dos cogumelos ocorre de forma sexuada e assexuada. Quando a reprodução dos cogumelos ocorre por meio de formação de esporos, é denominada sexuada. A reprodução assexuada ou vegetativa ocorre por multiplicação de qualquer fragmento do cogumelo.

Os esporos dos cogumelos formados nas estruturas (basídios) localizadas nas lamelas, quando ficam maduros são liberados, podendo ser dispersos pela água da chuva, por insetos ou pelo vento. Encontrando local favorável, onde existam matéria orgânica e 
umidade, os esporos começam a germinar e a produzir suas hifas; essas hifas crescem e se multiplicam formando o micélio (BONONI e col., 1999)

O cogumelo é, portanto, o corpo de frutificação com forma característica para cada espécie. No caso do champignon (Agaricus bisporus), o corpo de frutificação é formado por um estipe (pé) e um chapéu denominado píleo (BONONI e col., 1999).

Algumas espécies de cogumelos apresentam um corpo de frutificação formado apenas pelo píleo sem estipe, como no caso do popular "orelha-de-pau" (Hexagona hdynoides). Outras espécies apresentam uma estrutura denominada volva na face inferior do estipe e um anel logo abaixo do píleo.

A coloração do píleo entre as espécies de cogumelos é muito variada, ocorrendo tons de: vermelho, marrom, verde, amarelo, laranja e azul. A Figura 2.2 apresenta as principais estruturas do cogumelo, entretanto nem sempre estão presentes em todas as espécies de cogumelos sendo eles, comestíveis ou não.

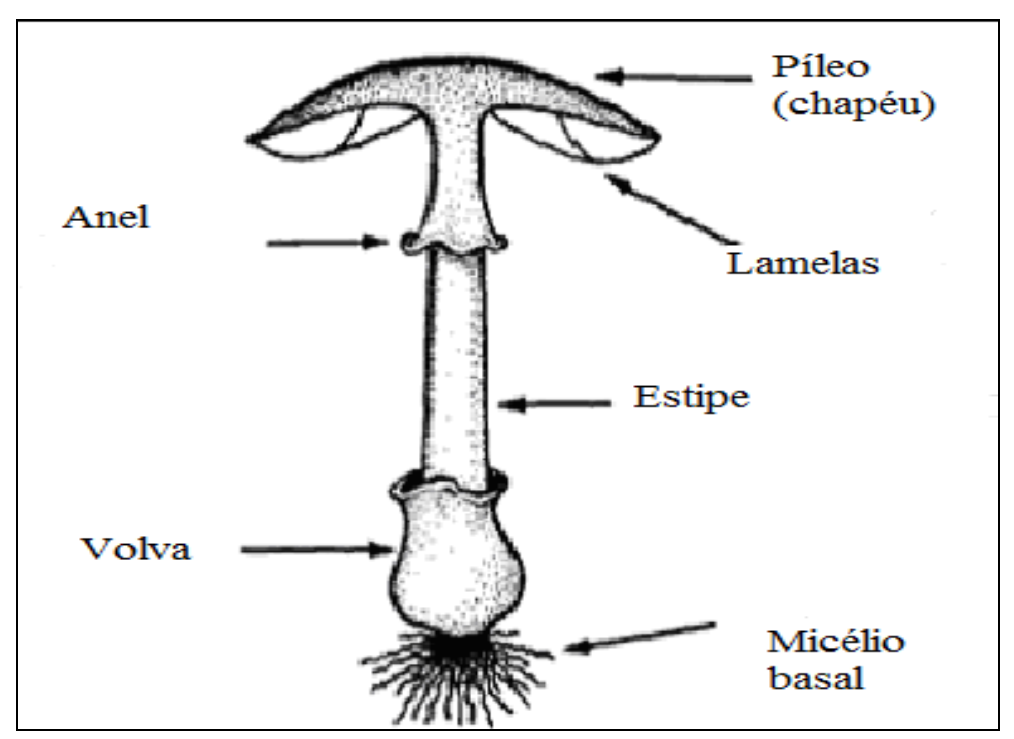

Figura 2.2- Partes do cogumelo 
Algumas estruturas como o píleo e estipe podem apresentar-se de forma variada entre uma espécie e outra, como mostram as Figuras 2.3 e 2.4, abaixo.

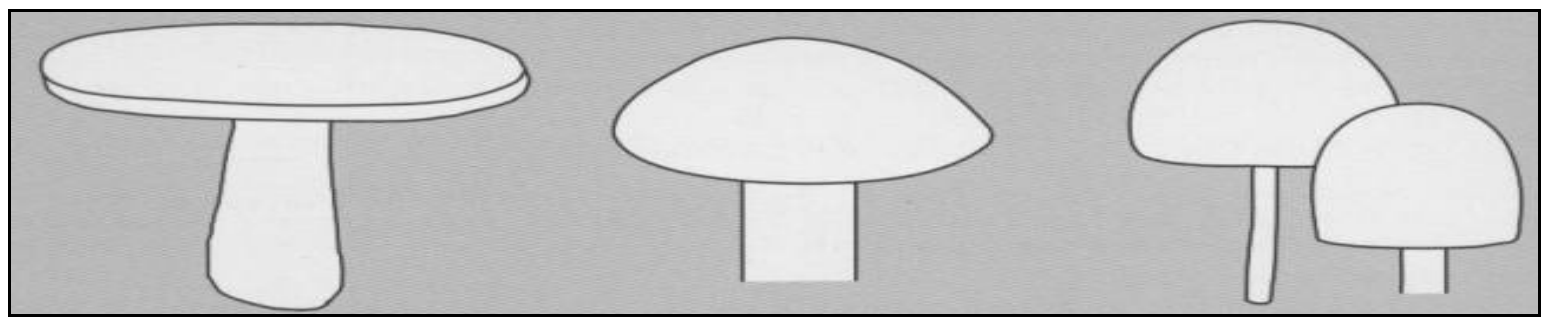

Aplanado

Hemisférico

Parabólico

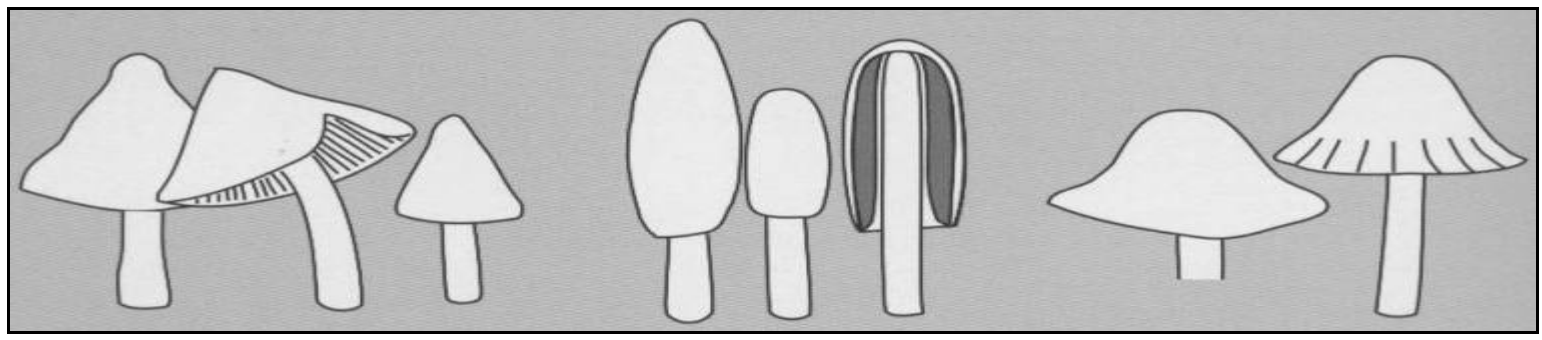

Cônico

Cilíndrico

Campanulado
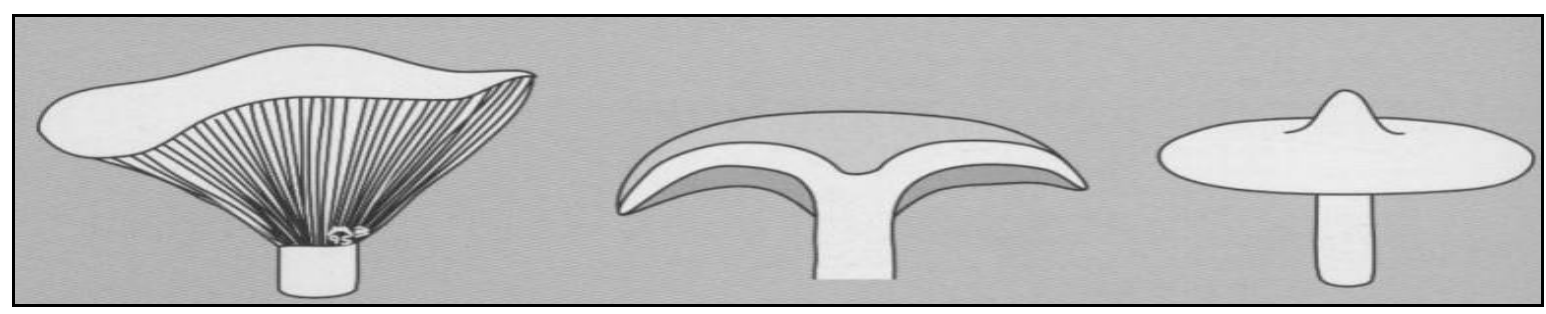

Infundiliforme

Depressão

Papilado

Figura 2.3- Diferentes tipos de píleo

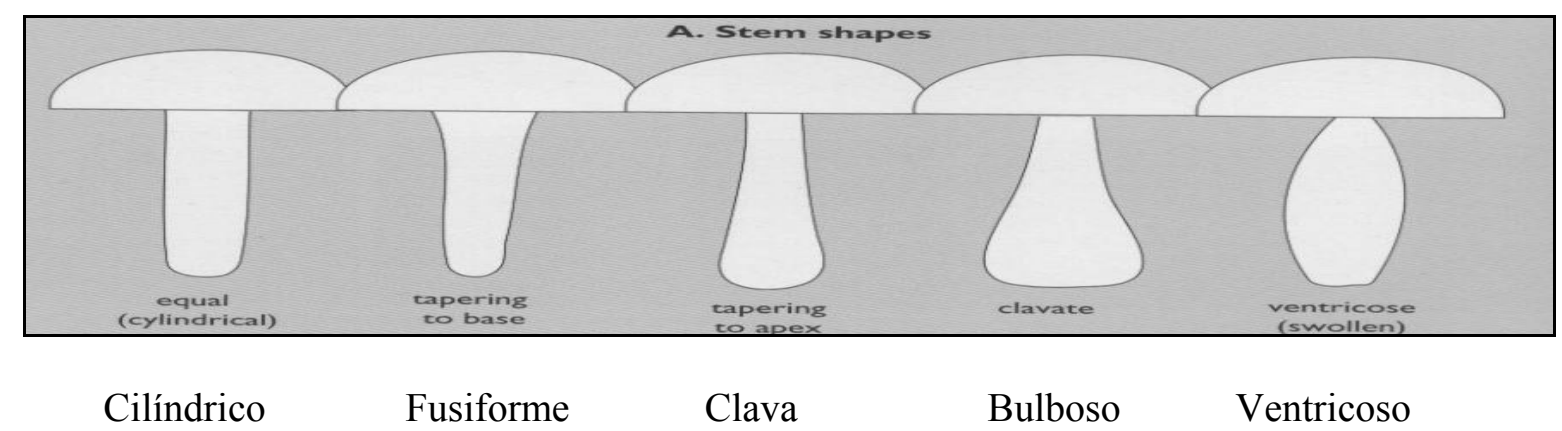

Figura 2.4- Diferentes tipos de estipe 
Dentre as partes do cogumelo, o píleo é a maior parte dos cogumelos comestíveis normalmente utilizada pela população, devido à sua textura, pois apresenta-se um pouco mais rígido.

Na Europa e na Ásia os cogumelos têm sido utilizados como alimento por mais de 2000 anos (MAKI e col., 2001). O nordeste de Portugal, devido às suas condições climáticas e flora diversificada, é uma das regiões da Europa com maior diversidade de cogumelos selvagens comestíveis, algumas com grande relevância gastronômica (BARROS e col., 2007).

Segundo MANZI e col. (1998), o relacionamento humano com cogumelos é bastante antigo e fascinante. Os egípcios acreditavam que os cogumelos eram presentes enviados pelo Deus Osíris, já os romanos chamavam de "alimento divino", pois eles pensavam que os cogumelos surgiam dos raios enviados por Júpiter durante as tempestades.

\subsection{Cogumelos tóxicos, venenosos e alucinógenos}

As primeiras referências escritas sobre cogumelos estão num epigrama de Eurípedes, datado de $450 \mathrm{AC}$, no qual é relatada a morte de uma mãe e seus três filhos envenenados por cogumelos (HERRERA, 2001).

Como reconhecer um cogumelo tóxico ou venenoso e separá-lo dos comestíveis? Essa é uma indagação freqüente da população, e de difícil resposta, pois não existe uma característica única e facilmente visível que permita essa separação. Existem várias características associadas que permitem a identificação de uma espécie, dentre elas a presença ou ausência de substâncias tóxicas. Quando um especialista encontra nos 
cogumelos substâncias desconhecidas, são feitos testes com animais para verificar seus efeitos (BONONI e col., 1999).

Existem nas tradições populares algumas práticas para verificar se um cogumelo é venenoso ou não. Um exemplo destas práticas é ferver o cogumelo com uma moeda ou utensílio de prata, se a prata ficar preta é interpretado como se o cogumelo fosse venenoso. A prata escurece porque ocorre uma reação química formando o sulfeto de prata de cor escura, porém isto não é venenoso. Portanto, crenças populares sem fundamento não servem para identificar se um cogumelo é venenoso ou não.

Algumas pessoas acreditam que a presença de anel no estipe, ou de escamas no píleo, coloração, odor etc., são indícios de toxicidade. Isso não é verdade, uma vez que são necessárias uma série de características associadas para a identificação de espécies venenosas e comestíveis.

Existem alguns cogumelos que só são tóxicos se ingeridos com bebidas alcoólicas, como o Coprinos atramentarius, que após curto período provoca vermelhidão no rosto e braços. Esta reação ocorre posteriormente à ingestão de bebida alcoólica (BONONI e col., 1999).

As toxinas dos cogumelos venenosos são produzidas naturalmente, sendo que cada espécie tem sua própria toxina. A maioria dos cogumelos que pode causar intoxicação em humanos não perde seu efeito tóxico por cozimento, congelamento ou outro método de processamento. A prevenção consiste em evitar o consumo de espécies tóxicas. As intoxicações ocorrem quando indivíduos coletam cogumelos selvagens confundindo-os com cogumelos comestíveis ou quando consomem intencionalmente cogumelos com compostos psicoativos porque desejam estes efeitos.

De acordo com Centro de Vigilância Epidemiológica - CVE da Secretaria de Estado da Saúde de São Paulo (2003) existem quatro categorias de toxinas de cogumelos: 
a) veneno protoplasmático - que causa a destruição generalizada de células, seguida de falência dos órgãos;

b) neurotoxinas - compostos que causam sintomas neurológicos como intensa transpiração, coma, convulsões, alucinações, excitação, depressão e cólon espástico;

c) irritantes gastrointestinais - compostos que produzem rapidamente náusea passageira, vômitos, dor abdominal e diarréia;

d) toxina tipo Dissulfiram (dissulfato de tetraetiltiuram). Cogumelos desta última categoria geralmente não são tóxicos e não produz sintomas ao menos que seja consumido álcool nas 72 horas após ingeri-los, o que causa uma síndrome tóxica aguda, de curta duração. O curso normal da doença varia com a dose e a espécie do cogumelo consumida. Cada espécie tóxica contém um ou mais compostos tóxicos que podem existir em outras espécies.

Há cogumelos pertencentes ao gênero Psilocybe, Panaeolus, Copelandia, Gymnopilus, Conocybe e Pluteus, que quando ingeridos produzem uma síndrome similar às intoxicações por álcool (algumas vezes acompanhados por alucinações e efeitos psicodélicos). Diversos desses cogumelos (ex: Psilocybes cubensis, P. mexicana, Conocybe cyanopus) são ingeridos devido a esses efeitos em cerimônias religiosas de certas tribos, uma prática antiga. Os efeitos tóxicos são causados por psilocina e psilocibina, substâncias produzidas pelo cogumelo. O início dos sintomas é geralmente rápido e os efeitos geralmente desaparecem com 2 horas, segundo dados do Centro de Vigilância Epidemiológica (2003).

No gênero Psilocybe há algumas características que geralmente distinguem as espécies alucinógenas: o corpo de frutificação torna-se azulado-esverdeado quando tocado e o cheiro é farináceo (BONONI e col., 1999). 
Segundo BONONI e col. (1999), conhecem-se cerca de 80 espécies de Psilocybe, distribuídas pelo mundo inteiro. No Brasil, sete espécies são citadas como alucinógenos: P. brasiliensis, P. furtadoana, P. plutonia, P. acutipilia, P. farinacea, P. caeruleoannulata e P. cubensis (Figura 2.5), sendo esta última espécie a mais conhecida.

Psilocybe não é o único gênero que possui espécies com propriedades alucinógenas, mas possui o maior número delas. A espécie Amanita muscaria (Figura 2.6) também é alucinógena e além de tóxica, era muito utilizada em rituais por uma tribo primitiva da Ásia.

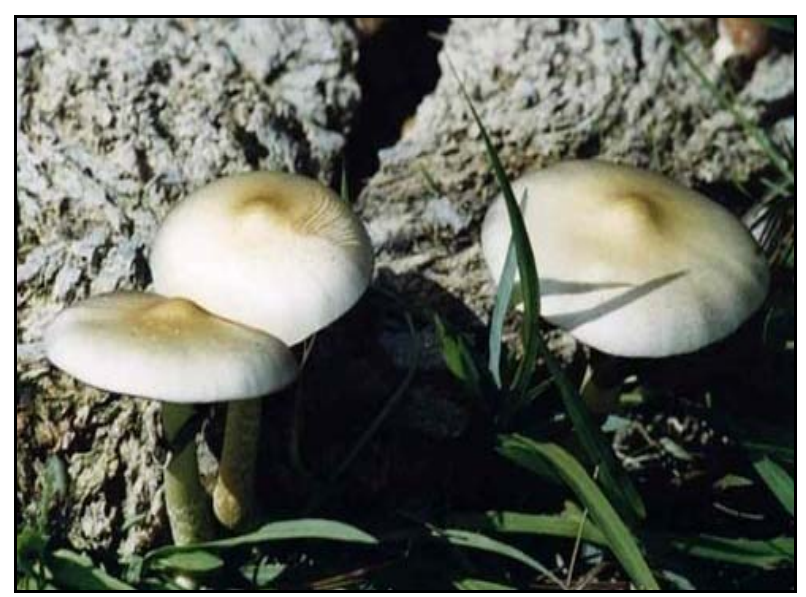

Figura 2.5- Espécie de cogumelo P. cubensis

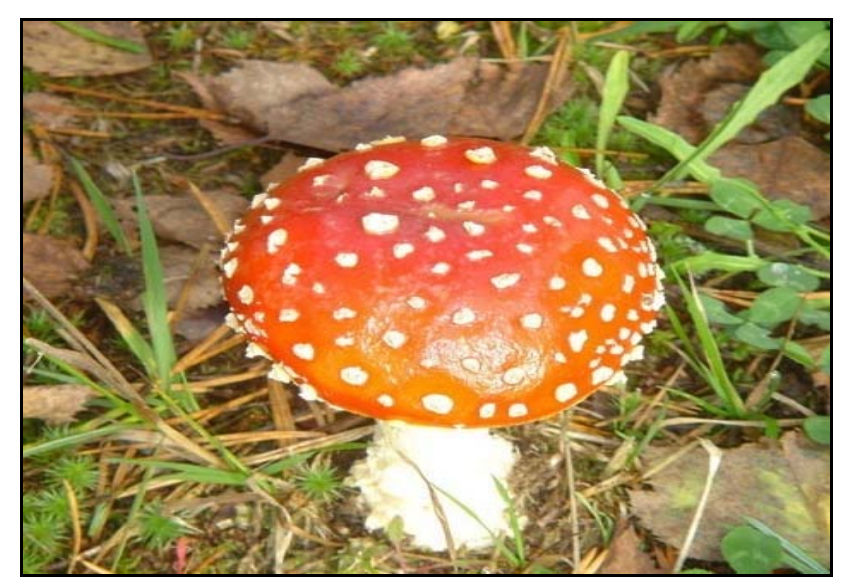

Figura 2.6- Espécie de cogumelo Amanita muscaria 
Entre os cogumelos mais perigosos, destaca-se o Amanita verna, que na Europa é conhecido como “Anjo da morte” ou “Anjo Branco” (Figura 2.7).

Como na natureza existem cogumelos tóxicos, venenosos e alucinógenos, além dos comestíveis, e que alguns apresentam características morfológicas semelhantes entre si, como tamanho, forma, coloração e espessura do corpo frutífero, uma atenção especial deve ser dada aos cogumelos comestíveis a serem consumidos pela população (URBEN e SIQUEIRA, 2003).

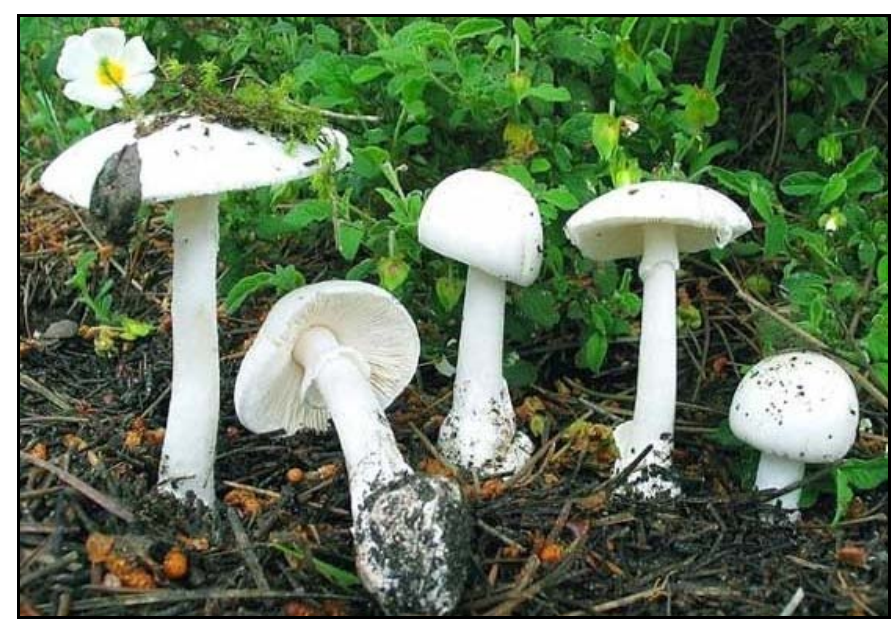

Figura 2.7- Espécie de cogumelo Amanita verna

\subsection{Cogumelos comestíveis}

A utilização de cogumelos como alimento, medicamento, veneno ou em rituais religiosos tem registro em todas as culturas e regiões do mundo, porém, foi na Ásia que eles começaram a ser cultivados sistematicamente para fins alimentícios e medicinais, segundo HERRERA (2001).

Embora muitas culturas venham usando os cogumelos tanto pela sua importância gastronômica quanto pelo seu valor medicinal, o seu emprego como alimento funcional é mais notado nas culturas orientais, nas quais a aplicação de cogumelos para se 
manter a saúde teve início há milhares de anos, como na China. Os chineses sempre trataram cogumelos como alimentos bons para a saúde, verdadeiro "elixir da vida" (FURLANI, 2004).

De acordo com SHIBATA e DEMIATE (2003), o consumo de cogumelos no Brasil ainda é muito pequeno em relação ao dos povos europeu e asiático. O consumo de cogumelos no país, segundo dados da EMBRAPA (2003), é cerca de 30g/ano por habitante, ainda é muito baixo quando comparado com outros países, como a França onde o consumo chega a $2 \mathrm{~kg} /$ ano por habitante, a Itália, cerca de 1,3 kg/ano e a Alemanha de $4 \mathrm{~kg} / \mathrm{ano}$.

É importante que a população conheça as vantagens nutricionais dos cogumelos, a nutrição e a saúde e passem a incluí-los em sua dieta alimentar (EMBRAPA, 2005). Nos últimos anos, no entanto, a procura por cogumelos comestíveis vem aumentando e ganhando destaque, em virtude do seu sabor refinado, valor nutritivo e, ainda, pelo potencial de uso medicinal.

Entre outros importantes componentes benéficos ao organismo, os cogumelos comestíveis poderiam contribuir para reduzir a desnutrição nos países pobres, devido ao seu alto valor nutritivo.

No Brasil, a primeira espécie de cogumelo comestível cultivada foi o champignon de Paris (Agaricus bisporus). Outras espécies atualmente cultivadas são o caetetuba ou cogumelo gigante, também conhecido como shimeji (Pleurotus ostreatus) e o shitake (Lentinus edodes). Além dos cogumelos cultivados, ocorrem várias espécies comestíveis nas matas brasileiras, entre elas Auricularia fuscosuccinea, Auricularia delicata, Oudemansiella canarri, Favolus brasiliensis, Laetiporus sulphureus, Agrocybe perfecta, Macrolepiota procera, Pleurotus ostreatoroseus, Lepista nuda, Suillus edulis, 
Armillaria mellea, Coprinus comatus, Agaricus silvaticus, Tricholoma pachymeres e Fistulina hepática (BONONI e col., 1999).

Além dos cogumelos comestíveis cultivados, existem cogumelos selvagens que são utilizados como alimento em diversos países. Estes cogumelos são coletados por moradores locais e vendidos em beira de estradas; algumas pessoas dão preferência a estes tipos de cogumelos devido ao sabor acentuado e textura (SANMEE e col., 2002).

Outro que se destaca devido às suas propriedades nutricionais e medicinais é o conhecido Cogumelo do Sol (Agaricus blazei), uma espécie nativa que foi coletada inicialmente no Brasil por um agricultor e pesquisador autônomo, Takatoshi Furumoto, que a cultivou entre as décadas de 60 e 70, no município de Piedade, sudoeste do estado de São Paulo (KUROZAWA, 2005).

O cogumelo do sol (Agaricus blazei) assemelha-se ao champignon de Paris (Agaricus bisporus), mas possui um talo mais grosso e comprido (Figura 2.8). Ele tornouse um ingrediente importante na culinária japonesa, ocidental e chinesa devido ao seu forte aroma, sua polpa adocicada e sua excelente textura (MIZUNO e col., 1990).

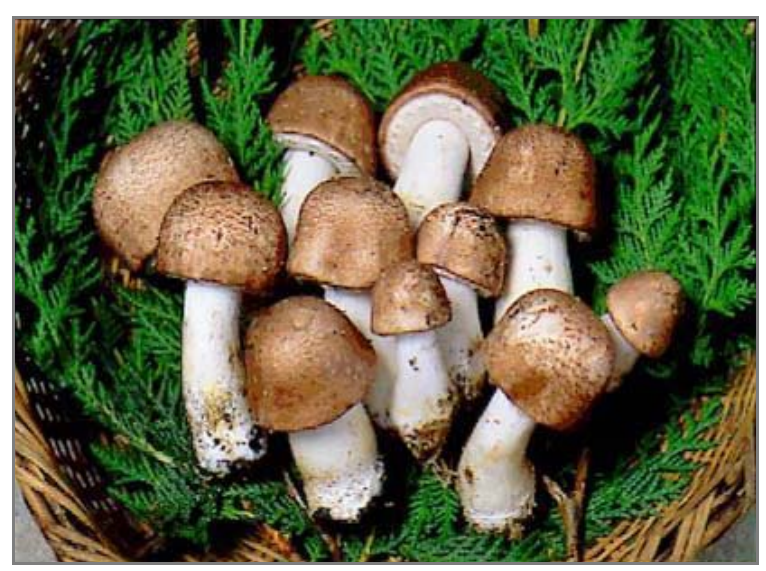

Figura 2.8- Cogumelo Agaricus blazei 


\subsubsection{As propriedades dos cogumelos comestíveis}

Os cogumelos são alimentos excelentes para dietas da população porque nutrem e não engordam. Se comparado a outros alimentos, os cogumelos só possuem teor de proteína menor que a soja, dentre os vegetais, e se compara com produtos de origem animal (Tabela 1).

Tabela 1: Composição química dos cogumelos em relação a outros alimentos em \% peso fresco (BONONI e col.,1999)

\begin{tabular}{cccccc}
\hline & ÁGUA & CALORIAS & PROTEÍNAS & CARBOIDRATOS & GORDURAS \\
\hline Cogumelos & $90-98$ & 28 & $2,8-4,8$ & 4,4 & 0,3 \\
Ovos & 74 & 163 & 12,9 & 9,0 & 11,5 \\
Leite & 87 & 65 & 3,5 & 4,9 & 3,5 \\
Cenoura & 88 & 42 & 1,1 & 9,7 & 0,2 \\
\hline
\end{tabular}

A quantidade de água presente nos cogumelos é em torno de $90 \%$,e nos $10 \%$ que restam encontram-se boa quantidade de fibras, carboidratos, proteínas e minerais.

RANZANI e STURION (1998) analisaram a composição de aminoácidos em espécies de Pleurotus spp. e em todas as espécies analisadas foram detectados todos os aminoácidos essenciais, que constituíam de 42 a $56 \%$ da proteína presente nesses cogumelos.

MANZI e col. (1998) estudaram diferentes espécies de cogumelos (Pleurotus ostreatus, Pleurotus eryngii, Pleurotus Pulmonaris e Lentinula edodes) cultivados na Itália e determinaram o potássio como o elemento mais abundante, demonstrado que esses cogumelos podem ser considerados como boa fonte de potássio. O elemento sódio foi 
determinado em baixa concentração entre as espécies analisadas. De acordo com os autores, a baixa concentração de sódio presente nos cogumelos, sugere a utilização deste alimento para pacientes com problemas de hipertensão.

Algumas espécies de cogumelos $A$. bisporus e $P$. ostreatus da região Itália foram analisadas por MANZI e col. (2001), onde eles determinaram nas amostras de $A$. bisporus $0,33 \%$ de lipídeos e nas amostras de $P$. ostreatus $0,36 \%$ de lipídeos, ambos em base úmida.

Comparando-se com os peixes e as aves, os cogumelos apresentam quantidades bem menores de colesterol e gordura saturada. A gordura bruta dos cogumelos é constituída por diversas classes de lipídeos, incluindo os ácidos graxos livres, monoditriglicérides, esteróis, terpenóides e fosfolipídios, destacando-se a lecitina15 (FORTES e NOVAIS, 2006).

Champignon de Paris (Agaricus bisporus) é o cogumelo mais consumido no mundo, devido ao seu sabor e textura. Este cogumelo contém elevado teor de proteínas $(23,9 \%$ a $48,3 \%)$ e também carboidratos $(24,5 \%$ a $62,0 \%)$ em peso seco. Além das propriedades nutricionais, esse tipo de cogumelo apresenta atividade antitumoral, tendo como principal componente ativo um $\beta-\mathrm{D}$ - glucan, que atua no sistema imunológico, aumentando as defesas do organismo (URBEN e SIQUEIRA, 2003).

A composição de gorduras, carboidratos, vitaminas e outros componentes encontrados nos cogumelos variam de acordo com cada espécie e também do local onde ele se desenvolveu. A Tabela 2 apresenta a composição química de algumas espécies de cogumelos comestíveis. 
Tabela 2: Composição química de algumas espécies de cogumelos em \% de matéria seca (BONONI e col.,1999)

\section{COGUMELOS GORDURAS CARBOIDRATOS FIBRAS PROTEÍNAS}

$\begin{array}{lcccc}\text { Pleurotus ostreatus } & 1,08-9,4 & 46,6-81,8 & 7,5-27,6 & 8,9-38,7 \\ \text { Agaricus bisporus } & 3,9 & 52,6 & 6,6 & 27,8 \\ \text { Auricularia fuscosuccina } & 1,5 & 81,0 & 6,9 & 8,1 \\ \text { Suillus edulis } & 3,1 & 59,7 & 8,0 & 29,7 \\ \text { Coprinus comatus } & 3,3 & 58,8 & 7,3 & 25,4 \\ \text { Lentinus edodes } & 1,2 & 79,2 & 14,7 & 13,1 \\ \text { Volvariella volvacea } & 13,3 & 54,8 & 5,5 & 21,9\end{array}$

Na Finlândia, MATTILA e col. (2001) verificaram que cogumelos das espécies A. bisporus (branco e marrom), L. edodes e P. ostreatus, são boas fontes vitaminas B1, B2, B12, C, D, niacina e folatos totais. A espécie L. edodes foi a que apresentou teores mais elevados das vitaminas C (2,1mg/100g), B12 $(0,07 \mu \mathrm{g} / 100 \mathrm{~g})$ e D $(0,1 \mu \mathrm{g} / 100 \mathrm{~g})$. A espécie P. ostreatus apresentou maiores teores das vitaminas B1 $(0,07 \mathrm{mg} / 100 \mathrm{~g})$ e folatos $(51 \mu \mathrm{g} / 100 \mathrm{~g})$ e a espécie A.bisporus (marrom) apresentou maior teor de niacina $(4,1 \mathrm{mg} / 100 \mathrm{~g})$ e a mesma espécie branca apresentou maior teor de vitamina B2 $(0,39 \mathrm{mg} / 100 \mathrm{~g})$.

SANMEE e col. (2002) realizaram o primeiro estudo para verificar a qualidade nutricional de cogumelos comestíveis coletados em florestas nativas na região da Tailândia. Neste estudo eles verificaram que os cogumelos comestíveis selvagens 
apresentam minerais importantes como $\mathrm{B}, \mathrm{Ca}, \mathrm{Fe}, \mathrm{K}, \mathrm{Mg}, \mathrm{Mn}, \mathrm{P}, \mathrm{Se}$ e $\mathrm{Zn}$, também são fontes de carboidratos e fibras. O mineral encontrado em maior concentração em todas as espécies por eles analisadas foi o Fe, cujos valores determinados foram de $162 \mathrm{mg} \mathrm{kg}^{-1} \mathrm{a}$ $3254 \mathrm{mg} \mathrm{kg}^{-1}$.

Alguns estudos (OLIVEIRA e col., 1999; FORTES e NOVAIS, 2006; SHIBATA e DEMIATE, 2003) têm demonstrado que substâncias isoladas nos cogumelos Agaricus blazei apresentam propriedades anticancerígenas.

FORTES e NOVAIS (2006) fizeram uma revisão em artigos relacionados aos efeitos da suplementação dietética com cogumelos na terapia contra o câncer. Os autores constataram que cogumelos Agaricales e outros fungos medicinais exercem efeitos nutricionais e farmacológicos imprescindíveis, podendo ser utilizados como coadjuvante na terapia contra o câncer. Os mecanismos de ação das substâncias bioativas presentes nos cogumelos ainda não estão completamente esclarecidos na literatura, mas evidências científicas sugerem que essas substâncias são capazes de modular a carcinogênese nos estágios de iniciação, promoção e progressão, promovendo benefícios aos portadores de diversos tipos de câncer, principalmente através da estimulação do sistema imunológico.

Inúmeras são as vantagens dos cogumelos como alimento como já foi descrito anteriormente, mas a presença de elementos tóxicos como chumbo, mercúrio, cádmio, arsênio vem aumentando nos últimos anos, despertando uma preocupação nos pesquisadores (COCCHI e col., 2006; VETTER, 2004; SVOBODA e col., 2006) na determinação destes elementos nas espécies comestíveis.

A composição química dos cogumelos pode estar relacionada à idade do corpo de frutificação, às condições de cultivo, à espécie e também ao substrato onde se desenvolveu (KALAC e SVOBODA, 1999). Durante o desenvolvimento as hifas dos 
cogumelos retiram os nutrientes necessários ao crescimento do substrato; neste processo alguns metais (chumbo, cádmio e mercúrio) podem ser absorvidos.

\subsubsection{Cultivo dos cogumelos comestíveis}

Em 1990, a China tornou-se o maior produtor mundial de cogumelos, gerando empregos e ajudando o desenvolvimento de diversas cidades (URBEN, 2006).

A primeira técnica utilizada pelos chineses para o cultivo de cogumelos consistia em encontrar troncos de árvores caídos pelas florestas e colocá-los próximo aos troncos frutificados que, por sua vez, eram expostos ao vento para capturar os esporos. Eventualmente, pedaços de cogumelos eram colocados dentro ou sobre os troncos (HERRERA, 2001).

Em 1650 no Ocidente, em Bonnefons na França, iniciou-se a produção de cogumelos em substrato feito com esterco de cavalos e resíduos úmidos. Naquela época, acreditava-se que a "semente" dos cogumelos estava presente no esterco dos cavalos, embora fosse reconhecido que uma pilha de composto pudesse ser inoculada com partes de outras pilhas.

A produção comercial de cogumelos foi formalizada aproximadamente em 1700. Nesse período, as cavernas dos arredores de Paris foram alargadas, devido à extração de pedras para a construção de edifícios parisienses. O ambiente úmido e escuro dessas cavernas constituiu o ambiente ideal para o crescimento dos cogumelos. A combinação entre a produtividade e o desenvolvimento da França nas artes culinárias impulsionou o cultivo comercial pelos próximos dois séculos. Existem descrições de que, em 1867 uma única caverna fora de Paris, com uma área de $54000 \mathrm{~m}^{2}$, produzia diariamente cerca de 1,4 toneladas de cogumelos (HERRERA, 2001). 
A Figura 2.9 apresenta a primeira espécie de cogumelo cultivado no Brasil, que foi o champignon de Paris (Agaricus bisporus). Seu cultivo no Brasil iniciou-se em 1953 por imigrantes chineses que se instalaram na região de Mogi das Cruzes e por italianos na região de Atibaia. Eles trouxeram a tecnologia e linhagens de seus países de origem (BONONI e col., 1999).

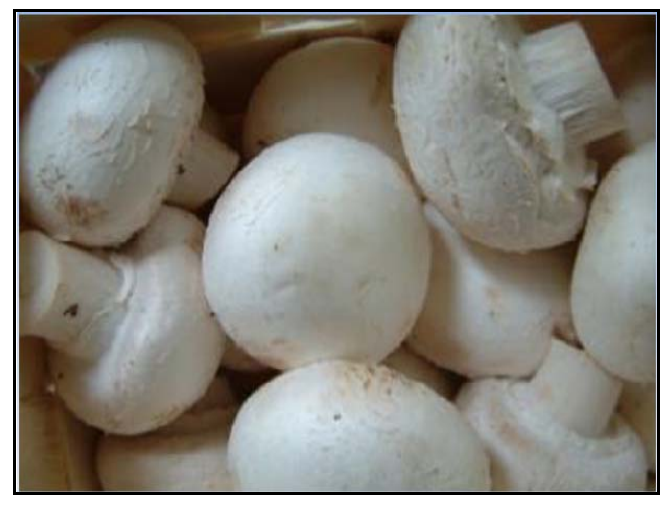

Figura 2.9- Cogumelo Agaricus bisporus

A maior parte dos cogumelos comestíveis necessita de condições climáticas, como temperatura oscilando entre 25 e $30^{\circ} \mathrm{C}$ na fase de crescimento do micélio, sendo que variações bruscas destes valores levam a estagnação do crescimento. Em alguns casos, pode ocorrer a inativação do micélio e, ainda, linhagens não adaptadas ao clima onde serão cultivadas não apresentarão potencial satisfatório de crescimento miceliano e produção de cogumelos (ROSSI e col., 2001).

Os cogumelos comestíveis em sua maioria apresentam bons índices de desenvolvimento miceliano em diferentes tipos de matéria-prima, sendo, portanto, imprescindível a seleção do substrato onde o micélio em questão desenvolva-se rapidamente e com vigor, visando maior produtividade do cogumelo.

A utilização dos diversos tipos de substratos pelo fungo depende da sua capacidade de secretar celulases, hemicelulases e ligninas, liberando nutrientes para seu 
crescimento. As trocas gasosas dos substratos, durante o crescimento vegetativo, são bastante importantes para a produção destas enzimas (ROSSI e col., 2001).

Os cogumelos comestíveis são cultivados em uma grande variedade de resíduos agrícolas e são considerados grandes transformadores desses resíduos, representando a biotransformação mais eficiente de reciclagem (SILVA e col. 2007).

A escolha da tecnologia de cultivo e o preparo do substrato de cultivo dependem da espécie de cogumelo que se pretende cultivar, da disponibilidade e custo de resíduos agroindustriais, além de outros insumos e matérias primas.

$\mathrm{Na}$ literatura encontram-se muitas fórmulas de compostos os quais, de maneira geral, podem ser divididos em: compostos clássicos, utilizando esterco eqüino, de galinha e outros, além de compostos sintéticos, cujas fontes de nitrogênio têm composição mais estável, possibilitando maior repetibilidade entre os ciclos de produção. Os compostos clássicos são ainda muito utilizados pelo seu baixo custo, sobretudo quando se emprega uma tecnologia de cultivo mais rústica. A formulação de "composto" para cultivo de cogumelos tem como primeira regra geral a escolha de materiais volumosos e fibrosos, à base de palhas de capim ou outras plantas, geralmente muito ricos em carbono (C) e pobres em nitrogênio $(\mathrm{N})$ e fósforo $(\mathrm{P})$.

OBODAI e col. (2003) citam a utilização de diferentes produtos lignocelulósicos como palha de arroz, folhas de bananeira, capim-elefante e serragem, para o cultivo de Pleurotus ostreatus. HERNANDEZ e col. (2003) utilizaram composto à base de capim e polpa de café no preparo do substrato para o cultivo deste cogumelo. Já SAGIR e YLLDIZ (2004) relataram o estudo do crescimento do micélio de cinco espécies de Pleurotus spp. em grãos de sorgo e de trigo, e de acordo com MODA e col. (2005), uma série de resíduos da agricultura podem ser utilizados para produção do cogumelo 
comestível Pleurotus spp., dentre os quais citam-se, o bagaço de cana-de-açúcar, o sabugo de milho, as folhas de bananeira e os resíduos de algodão.

A indústria madeireira também gera quantidade expressiva de serragem, a qual em países onde a cultura do cogumelo está estabelecida, também tem sido utilizada na produção de inóculo e no cultivo dos cogumelos (EIRA e BRAGA, 1997).

Cada produtor de cogumelos ou grupo de produtores de uma mesma região escolhe um tipo de composto formado por produtos de fácil aquisição no local, em função da disponibilidade e custo do transporte. Existe então uma infinidade de variações dentre os compostos utilizados pelos produtores. A base do composto é principalmente o bagaço de cana-de-açúcar, com esterco de cavalo, esterco de galinha, uréia, sulfato de amônia, farelo de soja ou farelo de arroz, gesso, entre outros produtos. O tempo de preparo do composto é de 15 dias, sendo muito importante que a cada três dias revire todo o material para promover a aeração (BONONI e col. 1999).

Para que o cogumelo cresça e se reproduza, é necessária a criação de um ambiente favorável, fornecendo condições e nutrientes adequados.

O processo de preparo do substrato é a parte mais dispendiosa do cultivo (MOLENA, 1996; EIRA e BRAGA 1997), por isso procuram-se novos métodos de compostagem rápida, que abreviem as operações e o tempo de ocupação das instalações, racionalizem materiais, evitando perda de nutrientes, minimizem o impacto ambiental e ofereçam produtividade e confiabilidade maiores.

\subsubsection{O cultivo de cogumelos: Gênero Agaricus}

Foi na França de forma casual que ocorreu o início do cultivo do champignon de Paris (Agaricus bisporus). Em 1650, cultivadores de melão em Paris perceberam 
cogumelos que se desenvolviam sobre a palha e esterco usados nas camas aquecidas dos melões. Os agricultores observaram que se regassem o esterco com a água onde haviam lavado cogumelos, eles nasciam em maior quantidade (BONONI e col.,1999).

Um jardineiro francês, em 1780, descobriu que as cavernas eram muito favoráveis ao cultivo de champignon e introduziu essa opção na Europa. Em 1865, o cultivo foi introduzido na América, onde passou a ser realizado em casas de cultivo com instalações semelhantes a uma fábrica; posteriormente esse sistema também passou a ser também utilizado na Europa (BONONI e col. 1999).

No estado de São Paulo, principalmente na região de Mogi das Cruzes, o cultivo ainda é realizado de forma rudimentar, geralmente realizado por famílias chinesas que herdaram as técnicas por muitas gerações e não possuem conhecimentos científicos mais aprofundados. O inicio do cultivo em escala comercial ocorreu nos anos 50 (COUTINHO, 2004).

Na Europa e na Ásia já se comercializam mais de 50 variedades de Agaricus que se diferenciam uma das outras quanto a: forma e cor (liso, escamoso, branco, creme, castanho, marrom), fragilidade, produtividade, resistência à doenças, necessidades nutritivas e condições climáticas. No Brasil e na Holanda, comercialmente dá-se preferência às variedades brancas. Na França e Estados Unidos preferem-se os pardos (BONONI e col. 1999).

As variedades tradicionalmente cultivadas no Brasil são linhagens de Agaricus bisporus, cuja temperatura de formação (frutificação) fica em torno dos $17^{\circ} \mathrm{C}$. Isso obriga a interrupção dos cultivos nos períodos de verão, a menos que se usem locais refrigerados. Outra espécie introduzida nos últimos cinco anos é o Agaricus bitorquis, cuja temperatura de formação é em torno de $23-25^{\circ}$ C. Esta espécie é mais adaptada ao clima brasileiro, 
permitindo o cultivo sem refrigeração em períodos mais longos do ano (EMBRAPA, 2006).

As principais etapas do cultivo de champignon são seqüencialmente: obtenção ou preparação da matriz (grãos, serragens ou blocos de madeira com esporos ou partes de cogumelos); preparação do composto e compostagem; pasteurização; semeadura; incubação; terra de cobertura; produção e colheita.

Após 15 a 30 dias da colocação da terra de cobertura, pequenos brotos ou bolinhas começam a se formar na superfície do substrato. Nessa etapa deve-se manter a ventilação e a umidade relativa do ar deve ser mantida entre 85 e $90 \%$. Nesse período não convém regar os cogumelos e a umidade é mantida molhando-se as paredes e o chão da sala.

Para a produção de cogumelos procura-se imitar o que ocorre na natureza. No caso do champignon o composto (Figura 2.10) é constituído por palha, principal fonte fornecedora de carbono e por esterco, principal fonte fornecedora de nitrogênio. A relação inicial entre o carbono e nitrogênio deve ser ao redor de 30 (relação $\mathrm{C} / \mathrm{N}=30$ ) $(\mathrm{BONONI}$ e col., 1999).

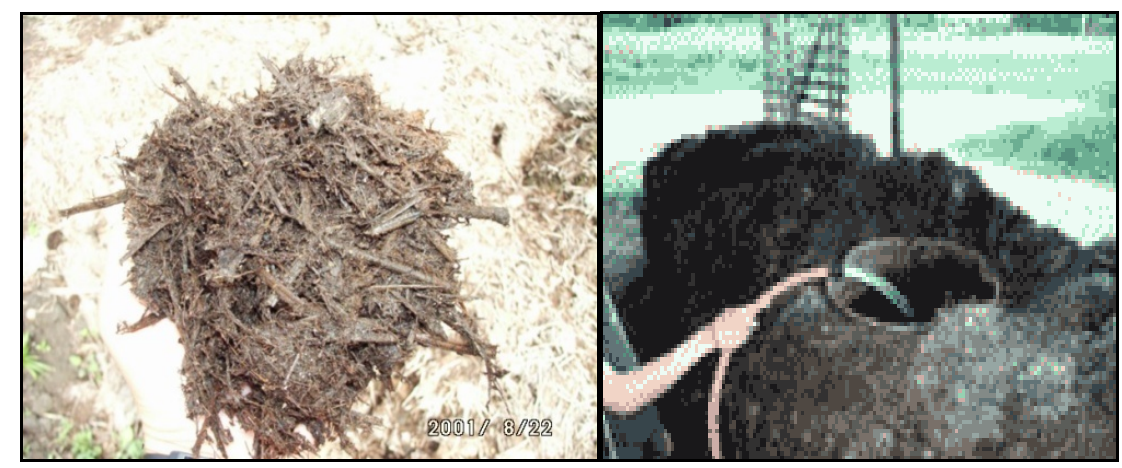

Figura 2.10- Composto a base de palha

Para melhor rendimento da produção, o galpão (Figura 2.11) para o cultivo do champignon deve ser climatizado promovendo melhor desenvolvimento do cogumelo, pois 
ele não suporta grandes variações de temperatura e umidade. O controle de contaminação deve ser feito periodicamente para evitar doenças e insetos que podem afetar diretamente a produção.

Dependendo do nível tecnológico do agricultor, a inoculação pode ser feita manualmente em sacos de polietileno (Figura 2.12) ou em caixas de cultivo ou ainda em camas dispostas em prateleiras. Como pode ser observado na Figura 2.11, o cogumelo pode também ser inoculado diretamente em canteiros feitos no solo (EIRA, 1997).

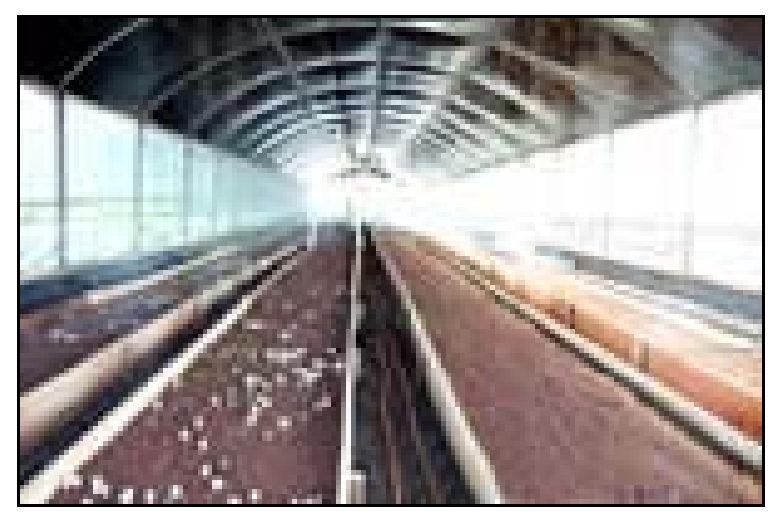

Figura 2.11- Galpão com cogumelos em canteiros

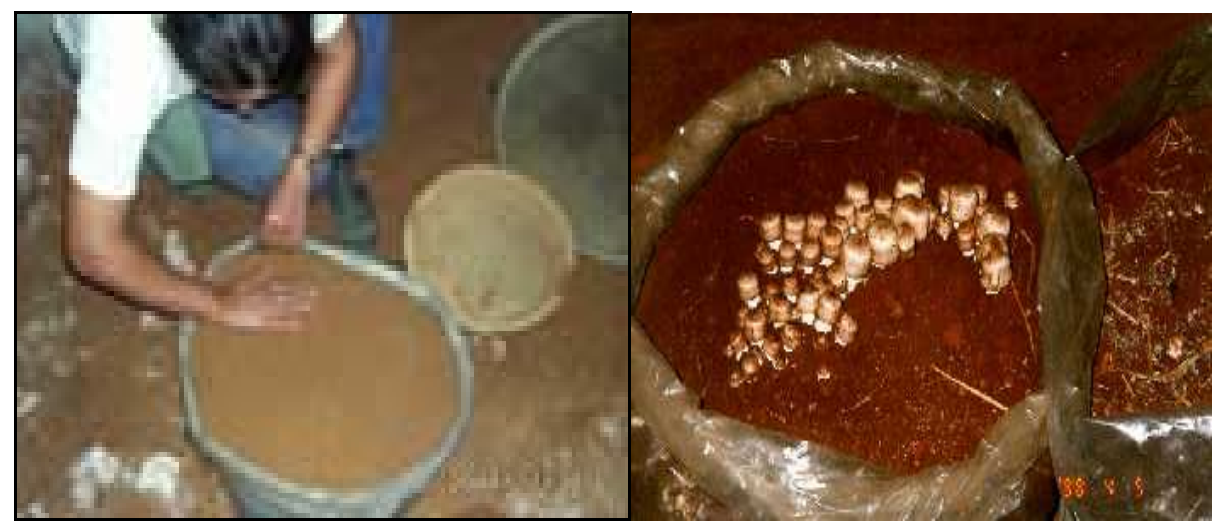

Figura 2.12- Sacos de polietileno com cogumelos

A colheita do champignon começa entre o $16^{\circ}$ e o $35^{\circ}$ dia após a colocação da terra de cobertura. O cogumelo deve ser colhido quando alcançar seu maior tamanho, antes 
da abertura ou rompimento do véu. Cogumelos grandes e fechados são os que alcançam melhor preço no mercado. A colheita no Brasil é sempre feita manualmente (Figura 2.13), por rotação do cogumelo; posteriormente os estipes são cortados com auxílio de faca ou tesoura (BONONI e col.,1999).

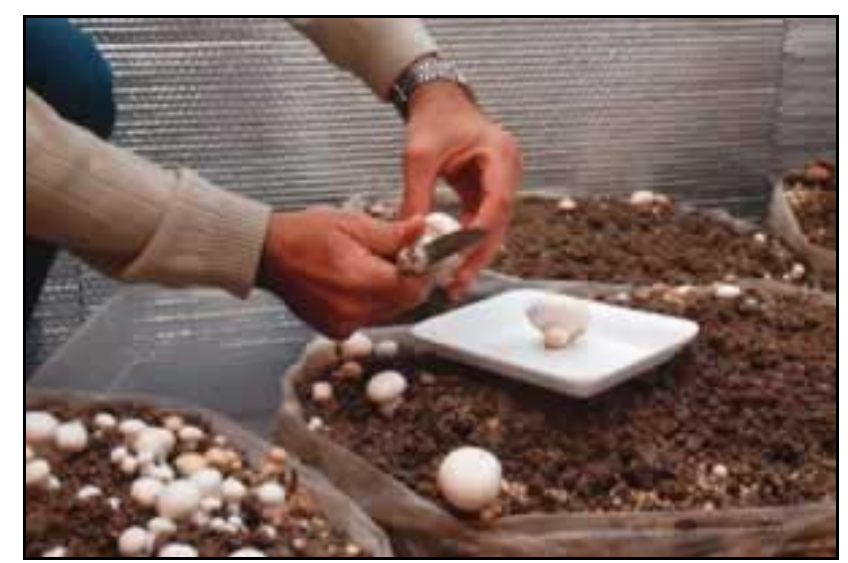

Figura 2.13-Colheita manual de Agaricus bisporus

\subsubsection{O cultivo de cogumelos: Gênero Pleurotus}

O gênero Pleurotus é um dos mais cultivados devido à sua rusticidade e alta eficiência biológica, adaptando-se bem à condição brasileira de clima tropical. É conhecido em diferentes partes do mundo como uma classe de cogumelos de alta habilidade saprofítica e por degradar resíduos lignocelulósicos como substrato (SILVA e col., 2007).

O cogumelo do gênero Pleurotus pode ser encontrado praticamente no mundo todo, sendo freqüente também nas matas brasileiras. Sendo este cogumelo um decompositor de madeira, é facilmente encontrado nas florestas. Até a década de 70, seu consumo era feito basicamente da coleta diretamente da natureza e, a partir de então, se iniciou o cultivo em escala comercial (BONONI e col.,1999). 
No gênero Pleurotus são encontradas várias espécies comestíveis, entre elas o Pleurotus ostreatus, P. pulmo-narius, P. sajor-caju, P.ostreatoroseus, P. eous, P.cornucopiae, P. platypus, P. citrinopileatus, P. florida e P. eryngüi. A cor do píleo ou chapéu difere para cada uma dessas espécies, assim como a temperatura de frutificação, necessidades nutricionais, tempo de incubação, etc. A espécie P.ostreatus, (Figura 2.14), por exemplo, possui coloração cinza e a temperatura para produção varia entre $15^{\circ}-18^{\circ} \mathrm{C}$, para a maioria de suas linhagens (BONONI e col. 1999).

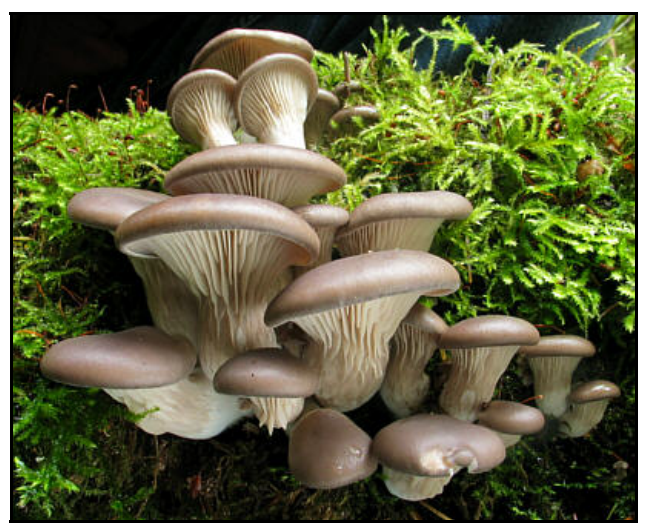

Figura 2.14- Cogumelo Pleurotus ostreatus

A maioria das espécies e linhagens utilizadas para o cultivo no Brasil foi introduzida da Europa e da Ásia. O cultivo do Pleurotus é basicamente o mesmo para todas as linhagens, com exceção das temperaturas de frutificação.

Após a formação dos primórdios dos cogumelos fora da embalagem de cultivo, a umidade relativa deve ser diminuída um pouco (por volta de $85 \%$ ) para assegurar a qualidade dos cogumelos. De quatro a sete dias, os cogumelos estarão prontos para a colheita. Para se saber o exato momento de se colher o cogumelo, é preciso observar as margens do chapéu. Quando estas estiverem planas, é preciso que sejam colhidos, pois em breve iniciará a liberação dos esporos, o que deve ser evitada por vários motivos, dentre eles, a perda de peso. 
Algumas espécies de Pleurotus crescem em "cachos", onde vários cogumelos são unidos na base do pé; neste caso a colheita deve ser feita de todo o cacho, mesmo que haja alguns cogumelos menores. O momento da colheita se dá quando os cogumelos maiores apresentam margens planas, antes da liberação de esporos, para que estes não caiam sobre os outros e, desta forma percam valor comercial (BONONI e col., 1999).

Durante o crescimento do cogumelo, a temperatura também tem grande influência. Se muito alta, haverá a maturação precoce ou morte do cogumelo; por outro lado, se muito baixa, retardará o desenvolvimento deste por vários dias.

Uma série de resíduos da agricultura como palhas de trigo, de arroz, gramíneas, serragens, polpa e casca de frutas, folhas de bananeira, polpa de café, bagaço de cana-deaçúcar entre outros podem ser utilizados para produção de cogumelos comestíveis como o P. ostreatus (EIRA, 2003; MANDEEL e col., 2005; MODA e col., 2005).

O cultivo de cogumelos do gênero Pleurotus tem vantagens como facilidade de manejo e produção; utilização de matérias primas abundantes e baratas como palhas, capins, bagaço; resistência a pragas e doenças; rápido retorno de investimento (MODA e col., 2005), também são pouco exigentes em relação ao substrato e de bom desenvolvimento em condições rústicas (SCHMIDT e col., 2003).

Outro aspecto importante dos cogumelos do gênero Pleurotus é que podem apresentar produtividade até três vezes maior que o gênero Agaricus, contribuindo, para isso, a sua rusticidade e resistência às doenças (COLAUTO e col., 1998).

A escolha do substrato para o desenvolvimento do cogumelo é das etapas mais importantes no processo de cultivo. Um bom composto (substrato) pode aumentar significativamente a produção. Alguns trabalhos têm sido realizados visando avaliar a 
qualidade dos diferentes tipos de compostos utilizados, principalmente nos cogumelos do gênero Pleurotus.

A eficiência biológica e alguns nutrientes nos corpos de frutificação de três espécies de Pleurotus (P. sajor-caju, P. platypus e P. citrinopileatus) cultivados em cinco tipos de substratos diferentes (palha de arroz, de milho, bagaço de cana, fibra de coco, e uma mistura desses resíduos), foram verificados por RAGUNATHAN e col. (1996). As diferentes espécies cultivadas em substratos distintos apresentaram valores de 84,7 a $91,9 \%$ de umidade, 40,6 a 46,6\% de carboidratos e 26,9 a 42,5\% de proteína. A eficiência biológica (produtividade) variou entre 25,1 a 46,6\%. Os autores concluíram que a palha de arroz favorece o crescimento da espécie $P$. sajor-caju, fibra de coco favorece $P$. platypus e bagaço de cana de açúcar, $P$. citrinopileatus, mas não fazem correlação entre as espécies e os substratos utilizados para os teores de nutrientes encontrados.

No Brasil, STURION e OETTERER (1995) determinaram a composição dos corpos de frutificação de três espécies de Pleurotus cultivados em quatro diferentes substratos. Foi avaliado o teor de água, nitrogênio, extrato aéreo, fibra bruta, celulose, hemicelulose, lignina, cinza, micro e macro nutrientes. Os resultados obtidos pelos autores demonstraram que a composição dos cogumelos variou, além da espécie, com o substrato utilizado sendo os componentes mais afetados a proteína, a fração fibrosa e os minerais.

RAGUNATHAN e SWAMINATHAB (2003) cultivaram espécies de Pleurotus em diferentes substratos (resíduos agrícolas). Nesse trabalho, verificaram que não houve interferência do tipo de resíduo utilizado na composição dos cogumelos.

Uma observação importante no cultivo dos cogumelos é que, muitas vezes, ao se utilizar os chamados "sacos de lixo" para acondicionar o composto, podem-se ter problemas de desenvolvimento do micélio, pois estes plásticos são elaborados a partir de resíduos e podem conter substâncias tóxicas (BONONI e col. 1999). 
O substrato mais utilizado no Brasil para o cultivo de Pleurotus é o bagaço de cana-de-açúcar acrescentado com farelo de arroz ou soja para aumentar a produtividade. Tem-se utilizado uma mistura de bagaço de cana mais $10-20 \%$ de farelo em peso seco, além disso, adiciona-se 2\% de carbonato de cálcio ou 4\% de cal hidratada, em relação ao peso seco do substrato. A função do carbonato de cálcio é corrigir o $\mathrm{pH}$ do composto, que deve estar por volta de 6,0 .

Em alguns países, o uso de troncos de árvores também ocorre na produção de cogumelos Pleurotus. No Canadá a produção do Pleurotus sobre pedaços de troncos de madeiras colocados em bosques (Figura 2.15), em áreas de reflorestamento é significativa, segundo BONONI e col. (1999). Os cogumelos Pleurotus crescem sobre diversas madeiras, fazendo exceção as muito resinosas, como no caso de alguns pinheiros (BONONI e col. 1999).

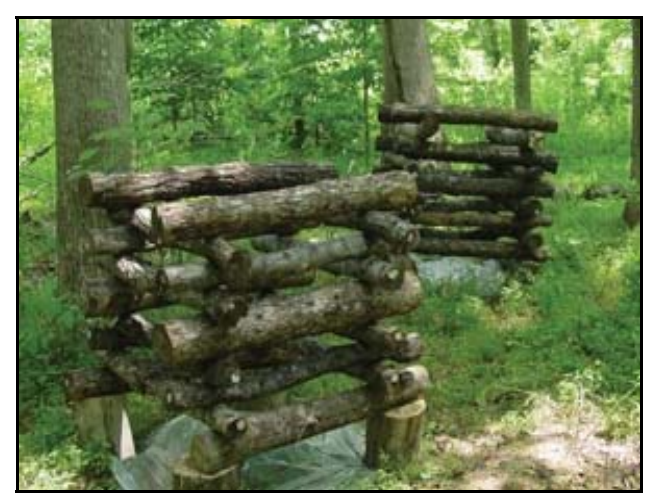

Figura 2.15- Troncos colocados sob florestas para

o cultivo de cogumelos Pleurotus

Quando o cultivo é realizado em toras, a colheita dos cogumelos Pleurotus tem inicio após 6 a 12 meses da inoculação. Pode ser feita manualmente ou com um auxílio de uma faca. De modo geral, a produtividade corresponde de 15 a $32 \%$ do peso da madeira 
inoculada, dependendo de vários fatores, tais como qualidade da madeira utilizada, linhagem do cogumelo e condições de temperatura e umidade (BONONI e col.,1999).

A duração da produtividade está relacionada ao tipo de madeira utilizada: madeiras moles podem produzir cogumelos por 2 a 3 anos, já as madeiras duras começam a produzir os cogumelos mais tarde, porém por um período mais longo, de 4 a 5 anos (BONONI e col.,1999).

\subsubsection{O cultivo de cogumelos: Gênero Lentinus}

Tradicionalmente, no estado de São Paulo o shitake (Lendinus edodes) é produzido em cepos de eucalipto, mas o cultivo axênico em substratos sintéticos à base de diversos resíduos agrícolas vem ganhando espaço na produção comercial deste cogumelo, uma vez que a colheita acontece mais rapidamente e a eficiência biológica do fungo é bastante elevada. Por ser apto a utilizar lignina, celulose e hemicelulose como fonte de carbono e nutrientes, o shitake pode ser cultivado em uma grande variedade de resíduos agrícolas, dentre eles o bagaço de cana.

O habitat natural dos cogumelos shitake (Lentinus edodes) compreende a zona temperada do Nordeste Asiático, onde ocorre em troncos de madeira de árvores decíduas (Figura 2.16).

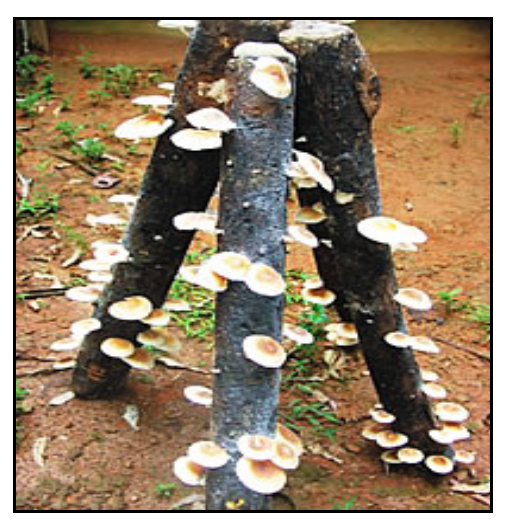

Figura 2.16- Cogumelos Lentinus edodes em troncos de árvores 
O cultivo de Lentinus edodes, é o mais antigo dentre todos os cogumelos comestíveis. Segundo a literatura, o seu consumo ocorre há milhares de anos. Um cultivo primitivo iniciou-se há aproximadamente 800 anos na China (BONONI e col.,1999).

Esse cogumelo é o de segundo maior consumo no mundo (COUTINHO, 2004; SUGUI e col., 2003). O Japão aperfeiçoou o cultivo e atualmente é o maior produtor mundial. São citados na literatura aspectos medicinais e terapêuticos do shitake (Lentinus edodes) devido ao grande número de compostos biologicamente ativos, que já foram isolados e purificados.

Muitas pesquisas estão sendo desenvolvidas para a melhor avaliação desse potencial (SUGUI e col. 2003). A medicina popular indica o shitake para fortificar e restaurar o organismo. É indicado para todas as enfermidades que envolvam o enfraquecimento do sistema imunológico. CHANG e MILES (1989) descrevem efeitos antivirais e antitumorais em extrato aquoso desse cogumelo.

Na China e no Japão, o cogumelo do gênero Lentinus faz parte do cardápio usual da população. No Brasil, devido à existência de uma grande colônia asiática, há mercado consumidor em potencial, tendo, porém, somente alguns pequenos produtores. Existem várias linhagens desse cogumelo, que têm sido melhoradas geneticamente para maior produtividade e tolerância às diferentes temperaturas.

O L. edodes, devido ao seu elevado potencial de biodegradação, é descrito como fungo da madeira e produtor da "podridão branca", responsável pela decomposição da lignina. Normalmente, utilizam-se árvores para o cultivo deste cogumelo, sendo que a Castanheira, o Carvalho e o Olmo são as mais comuns. No entanto, estas árvores não são nativas do Brasil, por isso, os produtores costumam fazer um cultivo paralelo dessas árvores para a produção do substrato. No Estado de São Paulo, o eucalipto é o substrato mais utilizado. 
Os troncos utilizados para o cultivo possuem, em geral, de 9 a $18 \mathrm{~cm}$ de diâmetro e de 1 a 1,20 m de comprimento. A árvore cortada permanece na floresta por cerca de 20 a 30 dias para diminuir a umidade e permitir que substâncias que possam ser nocivas ao desenvolvimento do micélio sejam eliminadas. Somente então é que se cortam os troncos nos tamanhos desejados e retiram-se os galhos.

De acordo com BONONI e col. (1999), para a inoculação dos troncos é preciso perfurá-los. O método mais simples para a realização desta tarefa é através de furadeira elétrica. Lembrando que os orifícios devem ser recobertos com parafina fundida, para impedir a perda de água e o ataque de insetos. É importante que a parafina não esteja muito quente, pois pode matar o micélio. No Brasil, um grande problema são as formigas que se alimentam da matriz, se estas não estiverem devidamente protegidas.

O local ideal para a incubação do Lentinus edodes deve possuir as seguintes características: terreno em declive e com boa drenagem, ventilação moderada e insolação de $30 \%$. Pode-se ainda realizar esta etapa em locais especialmente construídos, como casas de cultivo, onde se têm o controle de temperatura, umidade, luminosidade e ventilação. A temperatura ideal para o desenvolvimento do micélio da maioria das linhagens é de $24-28^{\circ}$ C. Após a total colonização, os troncos são transferidos para um local mais úmido, menos ensolarado e com temperaturas entre 12 e $20^{\circ} \mathrm{C}$, que são propícias para o desenvolvimento dos corpos de frutificação (EMBRAPA, 2006).

A colheita inicia-se geralmente de 12 a 18 meses após o inóculo. O pico da produção acontece no $2^{\circ}$ e $3^{\circ}$ ano de colheita, sendo que o ciclo total pode durar até 7 anos. Em média, colhem-se $20 \%$ do peso inicial da madeira em cogumelos. Os cogumelos estão bons para serem colhidos após 4 ou 5 dias do aparecimento dos botões (BONONI e col.,1999). 
Para o cultivo em barracão, a metodologia adotada é a mesma descrita anteriormente. No entanto, utilizam-se barracões climatizados tanto para incubação quanto para a produção dos cogumelos. Como conseqüência direta, o ciclo produtivo fica mais curto, sendo, portanto, mais rentável em curto prazo.

A técnica de cultivo de Lentinus edodes em serragem foi desenvolvida principalmente no Japão. Outros países como Holanda e Estados Unidos estão também utilizando este método para a produção em grande escala. As vantagens desta técnica estão na maior facilidade de manuseio, controle das condições climáticas e ciclo mais curto de produção (BONONI e col., 1999).

A serragem (Figura 2.17) utilizada é das mesmas árvores que se utilizam para o cultivo em troncos. A formulação mais tradicional é baseada em $90 \%$ da serragem e $10 \%$ de farelo de arroz. Se necessário deve-se adicionar $\mathrm{CaCO}_{3}$ para correção do $\mathrm{pH}$, que deve ficar em torno de 4,5-6,0\%. A umidade deve ser mantida entre 55 e 70\%, dependendo da capacidade de retenção de água da serragem utilizada. A mistura de serragem é acondicionada em sacos de plástico polipropileno com uma tampa de algodão para as trocas gasosas (BONONI e col., 1999).

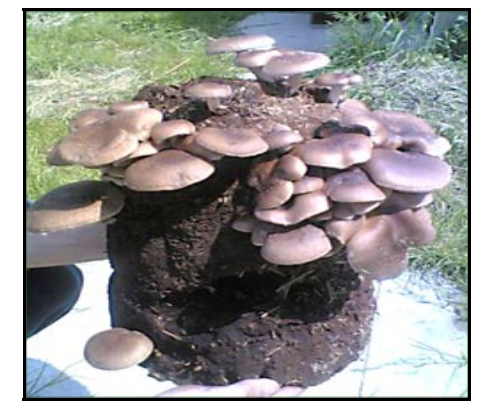

Figura 2.17- Serragem com Lentinus edodes

Para a indução do aparecimento dos corpos de frutificação dos cogumelos Lentinus deve-se dar um choque térmico de 24 a 48 horas a $10^{\circ} \mathrm{C}$, através do controle 
climático das salas de produção, elevando-se a umidade ao máximo possível. Outra opção é mergulhar os blocos colonizados em água fria, por 24 a 48 horas. Depois que aparecem os primórdios os cogumelos podem ser colhidos em 4 a 5 dias. A temperatura durante o período de produção deve ser mantida entre 15 e $20{ }^{\circ} \mathrm{C}$ e dura de 3 a 5 meses (BONONI e col., 1999).

A região de Mogi das Cruzes, no Estado de São Paulo é responsável pela produção de pelo menos $70 \%$ dos cogumelos comestíveis comercializados no Brasil. Os restantes $30 \%$ ocorrem por conta de outros municípios, sendo a maioria também no estado de São Paulo, como Ribeirão Pires, Suzano, Cabreúva, Atibaia e Mairiporã. Há alguns produtores em Porto Alegre, Sul de Minas Gerais e no Paraná (BONONI e col., 1999). 


\section{CAPÍTULO 3}

\section{METODOLOGIA}

A técnica analítica empregada para a determinação dos elementos nos cogumelos comestíveis foi a Análise por Ativação com nêutrons Instrumental (INAA).

A seguir será apresentado um resumo das principais características da técnica de Análise por Ativação com Nêutrons (NAA)

\subsection{Princípios da análise por ativação com nêutrons (NAA)}

A análise por ativação com nêutrons (NAA) é uma técnica nuclear de alta sensibilidade, com boa precisão e exatidão, útil para análises multielementares qualitativas e quantitativas dos macro e micro elementos e elementos traço, em amostras dos mais variados campos de aplicação (KELLER, 1981).

Um procedimento típico na análise por ativação com nêutrons é caracterizado por:

- Ativação da amostra a ser analisada, via irradiação com nêutrons;

- Medição da radiação gama induzida;

- Interpretação e análise do espectro gama para identificação dos radionuclídeos formados e cálculo das concentrações dos elementos. 
A ativação do elemento de uma amostra com nêutrons é o primeiro estágio do processo. Cada núcleo atômico pode capturar um nêutron durante a irradiação, dando início a uma reação nuclear. Imediatamente após a captura forma-se um núcleo composto, e o excesso de energia é liberado com a emissão de radiação gama (raios gama prontos) e/ou partículas. O núcleo produto, formado após a reação nuclear, pode ser um núcleo instável. Neste caso, já durante o processo de ativação, o núcleo produto instável começa a decair buscando uma configuração de estabilidade através da emissão de radiação pelos seguintes processos: decaimento $\alpha$, decaimento $\beta^{-}$, decaimento $\beta^{+}$, captura eletrônica. $\mathrm{Na}$ maioria dos casos, raios X e radiação gama (raios gama retardados ou de decaimento) são também emitidos.

A reação mais comum utilizada em NAA é a reação de captura de nêutrons térmicos, ou a reação $(n, \gamma)$.

Supondo-se que um nuclídeo $(\mathrm{X})$ sofra uma reação nuclear tipo (n, $\gamma$ ), um nuclídeo radioativo (Y) será formado, que decairá para um nuclídeo estável $(\mathrm{C})$ :

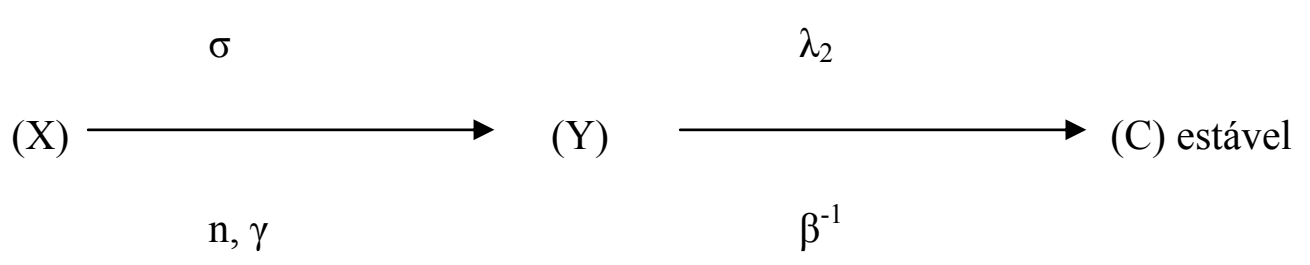

onde:

$\sigma_{1:}$ secção de choque de ativação do nuclídeo $(\mathrm{X})$

(n, $\gamma$ ): reação e captura radioativa, em que o núcleo captura um elétron e emite $\gamma$

$\lambda_{2}$ : constante de decaimento do nuclídeo formado $(\mathrm{Y})$

A Figura 3.1 ilustra como exemplo, o mecanismo de uma reação nuclear (n, $\gamma$ ). 


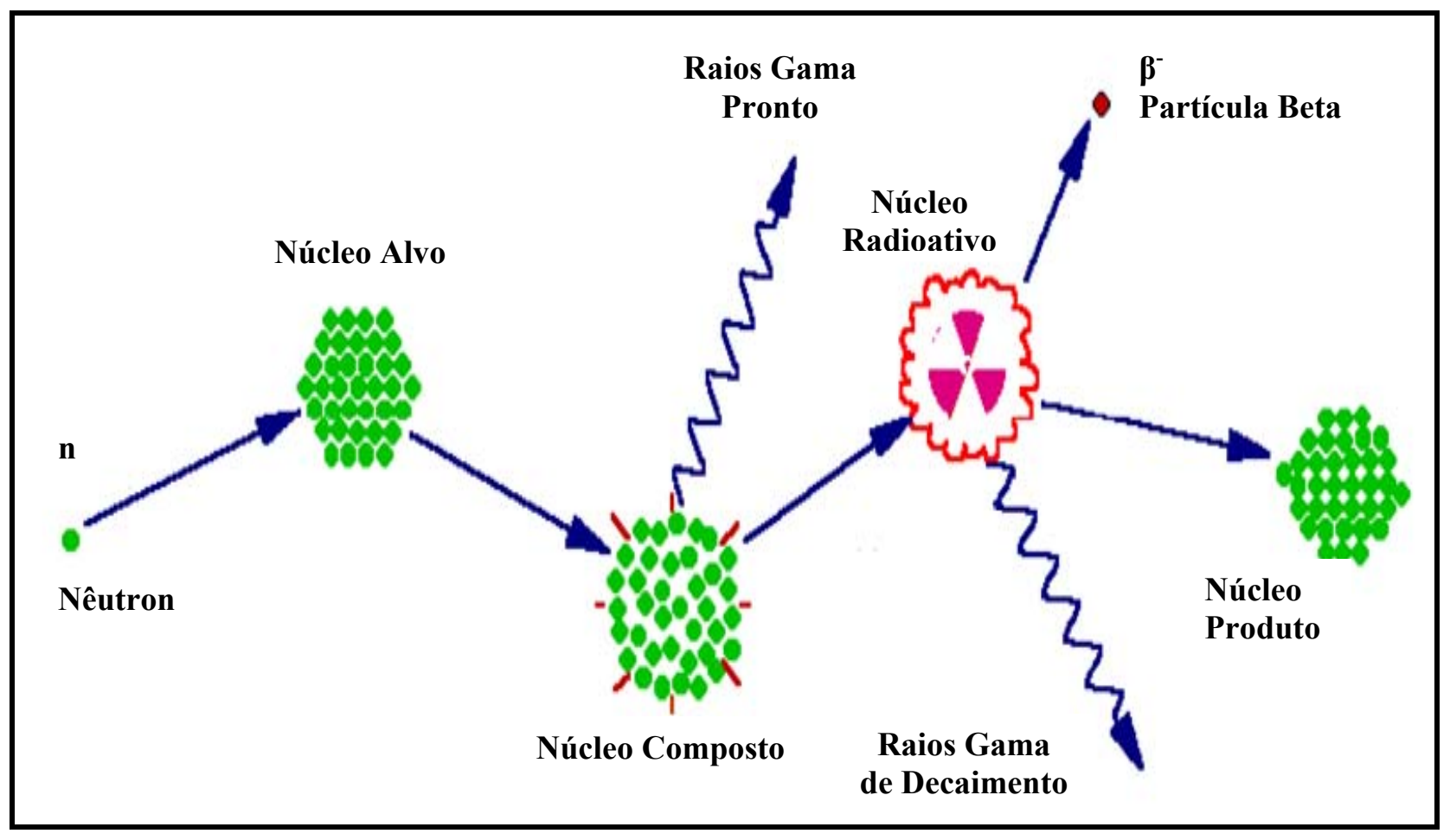

Figura 3.1- Seqüência de eventos do mecanismo da reação nuclear do tipo ( n, $\gamma$ )

A técnica deNAA pode pertencer a duas categorias:

a) Análise por ativação com nêutrons de raios gamas prontos, na qual a medição se dá durante a irradiação. Esta técnica é conhecida por PGNAA.

b) Análise por ativação com nêutrons de raios gama de decaimento

Esta última é a mais comum e, em geral, o termo NAA é empregado para este tipo de análise e será utilizado neste texto. A PGNAA é menos sensível que a NAA e tem aplicação em elementos de elevada secção de choque para captura de nêutrons, como o B, $\mathrm{Cd}, \mathrm{Gd}$ e $\mathrm{Sm}$; em elementos que decaem muito rapidamente para serem medidos por NAA; e em elementos que produzem apenas isótopos estáveis ou para elementos com intensidades de decaimento de raios gama fracas.

A sensibilidade disponível por NAA depende dos parâmetros de irradiação (fluxo de nêutrons, tempos de irradiação e decaimento), condições de medição (tempos de medição e eficiência do detector), e dos parâmetros nucleares dos elementos em estudo 
(abundância isotópica, secção de choque para nêutrons, meias vidas e abundâncias de raios gama).

Atividade induzida em um elemento alvo na NAA

A atividade de um radionuclídeo produzido em uma reação nuclear é uma medida direta da quantidade do elemento alvo presente da amostra irradiada. Com a finalidade de se obter a atividade induzida em um elemento Y após determinado tempo de irradiação, consideremos, como exemplo, a reação X (a, b) Y. A taxa de formação do núcleo produto Y é dada por:

$$
\frac{d N_{y}}{d t}=\sigma \cdot \phi \cdot N_{x}
$$

onde $\sigma$ é a secção de choque da reação, $\varnothing$ é o fluxo de nêutrons e $N_{X}$ é o número de átomos do núcleo alvo $\mathrm{X}$. Considerando que o tempo de irradiação de pequenas quantidades do elemento alvo seja curto, podemos assumir que o fluxo da partícula incidente (a) permaneça constante em todo o volume do elemento alvo durante o período de irradiação, e que $N_{X}$ permaneça constante, isto é, que o número de núcleos que sofreram transmutação na reação nuclear pode ser desprezado. Se o núcleo produto Y produzido pela reação $\mathrm{X}(\mathrm{a}, \mathrm{b}) \mathrm{Y}$ é radioativo, então a sua taxa de decaimento $\left(\lambda \mathrm{N}_{\mathrm{Y}}\right)$ durante o tempo de irradiação deve ser levada em consideração, a Equação (2) é então escrita como:

$$
\frac{d N_{y}}{d t}=\sigma \cdot \phi \cdot N_{x}-\lambda N_{y}
$$


onde $\lambda$ é a constante de decaimento do núcleo produto $\mathrm{Y}$.

Integrando a equação (3) desde o início da irradiação $(t=0)$ até o tempo final da irradiação $\left(t=t_{i}\right)$, e considerando que no instante $t=0, N_{Y}=0$, temos:

$$
N_{y}=\frac{\sigma \cdot \phi \cdot N_{x}}{\lambda} \cdot\left(1-e^{-\lambda t i}\right)
$$

Usualmente, o que se determina não é a quantidade $N_{Y}$ formada na irradiação, mas sim a taxa de decaimento de $N_{Y}$, conhecida por atividade (A):

$$
A=-\frac{d N_{y}}{d t}=\lambda \cdot N_{y}
$$

O número de átomos $N_{X}$ do núcleo alvo pode ser expresso em função da sua massa $m$ :

$$
N_{x}=\frac{N_{0}}{M} \cdot f \cdot m
$$

Onde $N_{0}$ é o número de Avogrado, $M$ é a massa atômica do elemento, $f$ é a abundância isotópica do núcleo alvo $\mathrm{X}$.

Substituindo as Equações (5) e (6) na Equação (4) temos que:

$$
A=\frac{\sigma \cdot \phi \cdot N_{0} \cdot f \cdot m}{M} \cdot\left(1-e^{-\lambda t i}\right)
$$

A Equação (7) mostra que a atividade produzida é diretamente proporcional à quantidade do núcleo alvo, desde que as condições de irradiação permaneçam inalteradas. Ainda, a atividade produzida e a sensibilidade da NAA aumentam com o aumento do fluxo $\varnothing$. 
Para a reação nuclear do tipo $(\mathrm{n}, \gamma)$, discutida no presente trabalho, a atividade induzida $A$ em um elemento alvo pode ser medida experimentalmente, após um tempo de irradiação $t_{i}$, por um meio de um sistema de detecção adequado. Sendo $\varepsilon$ a eficiência do sistema de detecção, a Equação (7) para a reação em questão é dada por:

$$
A=\frac{\varepsilon \cdot \sigma \cdot \phi \cdot N_{0} \cdot f \cdot m}{M} \cdot\left(1-e^{-\lambda t i}\right)
$$

onde,

$A$ - atividade induzida após o tempo de irradiação, em contagens por segundo;

$\varepsilon$ - eficiência do sistema de detecção;

$\sigma$ - secção de choque de captura de nêutrons térmicos, em $\mathrm{cm}^{2}$;

$\varnothing$ - fluxo de nêutrons térmicos incidentes no núcleo alvo, $\mathrm{em}^{-2} \mathrm{~s}^{-1}$;

$N_{0}$ - número de Avogrado;

$f$ - abundância isotópica do núcleo alvo;

$m$ - massa do núcleo alvo, em g;

$M$ - massa atômica do núcleo alvo;

$t_{i}$ - tempo de irradiação, em segundos;

$\lambda$ - é a constante de decaimento do núcleo produto, em s ${ }^{-1}$, sendo $\lambda=\frac{0,693}{t_{1 / 2}}$

Convém lembrar que, normalmente, a atividade induzida $A$ em um elemento alvo não é medida experimentalmente imediatamente após o tempo de irradiação $t_{i}$, existe um intervalo de tempo $t_{d}$ entre o final da irradiação e o tempo de início da medida experimental. Levando-se em consideração o tempo de decaimento $t_{d}$, a Equação (8) tornase:

$$
A=\frac{\varepsilon \cdot \sigma \cdot \phi \cdot N_{0} \cdot f \cdot m}{M} \cdot\left(1-e^{-\lambda t i}\right) \cdot e^{-\lambda t d}
$$

O método de NAA que utiliza a Equação (9) é conhecido como NAA absoluto. Teoricamente, é possível o uso do método absoluto na análise experimental, mas não é muito comum, uma vez que a maioria dos parâmetros nucleares apresentados na Equação (9) não são conhecidos com exatidão, o que torna este método absoluto bastante limitado. 
Dessa forma, uma vez que as secções de choque $\sigma$ de captura de nêutrons térmicos para a maioria dos radionuclídeos não são bem conhecidas e como o fluxo de nêutrons térmicos incidentes no núcleo alvo pode variar durante o período de irradiação, o método comparativo da NAA é normalmente utilizado no Laboratório de Análise por Ativação, LAN do IPEN/CNEN-SP

Método comparativo na NAA

No método comparativo de análise por ativação com nêutrons, a amostra e um padrão do elemento a ser determinado são irradiados simultaneamente, sob as mesmas condições, e ambos medidos com o mesmo detector. Desta forma, o fluxo $\varnothing$ de nêutrons térmicos incidentes no elemento, a secção de choque $\sigma$ de captura de nêutrons térmicos, o tempo de irradiação, a eficiência $\varepsilon$ do sistema de detecção e todas as outras variáveis associadas às contagens são constantes tanto para a amostra como para o padrão, tornando possível a determinação da concentração do elemento na amostra através de uma comparação entre as atividades induzidas na amostra e no padrão, uma vez que a taxa de emissão de radiação por um material é proporcional ao seu número de átomos. O método comparativo não exige a necessidade do conhecimento dos valores dos parâmetros nucleares mostrados na Equação (9), tornando mais simples o cálculo da concentração de um elemento presente na amostra em estudo.

De acordo com a Equação (9) e considerando o tempo de decaimento da amostra e do padrão, respectivamente, como $t_{d a}$ e $t_{d p}$ (com $t_{d a} \neq t_{d p}$, pois a taxa de contagem da amostra e do padrão não são obtidas simultaneamente), a atividade induzida $\mathrm{A}_{\mathrm{a}}$ em um elemento da amostra e a atividade induzida $A_{p}$ em um mesmo elemento padrão são dadas por: 


$$
\begin{aligned}
& A \underset{a}{\frac{\varepsilon \cdot \sigma \cdot \phi \cdot N_{0} \cdot f \cdot m_{a}}{M}} \cdot\left(1-e^{-\lambda t i}\right) \cdot e^{-\lambda t d a} \\
& A_{a} \frac{\varepsilon \cdot \sigma \cdot \phi \cdot N_{0} \cdot f \cdot m_{a}}{M} \cdot\left(1-e^{-\lambda t i}\right) \cdot e^{-\lambda t d p}
\end{aligned}
$$

Dividindo-se a Equação (10) pela Equação (11) temos:

$$
\begin{aligned}
& \frac{A_{a}}{A_{p}}=\frac{m_{a}}{m_{p}} \cdot \frac{e^{-\lambda t d a}}{e^{-\lambda t d p}} \\
& m_{a}=\frac{m_{p} \cdot A_{a} \cdot e^{\lambda\left(t_{d a}-t_{d p}\right)}}{A_{p}}
\end{aligned}
$$

A concentração $C_{a}$ do elemento contido na amostra é dada por:

$$
C_{a}=\frac{m_{a}}{M_{a}}
$$

Substituindo a Equação (13) na equação (14):

$$
C_{a}=\frac{m_{p} \cdot A_{a} \cdot e^{\lambda\left(t_{d a}-t_{d p}\right)}}{M_{a} \cdot A_{p}}
$$

onde:

os índices $p$ e $a$ referem-se a padrão e amostra, respectivamente;

$m_{p}$ - massa do elemento no padrão, em $\mu \mathrm{g}$;

$M_{a}$ - massa total da amostra, em gramas; 
A concentração do elemento contido na amostra, pelo método comparativo, é calculada através da Equação (15). O termo exponencial da Equação (15) leva em consideração o decaimento da amostra e do padrão, uma vez que a taxa de contagem da amostra e do padrão não são obtidas simultaneamente. A simplicidade deste cálculo é uma grande vantagem do método comparativo, pois não é necessário conhecer todos os parâmetros nucleares envolvidos no processo. De uma forma geral, a massa $m_{a}$ de uma amostra é medida e depois irradiada simultaneamente com um material cuja concentração do elemento a ser determinado já é conhecida (elemento padrão). Em seguida, obtém-se a taxa de contagem para a amostra e para o padrão utilizando-se um sistema de detecção adequado. A comparação entre estas taxas de contagens é a base para o cálculo da concentração do elemento contido na amostra.

No presente trabalho foi utilizado o método de Análise por Ativação com Nêutrons Instrumental (INAA), que consiste em analisar a amostra sem destruí-la, ou seja, não é necessário dissolver a amostra em solução para análise. Está técnica permite, em alguns casos, determinar simultaneamente as concentrações de cerca de 20 elementos numa única análise. Para uma análise multielementar completa, os elementos são divididos em 3 grupos dependendo da meia-vida de seus produtos da irradiação com nêutrons.

a) curta (2min- 15 horas) tais como: ${ }^{35} \mathrm{Cl},{ }^{27} \mathrm{Mg},{ }^{56} \mathrm{Mn},{ }^{24} \mathrm{Na}$

b) intermediária (0,5-5 dias) tais como: ${ }^{76} \mathrm{As},{ }^{82} \mathrm{Br},{ }^{47} \mathrm{Ca},{ }^{140} \mathrm{La}$

c) longa (maior que 5 dias) tais como: ${ }^{51} \mathrm{Cr},{ }^{59} \mathrm{Fe},{ }^{75} \mathrm{Se},{ }^{65} \mathrm{Zn}$ 


\subsection{PARTE EXPERIMENTAL}

\subsubsection{Aquisição das amostras de cogumelos}

As amostras de cogumelos foram adquiridas nos grandes centros de compra (supermercados), mercados municipais da cidade de São Paulo e diretamente dos produtores da região de Mogi das Cruzes, Suzano, Juquitiba e Mirandópolis.

A aquisição das amostras ocorreu no período de novembro de 2006 a março 2007. Foram adquiridas em embalagens de $400 \mathrm{~g}$ de cada espécie, amostras dos gêneros Agaricus, Pleurotus e Lentinus, (Figura 3.2).

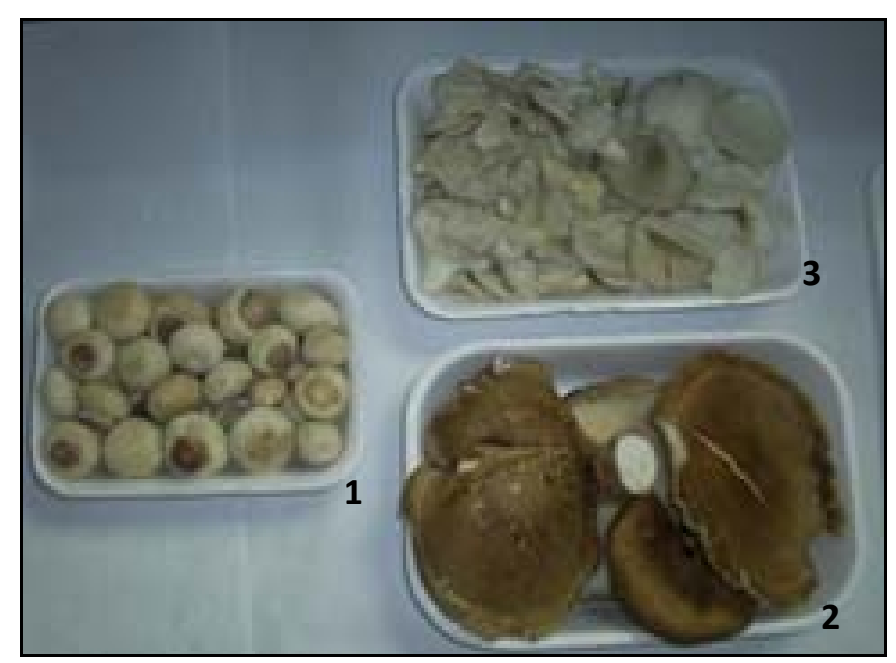

Figura 3.2- Foto das amostras de cogumelos 1- Agaricus bisporus, 2-Lentinus edodes, 3-Pleurotus eryngüi

Foram adquiridas 8 espécies de cogumelos diferentes, sendo 5 amostras do gênero Agaricus, 7 amostras do gênero Lentinus e 6 amostras do gênero Pleurotus, totalizando 18 amostras de cogumelos. A Tabela 3 apresenta as 8 espécies de cogumelos adquiridas, com as respectivas nomenclaturas científicas, nomes comerciais, suas procedências e características. 
Tabela 3: Nomenclaturas científicas, comerciais, procedências e características das amostras de cogumelos comestíveis.

\begin{tabular}{|c|c|c|c|}
\hline NOME CIENTÍFICO & $\begin{array}{c}\text { NOME } \\
\text { COMERCIAL }\end{array}$ & PROCEDÊNCIA & CARACTERÍSTICA \\
\hline Lentinus edodes & Shitake & $\begin{array}{l}\text { - } \text { São Paulo } \\
\text { - } \text { Suzano * } \\
\text { - } \text { Juquitiba * } \\
\text { - } \text { Mirandópolis * } \\
\text { - } \text { Mogi das Cruzes * } \\
\text { - Japão } \\
\text { - } \text { China }\end{array}$ & $\begin{array}{l}\text { in natura } \\
\text { in natura } \\
\text { in natura } \\
\text { in natura } \\
\text { in natura } \\
\text { desidratado } \\
\text { desidratado }\end{array}$ \\
\hline Pleurotus ostreatus & Shimeji escuro & $\begin{array}{l}\text { - São Paulo } \\
\text { - } \text { Mogi das Cruzes * }\end{array}$ & $\begin{array}{l}\text { in natura } \\
\text { in natura }\end{array}$ \\
\hline Pleurotus florida & Shimeji branco & - São Paulo & in natura \\
\hline Pleurotus ssp & Hiratake & - São Paulo & in natura \\
\hline Pleurotus ostreatoroseus & Salmão Rosa & - São Paulo & in natura \\
\hline Pleurotus eryngüi & Eringue & - São Paulo & in natura \\
\hline Agaricus bisporus & Champignon de Paris & $\begin{array}{l}\text { - } \text { São Paulo } \\
\text { - } \text { São Paulo } \\
\text { - } \text { Mogi das Cruzes } \\
\text { - } \text { Mogi das Cruzes* }\end{array}$ & $\begin{array}{l}\text { in natura } \\
\text { em conserva } \\
\text { in natura } \\
\text { in natura }\end{array}$ \\
\hline Agaricus sp & Porto Belo & - São Paulo & in natura \\
\hline
\end{tabular}




\subsubsection{Preparação das amostras}

Após a aquisição, as amostras foram levadas ao laboratório de Análise por Ativação Neutrônica - LAN-IPEN/CNEN-SP e passaram pelas seguintes etapas antes das análises:

No inicio do estudo, algumas amostras foram divididas em duas partes, onde uma parte foi lavada e para isso ficaram submersas por 10 minutos em água Milli-Q e outra não sofreu lavagem. As amostras que sofreram lavagem foram colocadas em peneiras de plásticos limpas para retirar o excesso de água, antes de serem cortadas.

No decorrer da preparação das amostras foi observado que muitos cogumelos apresentavam sujeiras (restos de terra e pedaços de madeira), que necessitavam serem retiradas. Mesmo sabendo que os grandes chefes da culinária recomendam não lavar o cogumelo para o consumo, pois esta prática pode altera seu sabor e textura, optou-se por lavar todas as amostras, uma vez que grande parte da população lava os cogumelos para o consumo. Desta forma, apenas algumas amostras adquiridas no inicio do estudo foram analisadas sem lavar.

Todas as partes dos cogumelos (estipe e píleo) foram cortadas em pequenas fatias utilizando-se facas plásticas previamente limpas em ácido nítrico diluído a $10 \%$ ou faca de titânio e colocadas em placas de Petri ou potes plásticos, ambos limpos com ácido nítrico diluído a $10 \%$. As placas ou potes com cogumelos ficaram no freezer por no mínimo 12 horas.

As Figuras 3.3, 3.4 e 3.5, apresentam algumas etapas da preparação das amostras. 


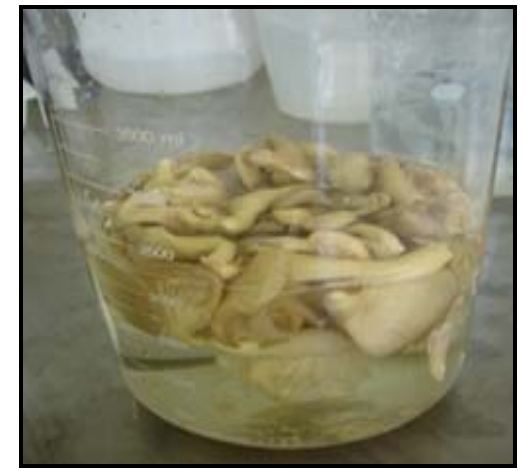

Figura 3.3- Lavagem do cogumelo com agua Milli-Q

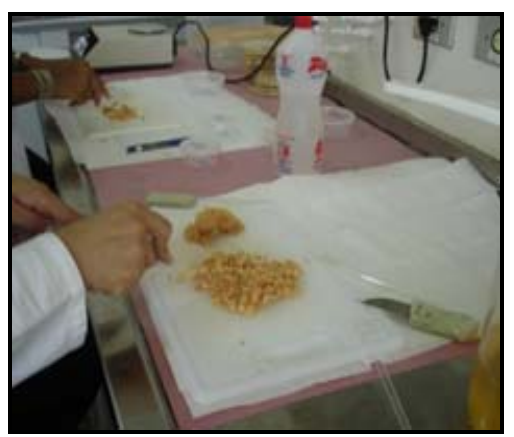

Figura 3.4- Corte dos cogumelos para liofilização

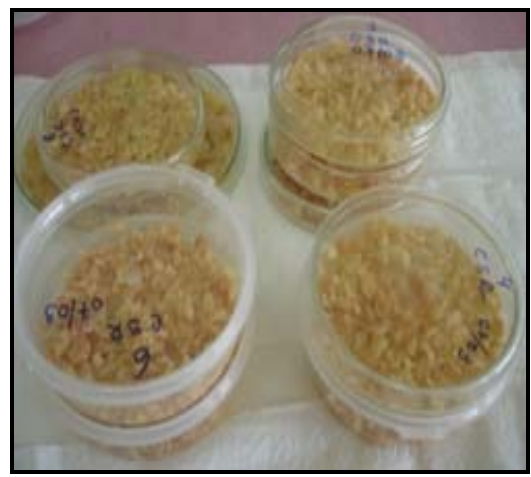

Figura 3.5- Cogumelos para liofilização

Todas as amostras congeladas foram liofilizadas por aproximadamente $10 \mathrm{a}$ 15 horas até a pressão de $45 \mu$ bar no liofilizador Modulyo D-115 da Thermo Electron Corporation (Figura 3.6). As amostras já liofilizadas foram então homogeneizadas em liquidificador doméstico, adaptado com lâminas de titânio (Figura 3.7). 


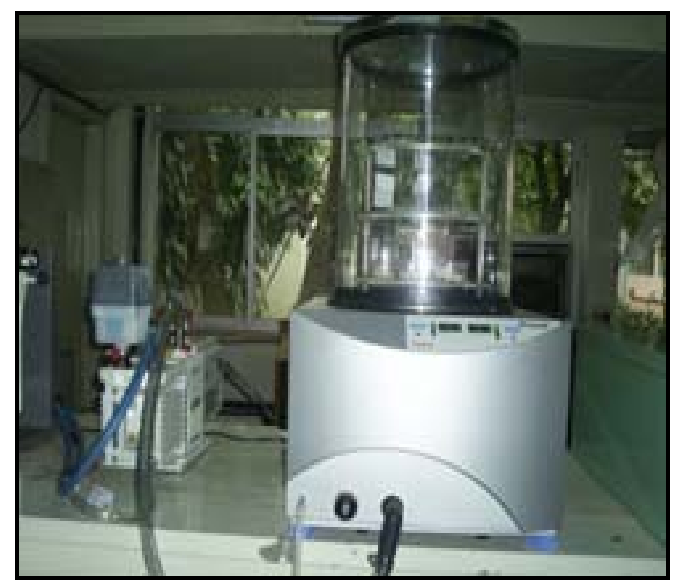

Figura 3.6- Liofilizador Modulyo D-115

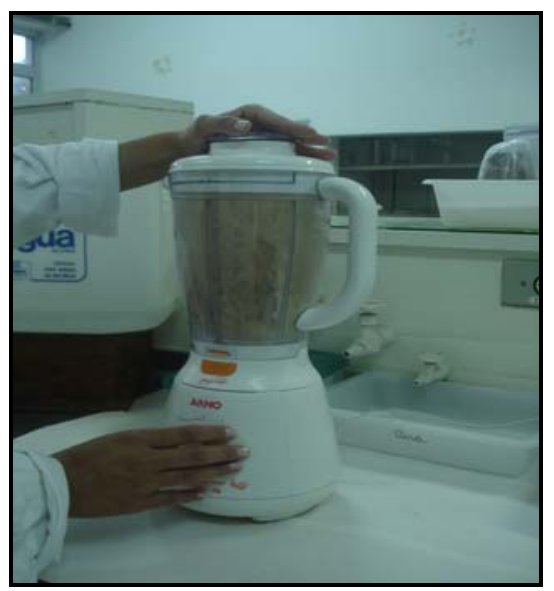

Figura 3.7-Liquidificador para homogeneização dos cogumelos

Para a determinação do teor de umidade residual das amostras de cogumelos, foi utilizado o Analisador de umidade Modelo MB45 da OHAUS. Todas as amostras tiveram sua umidade residual determinada. Os valores médios para cada gênero foram: 9,08 \% Gênero Agaricus, 7,74 \% Gênero Lentinus e 8,47\% Gênero Pleurotus. 


\subsubsection{Preparação das amostras para irradiação}

Cerca de 150 a $200 \mathrm{mg}$ de cada amostra de cogumelo liofilizado e homogeneizado foram pesados em invólucros de plásticos previamente limpos e desmineralizados com água deionizada e ácido nítrico PA diluído.

\subsubsection{Preparação dos padrões sintéticos dos elementos}

Padrões dos elementos $\mathrm{As}, \mathrm{Br}, \mathrm{Co}, \mathrm{Cr}, \mathrm{Cs}, \mathrm{Fe}, \mathrm{K}, \mathrm{Na}, \mathrm{Rb}$, Se, e $\mathrm{Zn}$ foram preparados a partir das soluções padrão certificadas da marca SPEX CERTI PREP, as quais após as diluições apropriadas, foram pipetadas em tiras de papel de filtro Whatman 40.

Solução padrão diluída de As $\left(100 \mu \mathrm{g} \mathrm{L}^{-1}\right)$ foi preparada, pipetada individualmente e seca em temperatura ambiente. Padrão pipetado de $\mathrm{Br}$ foi seco também em temperatura ambiente.

Uma solução multielementar de Co, Cr, Cs e Se $\left(100 \mu \mathrm{g} \mathrm{Co} \mathrm{L}{ }^{-1}, 201 \mu \mathrm{g} \mathrm{Cr} \mathrm{L}{ }^{-1}\right.$, 9,91 $\mu \mathrm{g} \mathrm{Cs} \mathrm{L}{ }^{-1}$ e $202 \mu \mathrm{g} \mathrm{SeL}^{-1}$ ), foi preparada e $25 \mu \mathrm{L}$ dessa solução foi pipetada e seca sob lâmpada de infravermelho. Os padrões de $\mathrm{Fe}, \mathrm{Zn}$, Na e K foram pipetadas diretamente das soluções estoques e secas sob lâmpada de infravermelho.

Após a secagem, as tiras de papel de filtro foram acondicionadas em invólucros de plásticos limpos e desmineralizados. A Tabela 4 apresenta as concentrações das soluções estoques iniciais e as soluções diluídas dos padrões e suas respectivas massas pipetadas. 
Tabela 4: Concentração dos elementos nas soluções estoque dos padrões e massa dos elementos irradiados

\begin{tabular}{|c|c|c|}
\hline ELEMENTO & $\begin{array}{c}\text { CONCENTRAÇÃO DO } \\
\text { ELEMENTO } \\
\left(\mathrm{mg} \mathrm{L}^{-1}\right)\end{array}$ & $\begin{array}{c}\text { MASSA DO } \\
\text { ELEMENTO } \\
\text { IRRADIADA }(\mu \mathrm{g})\end{array}$ \\
\hline As & $1003,5 \pm 3,0$ & 2,48 \\
\hline $\mathrm{Br}$ & $997 \pm 3$ & 1,20 \\
\hline Co & $1001 \pm 4$ & 2,48 \\
\hline $\mathrm{Cr}$ & $999,5 \pm 3,0$ & 2,48 \\
\hline Cs & $1005 \pm 3$ & 0,12 \\
\hline $\mathrm{Fe}$ & $10032 \pm 30$ & 496 \\
\hline $\mathrm{K}$ & $10016 \pm 30$ & 990 \\
\hline $\mathrm{Na}$ & $9982 \pm 30$ & 12,4 \\
\hline $\mathrm{Rb}$ & $999 \pm 3$ & 7,03 \\
\hline $\mathrm{Se}$ & $10009 \pm 30$ & 0,25 \\
\hline $\mathrm{Zn}$ & $1000 \pm 3$ & 24,6 \\
\hline
\end{tabular}

\subsubsection{Preparação dos materiais de referência para análise}

Foram pesados em invólucros de plásticos desmineralizados, cerca de 150-200 mg de cada um dos seguintes materiais de referência: INCT-MPH-2 Mixed Polish Herbs e INCT-TL-1 Tea Leaves, ambos do Institute of Nuclear Chemistry and Technology da Polônia, NIST SRM 1577b Bovine Liver do National Institute Standard of Tecnology (NIST) e o material Mushroom da Agência Internacional de Energia Atômica (IAEA). 


\subsubsection{Irradiação das amostras e dos padrões sintéticos}

As amostras de cogumelos foram irradiadas juntamente com os padrões pipetados e os materiais de referência sob fluxo de nêutrons térmicos da ordem de $10^{12} \mathrm{~cm}^{-2} \mathrm{~s}^{-1}$ por 8 horas no reator nuclear de pesquisa IEA-R1 do IPEN/CNEN-SP.

Após períodos de decaimento de 4 e 15 dias, as atividades gama induzidas das amostras, dos padrões e dos materiais de referência foram medidas em espectrômetros gama.

\subsubsection{Medições das atividades gama induzidas}

As medidas das atividades emitidas pelos radioisótopos formados na irradiação das amostras, padrões e materiais de referência foram feitas em dois espectrômetros gama: um composto por um detector de Ge hiperpuro (Modelo POP TOP) da EG\&G ORTEC e outro por detector da Canberra Modelo GX2020, com valores de resolução de 1,90 keV e 1,76 keV para o fotopico $1332 \mathrm{keV}$ do ${ }^{60} \mathrm{Co}$. Ambos os detectores são acoplados a analisadores multicanais, a eletrônica associada e a microcomputadores ( Figura 3.8). Os espectros gama obtidos foram analisados utilizando-se os programas VISPECT 2 ou VERSÃO 2, desenvolvidos no próprio laboratório (PICCOT, 1989), que fornecem as energias da radiação gama dos radioisótopos formados e as respectivas áreas dos picos. 


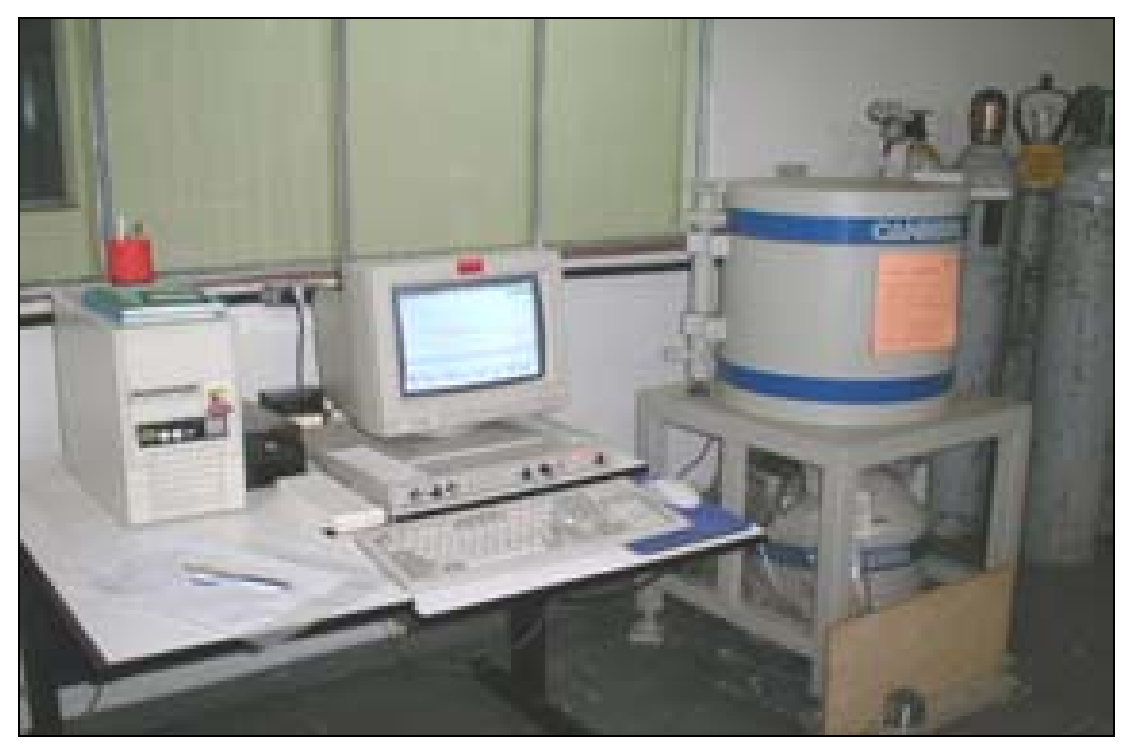

Figura 3.8-Sistema de Espectrometria gama com detector de Ge hiperpuro

As meias-vida e as energias da radiação gama dos radioisótopos ${ }^{76} \mathrm{As},{ }^{82} \mathrm{Br}$, ${ }^{60} \mathrm{Co},{ }^{51} \mathrm{Cr},{ }^{134} \mathrm{Cs}{ }^{59} \mathrm{Fe},{ }^{42} \mathrm{~K},{ }^{24} \mathrm{Na},{ }^{87} \mathrm{Rb},{ }^{75} \mathrm{Se}$ e ${ }^{65} \mathrm{Zn}$ utilizadas para a determinação de suas concentrações, estão apresentados na Tabela 5.

As concentrações dos elementos nas amostras, padrões e materiais de referência foram determinadas a partir da equação 15, apresentada na página 48 deste capítulo. 
Tabela 5: Meia-vida e energia da radiação gama dos radioisótopos (IAEA, 1990)

\begin{tabular}{|c|c|c|}
\hline RADIOISÓTOPO & MEIA VIDA & $\begin{array}{c}\text { ENERGIA DA } \\
\text { RADIAÇÃO GAMA } \\
(\mathrm{keV})\end{array}$ \\
\hline${ }^{76}$ As & 26,32 horas & 559,10 \\
\hline${ }^{82} \mathrm{Br}$ & 35,3 horas & 554,35 \\
\hline${ }^{60} \mathrm{Co}$ & 5,27 anos & 1332,50 \\
\hline${ }^{51} \mathrm{Cr}$ & 27,7 dias & 320,08 \\
\hline${ }^{134} \mathrm{Cs}$ & 2,06 anos & 604,70 \\
\hline${ }^{59} \mathrm{Fe}$ & 44,5 dias & 1099,25 \\
\hline${ }^{42} \mathrm{~K}$ & 12,36 horas & 1524,58 \\
\hline${ }^{24} \mathrm{Na}$ & 15 horas & 1368,60 \\
\hline${ }^{87} \mathrm{Rb}$ & 18,66 dias & 1076,60 \\
\hline${ }^{75} \mathrm{Se}$ & 119,8 dias & 264,66 \\
\hline${ }^{65} \mathrm{Zn}$ & 243,9 dias & 1115,55 \\
\hline
\end{tabular}




\section{CAPÍTULO 4}

\section{RESULTADOS E DISCUSSÃO}

Neste capítulo serão apresentados os valores das concentrações de elementos As, Br, Co, Cr, Cs, Fe, K, Na, Rb, Se e Zn obtidos nos materiais de referência certificados, resultados do cálculo de $\mathrm{E}_{\mathrm{n}}$ score (ISO/DIS 13528, 2002), concentrações dos elementos nas amostras de cogumelos, valores dos limites de detecção e comparação dos valores obtidos nas amostras com encontrados na literatura.

\subsection{Validação da Metodologia}

Para a validação da metodologia com relação à exatidão e à precisão foram analisados quatro materiais de referência: INCT-MPH-2 Mixed Polish Herbs e INCT-TL-1 Tea Leaves, ambos do Institute of Nuclear Chemistry and Technology da Polônia, NIST SRM 1577b Bovine Liver do National Institute Standard of Tecnology (NIST) e o material Mushroom da Agência Internacional de Energia Atômica (IAEA). O material de referência IAEA-Mushroom se refere ao material certificado no projeto interregional da IAEA, INT/1/ 054 "Preparation of reference materials and organization of proficiency test rounds" (POLKOWSKA, M e ROSSBACH,.2007).

As Tabelas 4.1, 4.2, 4.3 e 4.4 mostram os resultados obtidos nos materiais de referência Mixed Polish Herbs (INCT-MPH-2), Tea Leaves (INCT-TL-1), Bovine Liver 
(NIST-SRM 1577b) e IAEA Mushroom respectivamente, com os valores de $\mathrm{E}_{\mathrm{n} \_}$score para cada elemento determinado.

O valor de En é obtido pela seguinte equação:

$$
E_{n}=\frac{C_{i}-C_{r e f, i}}{\sqrt{\sigma_{i}^{2}+\sigma_{r e, i}^{2}}}
$$

Onde:

$\mathrm{C}_{\mathrm{i}}$ : concentração do elemento i obtido no trabalho

$\mathrm{C}_{\text {ref,i }}$ : concentração no certificado ou de consenso para o elemento $\mathrm{i}$

$\sigma_{\mathrm{i}}:$ incerteza da concentração obtida para o elemento i

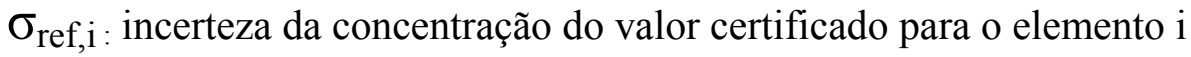

De acordo com este critério, valores de $E_{n}$ obtidos entre $0<\left|E_{n}\right|<2$ são considerados satisfatórios e os resultados estão dentro da faixa dos valores certificados (ou aceitos) a um nível de significância de 95\%.

Tabela 4.1: Concentração dos elementos obtidos no material de referência Mixed Polish Herb (INCT-MPH-2).

\begin{tabular}{|c|c|c|c|c|c|}
\hline \multirow[b]{2}{*}{ Elementos } & \multicolumn{4}{|c|}{ Este trabalho } & \multirow[b]{2}{*}{$\begin{array}{c}\text { Valor do } \\
\text { certificado }\end{array}$} \\
\hline & $(\text { Média } \pm D P)^{a}$ & $\begin{array}{c}\text { Desvio Padrão } \\
\text { Rel (\%) }\end{array}$ & Erro Rel (\%) & 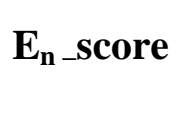 & \\
\hline As $\left(\mu \mathrm{g} \mathrm{kg}^{-1}\right)$ & $176 \pm 16$ & 9,1 & 7,8 & $-0,53$ & $191 \pm 23$ \\
\hline $\mathrm{Br}\left(\mathrm{mg} \mathrm{kg}^{-1}\right)$ & $7,7 \pm 0,2$ & 2,0 & 0,3 & $-0,02$ & $7,71 \pm 0,61$ \\
\hline $\mathrm{Co}\left(\mu \mathrm{g} \mathrm{kg}^{-1}\right)$ & $211 \pm 4$ & 2,0 & 0,3 & 0,04 & $210 \pm 25$ \\
\hline $\mathrm{Cr}\left(\mu \mathrm{g} \mathrm{kg}^{-1}\right)$ & $1693 \pm 38$ & 2,2 & 0,2 & 0,02 & $1690 \pm 130$ \\
\hline Cs $\left(\mu \mathrm{g} \mathrm{kg}^{-1}\right)$ & $74 \pm 2$ & 2,6 & 2,6 & $-0,28$ & $76 \pm 7$ \\
\hline $\mathrm{Fe}\left(\mathrm{mg} \mathrm{kg}^{-1}\right)$ & $497 \pm 32$ & 6,4 & - & - & $460^{b}$ \\
\hline $\mathrm{K}\left(\mathrm{mg} \mathrm{kg}^{-1}\right)$ & $19349 \pm 427$ & 2,2 & 1,3 & 0,20 & $19100 \pm 1200$ \\
\hline $\mathrm{Na}\left(\mathrm{mg} \mathrm{kg}^{-1}\right)$ & $351 \pm 3$ & 0,9 & - & - & $350^{\mathrm{b}}$ \\
\hline $\mathrm{Rb}\left(\mathrm{mg} \mathrm{kg}^{-1}\right)$ & $10,7 \pm 0,4$ & 3,8 & 0,3 & 0,04 & $10,7 \pm 0,7$ \\
\hline $\mathrm{Zn}\left(\mathrm{mg} \mathrm{kg}^{-1}\right)$ & $34 \pm 1$ & 2,6 & 1,5 & 0,29 & $33,5 \pm 2,1$ \\
\hline
\end{tabular}

a: Média e o desvio padrão de 6 determinações

b: Valor informativo 
Tabela 4.2: Concentração dos elementos obtidos no material de referência Tea Leaves

(INCT-TL-1)

\begin{tabular}{c|c|c|c|c|c}
\hline & \multicolumn{4}{|c|}{ Este trabalho } & \multirow{2}{*}{$\begin{array}{c}\text { Valor do } \\
\text { certificado }\end{array}$} \\
\cline { 2 - 5 } Elementos & ${\mathbf{~ M e ́ d i a ~} \pm \mathbf{D P})^{\mathbf{a}}}$ & $\begin{array}{c}\text { Desvio Padrão } \\
\text { Rel (\%) }\end{array}$ & Erro Rel (\%) & En_score & \\
\hline $\mathrm{As}\left(\mu \mathrm{g} \mathrm{kg}^{-1}\right)$ & $78 \pm 7$ & 9,0 & 26 & $-1,25$ & $106 \pm 21$ \\
\hline $\mathrm{Br}\left(\mathrm{mg} \mathrm{kg}^{-1}\right)$ & $12,1 \pm 0,3$ & 2,7 & 2,0 & $-0,15$ & $12,3 \pm 1$ \\
\hline $\mathrm{Co}\left(\mu \mathrm{g} \mathrm{kg}^{-1}\right)$ & $372 \pm 9$ & 2,5 & 3,8 & $-0,35$ & $387 \pm 42$ \\
\hline $\mathrm{Cr}\left(\mu \mathrm{g} \mathrm{kg}^{-1}\right)$ & $1876 \pm 138$ & 7,3 & 1,8 & $-0,13$ & $1910 \pm 220$ \\
\hline $\mathrm{Cs}\left(\mu \mathrm{g} \mathrm{kg}^{-1}\right)$ & $3550 \pm 86$ & 2,4 & 1,7 & $-0,16$ & $3610 \pm 370$ \\
\hline $\mathrm{Fe}\left(\mathrm{mg} \mathrm{kg}^{-1}\right)$ & $497 \pm 22$ & 4,0 & - & - & $432^{\mathrm{b}}$ \\
\hline $\mathrm{K}\left(\mathrm{mg} \mathrm{kg}^{-1}\right)$ & $16668 \pm 389$ & 2,3 & 2,0 & -082 & $17000 \pm 120$ \\
\hline $\mathrm{Na}\left(\mathrm{mg} \mathrm{kg}^{-1}\right)$ & $22 \pm 2$ & 11 & 11,4 & $-0,25$ & $24,7 \pm 3,2$ \\
\hline $\mathrm{Rb}\left(\mathrm{mg} \mathrm{kg}^{-1}\right)$ & $77 \pm 4$ & 5,5 & 5,0 & $-0,58$ & $81,5 \pm 6,5$ \\
\hline $\mathrm{Se}\left(\mu \mathrm{g} \mathrm{kg}^{-1}\right)$ & $77 \pm 11$ & 14 & - & - & $76^{\mathrm{b}}$ \\
\hline $\mathrm{Zn}\left(\mathrm{mg} \mathrm{kg}^{-1}\right)$ & $33,2 \pm 1,0$ & 3,0 & 4,4 & $-0,53$ & $34,7 \pm 2,7$ \\
\hline
\end{tabular}

${ }^{a}$ : Média e o desvio padrão de 6 determinações

b: Valor informativo

Tabela 4.3.Concentração dos elementos obtidos no material de referência IAEA Mushroom

\begin{tabular}{c|c|c|c|c|c}
\hline \multirow{2}{*}{ Elementos } & \multicolumn{4}{|c|}{ Este trabalho } & \multirow{2}{*}{$\begin{array}{c}\text { Valor do } \\
\text { certificado }\end{array}$} \\
\cline { 2 - 5 } & (Média $\pm \mathbf{D P})^{\mathbf{a}}$ & $\begin{array}{c}\text { Desvio Padrão } \\
\text { Rel (\%) }\end{array}$ & $\begin{array}{c}\text { Erro Rel } \\
(\%)\end{array}$ & En_score & \\
\hline $\mathrm{As}\left(\mu \mathrm{g} \mathrm{kg}^{-1}\right)$ & $419 \pm 33$ & 7,8 & 0,4 & 0,02 & $417 \pm 57$ \\
\hline $\mathrm{Br}\left(\mathrm{mg} \mathrm{kg}^{-1}\right)$ & $0,8 \pm 0,1$ & 11 & - & - & $0,8^{\mathrm{b}}$ \\
\hline $\mathrm{Co}\left(\mu \mathrm{g} \mathrm{kg}^{-1}\right)$ & $40 \pm 5$ & 13 & 12 & $-0,93$ & $45 \pm 2$ \\
\hline $\mathrm{Cr}\left(\mu \mathrm{g} \mathrm{kg}^{-1}\right)$ & $873 \pm 231$ & 26 & - & - & $970^{\mathrm{b}}$ \\
\hline $\mathrm{Cs}\left(\mu \mathrm{g} \mathrm{kg}^{-1}\right)$ & $14632 \pm 1356$ & 9,3 & - & - & $14456^{\mathrm{b}}$ \\
\hline $\mathrm{Fe}\left(\mathrm{mg} \mathrm{kg}^{-1}\right)$ & $111 \pm 7$ & 6,3 & - & - & $116^{\mathrm{b}}$ \\
\hline $\mathrm{K}\left(\mathrm{mg} \mathrm{kg}^{-1}\right)$ & $30971 \pm 1725$ & 5,6 & 12,5 & $-1,68$ & $35403 \pm 2000$ \\
\hline $\mathrm{Na}\left(\mathrm{mg} \mathrm{kg}^{-1}\right)$ & $362 \pm 39$ & 11 & 4,5 & $-0,03$ & $379 \pm 24$ \\
\hline $\mathrm{Rb}\left(\mathrm{mg} \mathrm{kg}^{-1}\right)$ & $350 \pm 28$ & 8,0 & 8,1 & $-0,78$ & $381 \pm 28$ \\
\hline $\mathrm{Se}\left(\mu \mathrm{g} \mathrm{kg}^{-1}\right)$ & $515 \pm 82$ & 16 & 12,7 & 0,70 & $457,5 \pm 8,3$ \\
\hline $\mathrm{Zn}\left(\mathrm{mg} \mathrm{kg}^{-1}\right)$ & $161 \pm 8$ & 4,9 & - & - & $168^{\mathrm{b}}$ \\
\hline
\end{tabular}

${ }^{a}$ : Média e o desvio padrão de 6 determinações

b: Valor informativo 
Tabela 4.4: Concentração dos elementos obtidos no material de referência Bovine Liver NIST SRM $1577 b$

\begin{tabular}{c|c|c|c|c|c}
\hline \multirow{2}{*}{ Elementos } & \multicolumn{4}{|c|}{ Este trabalho } & \multirow{2}{*}{$\begin{array}{c}\text { Valor do } \\
\text { certificado }\end{array}$} \\
\cline { 2 - 5 } & (Média $\pm \mathbf{D P})^{\mathbf{a}}$ & $\begin{array}{c}\text { Desvio } \\
\text { Padrão Rel } \\
\mathbf{( \% )}\end{array}$ & Erro Rel (\%) & En_score & \\
\hline $\mathrm{Br}\left(\mathrm{mg} \mathrm{kg}^{-1}\right)$ & $9,0 \pm 1,4$ & 16 & - & - & $9,7^{\mathrm{b}}$ \\
\hline $\mathrm{Co}\left(\mu \mathrm{g} \mathrm{kg}^{-1}\right)$ & $257 \pm 46$ & 18 & - & - & $250^{\mathrm{b}}$ \\
\hline $\mathrm{Fe}\left(\mathrm{mg} \mathrm{kg}^{-1}\right)$ & $183 \pm 8$ & 5,0 & 0,5 & $-0,06$ & $184 \pm 15$ \\
\hline $\mathrm{K}\left(\mathrm{mg} \mathrm{kg}^{-1}\right)$ & $9287 \pm 839$ & 9 & 6,6 & $-0,78$ & $9940 \pm 20$ \\
\hline $\mathrm{Na}\left(\mathrm{mg} \mathrm{kg}^{-1}\right)$ & $2085 \pm 253$ & 12 & 14 & $-0,09$ & $2420 \pm 60$ \\
\hline $\mathrm{Rb}\left(\mathrm{mg} \mathrm{kg}^{-1}\right)$ & $12,6 \pm 0,7$ & 6 & 8,0 & $-0,84$ & $13,7 \pm 1,1$ \\
\hline $\mathrm{Se}\left(\mu \mathrm{gg}^{-1}\right)$ & $785 \pm 70$ & 9 & 7,6 & 0,60 & $730 \pm 60$ \\
\hline $\mathrm{Zn}\left(\mathrm{mg} \mathrm{kg}^{-1}\right)$ & $127 \pm 9$ & 7 & 0,3 & 0 & $127 \pm 16$ \\
\hline
\end{tabular}

a: Média e o desvio padrão de 6 determinações

b: Valor informativo

Os resultados obtidos nos 4 materiais de referência analisados, podem ser considerados concordantes com os valores certificados, uma vez que a maioria dos elementos determinados apresentaram erros relativos inferiores ou próximos de $10 \%$, exceto para os elementos As (26\%) no material Te Leaves e para o elemento $\mathrm{Na}(14 \%)$ no Bovine Liver.

Para uma melhor visualização dos resultados obtidos para os materiais de referência, estes são apresentados na Figura 4.1, utilizando-se o critério de $\mathrm{E}_{\mathrm{n}}$-score. Por meio deste gráfico de controle pode-se visualizar a variabilidade relativa de dados repetitivos (KEITH e col., 1983). Pode-se observar que os valores de $\mathrm{E}_{\mathrm{n}}$-score para praticamente todos os elementos estiveram entre -1 e 1 em todos os materiais de referência analisados no presente trabalho, indicando que os valores obtidos são concordantes com os valores certificados a um nível de significância de 95\%. 


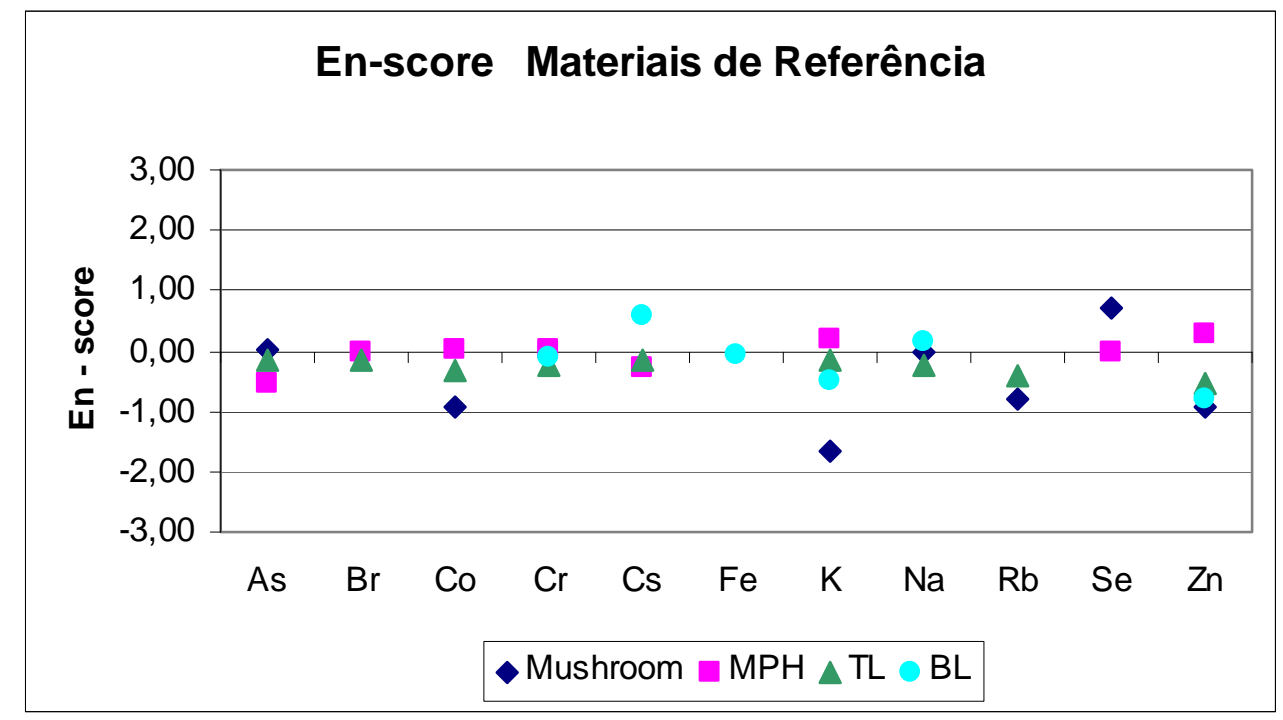

Figura 4.1 - Valores de $\mathrm{E}_{\mathrm{n}}$ - score para os elementos determinados nos materiais de referência Mushroom, Mixed Polish Herb(MPH), Tea Leaves (TL) e Bovine Liver (BL)

\subsection{Resultados dos valores dos limites de detecção}

Os limites de detecção da técnica de INAA para os elementos estudados neste trabalho foram obtidos utilizando-se a expressão apresentada abaixo (CURRIE, 1995). Esse limite foi calculado nas amostras dos três gêneros de cogumelos.

O método da IUPAC é um dos mais utilizados para cálculo de limites de detecção em análise por ativação com nêutrons.

$$
\begin{aligned}
& \mathrm{L}_{\mathrm{D}}=3,29 \sigma_{0} \\
& \sigma_{0}=\frac{\sqrt{B G}}{t_{v}}
\end{aligned}
$$

onde:

BG: número de contagens da radiação de fundo sob o pico do analítico; $t_{v}$ : tempo vivo é o tempo total da medição da amostra 
A Tabela 4.5 apresenta os valores obtidos de limite de detecção dos elementos nos três gêneros de cogumelo nas condições experimentais utilizadas. O gênero Agaricus apresenta valores de limite de detecção maiores para alguns elementos como $\mathrm{Na}$ e $\mathrm{K}$ provavelmente devido às características das espécies desses cogumelos. Os gêneros Pleurotus e Lentinus apresentam valores de limite de detecção próximos para alguns elementos como $\mathrm{Br}, \mathrm{Co}, \mathrm{K}$ e $\mathrm{Na}$. As diferenças encontradas nos valores de limite de detecção para os três gêneros de cogumelos, podem estar associadas às várias características, dentre elas pode se destacar: a procedência de cada amostra, a forma de cultivo de cada gênero, a idade dos cogumelos ou o tipo de tratamento que o cogumelo sofre após colheita.

Tabela 4.5 :Valores de limite de detecção para amostra de cogumelo por INAA

\section{Elementos}

\section{Limite de Detecção}

Gênero Pleurotus

Gênero Lentinus ${ }^{\text {a }}$

Gênero Agaricus ${ }^{\text {a }}$

\begin{tabular}{|c|c|c|c|}
\hline As $\left(\mu \mathrm{g} \mathrm{kg}^{-1}\right)$ & $6,4 \pm 1,0$ & $12,16 \pm 0,33$ & $36 \pm 6$ \\
\hline $\operatorname{Br}\left(\mathrm{mg} \mathrm{kg}^{-1}\right)$ & $0,099 \pm 0,001$ & $0,099 \pm 0,001$ & $0,08 \pm 0,02$ \\
\hline $\mathrm{Co}\left(\mu \mathrm{g} \mathrm{kg}^{-1}\right)$ & $1,2 \pm 0,1$ & $1,2 \pm 0,7$ & $3,1 \pm 0,5$ \\
\hline $\mathrm{Cr}\left(\mu \mathrm{g} \mathrm{kg}^{-1}\right)$ & $103,5 \pm 8,4$ & $91,40 \pm 4,05$ & $92 \pm 7$ \\
\hline $\mathrm{Cs}\left(\mu \mathrm{g} \mathrm{kg}^{-1}\right)$ & $0,64 \pm 0,07$ & $3,7 \pm 0,3$ & $9,7 \pm 1,0$ \\
\hline $\mathrm{Fe}\left(\mathrm{mg} \mathrm{kg}^{-1}\right)$ & $0,9 \pm 0,2$ & $2,0 \pm 0,1$ & $2,3 \pm 0,2$ \\
\hline $\mathrm{K}\left(\mathrm{mg} \mathrm{kg}^{-1}\right)$ & $7,1 \pm 1,2$ & $8,5 \pm 0,5$ & $161 \pm 21$ \\
\hline $\mathrm{Na}\left(\mathrm{mg} \mathrm{kg}^{-1}\right)$ & $0,08 \pm 0,01$ & $0,11 \pm 0,02$ & $1,18 \pm 0,17$ \\
\hline $\mathrm{Rb}\left(\mathrm{mg} \mathrm{kg}^{-1}\right)$ & $0,25 \pm 0,02$ & $0,56 \pm 0,05$ & $0,22 \pm 0,01$ \\
\hline $\mathrm{Se}\left(\mu \mathrm{g} \mathrm{kg}^{-1}\right)$ & $83,2 \pm 29,6$ & $30,3 \pm 7,3$ & $120 \pm 2$ \\
\hline $\mathrm{Zn}\left(\mathrm{mg} \mathrm{kg}^{-1}\right)$ & $0,08 \pm 0,02$ & $0,080 \pm 0,004$ & $0,28 \pm 0,02$ \\
\hline
\end{tabular}

${ }^{\mathrm{a}}$ Média e DP de 3 determinações 


\subsection{Determinação dos elementos presentes nos cogumelos comestíveis}

Foram analisadas 24 amostras das oito espécies de cogumelos com procedências diversas pelo método de Análise por Ativação com Nêutrons Instrumental.

Para cada amostra realizou-se determinação em triplicatas, onde as médias das concentrações obtidas para os elementos: As, Br, Co, Cr, Cs , Fe, K, Na, Rb, Se e Zn, em cada espécie analisada estão representados nas Tabelas 4.6, 4.7 e 4.8. Nestas Tabelas são apresentados os resultados individuais para os gêneros Pleurotus, Agaricus e Lentinus, respectivamente.

As amostras das espécies P.ostreatoroseus (Salmão rosa), P.ostreatus (Shimeji escuro), P.florida (Shimeji branco), Agaricus bisporus (Porto belo) e Lentinus edodes (Shitake) somente da região de Suzano foram analisadas com e sem lavagem. Todas as outras amostras analisadas foram lavadas, conforme já discutido no item 3.2.2 do capítulo 3.

Os resultados apresentados nas Tabelas 4.6, 4.7 e 4.8 mostram que ocorreu uma diminuição considerável na maior parte dos elementos na mesma espécie após a lavagem, com exceção para os elementos Fe, $\mathrm{Zn}, \mathrm{Cs}, \mathrm{Cr}$ e $\mathrm{Rb}$ nas espécies Pleurotus ostreatus , Na, Co, Cr, Se e Zn na espécie Pleurotus florida e Cs no Lentinus. 
Tabela 4.6: Concentrações dos elementos presentes nos cogumelos do gênero Pleurotus obtidos por INAA (em peso seco)

\begin{tabular}{|c|c|c|c|c|c|c|c|c|c|c|c|c|}
\hline \multirow{2}{*}{$\begin{array}{l}\text { MOSTRAS } \\
\text { (CÓDIGO) }\end{array}$} & \multirow{2}{*}{ PROCEDÊNCIA } & \multicolumn{6}{|c|}{ Concentraçãa ${ }^{\mathrm{a}}, \mathrm{mg} \mathrm{kg}^{-1}$} & \multicolumn{5}{|c|}{ Concentração ${ }^{\mathrm{a}}$, $\mathrm{gg} \mathrm{kg}^{-1}$} \\
\hline & & Br & $\mathbf{F e}$ & $\mathbf{K}$ & $\mathrm{Na}$ & $\mathbf{R b}$ & Zn & As & Co & $\mathrm{Cr}$ & Cs & Se \\
\hline $\begin{array}{c}\text { P.ostreatoroseus } \\
\text { (CSR) }^{\mathbf{b}}\end{array}$ & São Paulo & $1,82 \pm 0,08$ & $98 \pm 6$ & $25591 \pm 1492$ & $18,3 \pm 0,4$ & $33 \pm 3$ & $116 \pm 2$ & $45 \pm 4$ & $21 \pm 2$ & $208 \pm 17$ & $210 \pm 15$ & $150 \pm 6$ \\
\hline $\begin{array}{c}\text { P.ostreatoroseus } \\
\text { (CSI) }^{\mathrm{c}}\end{array}$ & São Paulo & $2,31 \pm 0,16$ & $164 \pm 10$ & $31559 \pm 900$ & $51,5 \pm 0,8$ & $45 \pm 4$ & $175 \pm 8$ & $76 \pm 16$ & $50 \pm 6$ & $395 \pm 61$ & $276 \pm 29$ & $539 \pm 31$ \\
\hline $\begin{array}{c}\begin{array}{c}\text { P.ostreatoroseus } \\
\text { (SFZ) }\end{array} \\
\end{array}$ & São Paulo & $2,15 \pm 0,02$ & $91 \pm 2$ & $18243 \pm 214$ & $18,0 \pm 0,5$ & $35 \pm 1$ & $93,4 \pm 0,3$ & $80 \pm 4$ & $18 \pm 1$ & $279 \pm 61$ & $253 \pm 7$ & $214 \pm 18$ \\
\hline $\begin{array}{c}\text { P.eryngui } \\
\text { (CEU) }\end{array}$ & São Paulo & $0,30 \pm 0,02$ & $31 \pm 2$ & $20913 \pm 322$ & $29 \pm 1$ & $11 \pm 1$ & $77 \pm 2$ & nd & $15 \pm 3$ & $151 \pm 53$ & $121 \pm 2$ & nd \\
\hline $\begin{array}{c}\text { P.ssp } \\
(\mathrm{CHH})^{\mathrm{b}}\end{array}$ & São Paulo & $0,38 \pm 0,04$ & $119 \pm 1$ & $17134 \pm 1853$ & $26 \pm 2$ & $13,9 \pm 0,8$ & $93 \pm 3$ & $56 \pm 4$ & $44 \pm 1$ & $186 \pm 19$ & $123 \pm 3$ & $279 \pm 22$ \\
\hline $\begin{array}{l}\text { P.ostreatus } \\
\text { (CSE) }^{\text {b }}\end{array}$ & São Paulo & $0,51 \pm 0,02$ & $72 \pm 3$ & $18332 \pm 46$ & $42 \pm 4$ & $19,7 \pm 0,4$ & $102 \pm 4$ & $27 \pm 4$ & $8,1 \pm 2,1$ & $272 \pm 57$ & $168 \pm 2$ & $128 \pm 39$ \\
\hline $\begin{array}{l}\text { P.ostreatus } \\
\text { (SES) }^{\mathrm{c}}\end{array}$ & São Paulo & $0,74 \pm 0,05$ & $63 \pm 1$ & $21686 \pm 947$ & $46 \pm 2$ & $14,8 \pm 0,9$ & $90 \pm 2$ & $26 \pm 12$ & $11 \pm 2$ & nd & $107 \pm 8$ & $190 \pm 30$ \\
\hline $\begin{array}{l}\text { P.ostreatus } \\
\text { (SEM) }\end{array}$ & Mogi das Cruzes & $0,42 \pm 0,01$ & $47 \pm 2$ & $26019 \pm 373$ & $45,6 \pm 0,8$ & $10,5 \pm 0,4$ & $75 \pm 2$ & $45 \pm 3$ & $8,9 \pm 0,3$ & nd & $91 \pm 7$ & nd \\
\hline $\begin{array}{c}\text { P.florida } \\
\text { (CSB) }^{b}\end{array}$ & São Paulo & $0,31 \pm 0,02$ & $93 \pm 3$ & $12470 \pm 865$ & $38 \pm 1$ & $14 \pm 1$ & $79 \pm 5$ & $57 \pm 3$ & $48 \pm 9$ & $552 \pm 48$ & $92 \pm 9$ & $297 \pm 23$ \\
\hline $\begin{array}{l}\text { P.florida } \\
\text { (SBS) }^{c}\end{array}$ & São Paulo & $0,32 \pm 0,02$ & $113 \pm 3$ & $29354 \pm 2478$ & $33 \pm 3$ & $107 \pm 7$ & $75 \pm 5$ & $62 \pm 1$ & $24 \pm 3$ & $108 \pm 6$ & $223 \pm 6$ & $167 \pm 13$ \\
\hline
\end{tabular}


Tabela 4.7: Concentrações dos elementos presentes nos cogumelos do gênero Agaricus obtidos por INAA (em peso seco)

\begin{tabular}{|c|c|c|c|c|c|c|c|c|c|c|c|c|}
\hline \multirow{2}{*}{$\begin{array}{c}\text { AMOSTRAS } \\
\text { (CÓDIGO) }\end{array}$} & \multirow{2}{*}{ PROCEDÊNCIA } & \multicolumn{6}{|c|}{ Concentração ${ }^{\mathrm{a}}, \mathrm{mg} \mathrm{kg}^{-1}$} & \multicolumn{5}{|c|}{ Concentração ${ }^{\mathrm{a}}, \mu \mathrm{g} \mathbf{k g}^{-1}$} \\
\hline & & $\mathrm{Br}$ & $\mathbf{F e}$ & $\mathbf{K}$ & $\mathrm{Na}$ & $\mathbf{R b}$ & Zn & As & Co & $\mathrm{Cr}$ & Cs & Se \\
\hline $\begin{array}{c}\text { A.sp } \\
(\mathrm{PBL})^{\mathrm{b}}\end{array}$ & São Paulo & $2,72 \pm 0,12$ & $220 \pm 7$ & $33633 \pm 1371$ & $271 \pm 8$ & $11 \pm 3$ & $63 \pm 2$ & $125 \pm 14$ & $23,7 \pm 0,5$ & $633 \pm 31$ & $143 \pm 9$ & $495 \pm 62$ \\
\hline $\begin{array}{c}\text { A.sp } \\
(\mathrm{CPB})^{\mathrm{c}}\end{array}$ & São Paulo & $4,14 \pm 0,07$ & $251 \pm 7$ & $53120 \pm 688$ & $327 \pm 2$ & $48 \pm 1$ & $70 \pm 2$ & $402 \pm 28$ & $27 \pm 2$ & $1362 \pm 76$ & $240 \pm 8$ & $250 \pm 53$ \\
\hline $\begin{array}{c}\text { A.bisporus } \\
\text { (CCG) }^{\mathrm{b}}\end{array}$ & São Paulo & $1,87 \pm 0,06$ & $100 \pm 8$ & $21778 \pm 1177$ & $2498 \pm 240$ & $9,7 \pm 0,6$ & $60 \pm 4$ & nd & $81 \pm 9$ & $285 \pm 24$ & $123 \pm 7$ & $440 \pm 24$ \\
\hline $\begin{array}{l}\text { A.bisporus } \\
\text { (CPI) }^{\mathrm{b}}\end{array}$ & São Paulo & $1,60 \pm 0,03$ & $56 \pm 1$ & $33908 \pm 989$ & $243 \pm 8$ & $38 \pm 2$ & $73 \pm 1$ & $433 \pm 7$ & $7,7 \pm 1,5$ & $255 \pm 12$ & $365 \pm 9$ & $270 \pm 6$ \\
\hline $\begin{array}{c}\text { A.bisporus } \\
\text { (CML) }^{\mathrm{b}}\end{array}$ & Mogi das Cruzes & $1,64 \pm 0,27$ & $118 \pm 11$ & $23804 \pm 1162$ & $1191 \pm 60$ & $14 \pm 1$ & $84 \pm 6$ & $94 \pm 1$ & nd & $1193 \pm 141$ & $115 \pm 5$ & $336 \pm 42$ \\
\hline $\begin{array}{l}\text { A.bisporus } \\
\text { (CIC) }^{\mathrm{d}}\end{array}$ & São Paulo & $0,85 \pm 0,07$ & $130 \pm 5$ & $5194 \pm 503$ & $5476 \pm 464$ & $5,2 \pm 0,2$ & $22 \pm 2$ & $165 \pm 15$ & $17 \pm 2$ & $442 \pm 32$ & $41 \pm 3$ & $348 \pm 7$ \\
\hline
\end{tabular}


Tabela 4.8: Concentrações dos elementos presentes nos cogumelos do gênero Lentinus obtidos por INAA (em peso seco)

\begin{tabular}{|c|c|c|c|c|c|c|c|c|c|c|c|c|}
\hline \multirow{2}{*}{$\begin{array}{c}\text { AMOSTRAS } \\
\text { (CÓDIGO) }\end{array}$} & \multirow{2}{*}{ PROCEDÊNCIA } & \multicolumn{6}{|c|}{ Concentração $^{\mathrm{a}}$, mg kg ${ }^{-1}$} & \multicolumn{5}{|c|}{ Concentração ${ }^{a}, \mu g$ kg $^{-1}$} \\
\hline & & $\mathrm{Br}$ & $\mathbf{F e}$ & $\mathbf{K}$ & $\mathrm{Na}$ & $\mathbf{R b}$ & Zn & As & Co & $\mathrm{Cr}$ & Cs & Se \\
\hline $\begin{array}{l}\text { L.edodes } \\
\text { (CSS) }\end{array}$ & São Paulo & $0,25 \pm 0,01$ & $21,7 \pm 1,5$ & $17519 \pm 686$ & $76 \pm 4$ & $60 \pm 2$ & $88 \pm 7$ & $206 \pm 15$ & $35 \pm 3$ & nd & $308 \pm 13$ & $229 \pm 28$ \\
\hline $\begin{array}{c}\text { L.edodes } \\
\text { (SPL) }\end{array}$ & Suzano & $0,15 \pm 0,01$ & $22,3 \pm 1,8$ & $18467 \pm 1708$ & $57 \pm 4$ & $32 \pm 3$ & $34 \pm 1$ & $20 \pm 4$ & $19 \pm 3,0$ & $129 \pm 33$ & $703 \pm 70$ & nd \\
\hline $\begin{array}{l}\text { L.edodes } \\
\text { (SPS) }^{\text {c }}\end{array}$ & Suzano & $0,18 \pm 0,02$ & $22,0 \pm 1,8$ & $19781 \pm 1258$ & $53 \pm 3$ & $38 \pm 4$ & $36 \pm 3$ & $36 \pm 2$ & $22 \pm 1$ & nd & $384 \pm 21$ & nd \\
\hline $\begin{array}{l}\text { L.edodes } \\
\text { (SMM) }\end{array}$ & Mirandópolis & $0,17 \pm 0,02$ & $21,7 \pm 0,5$ & $14215 \pm 1212$ & $63 \pm 1$ & $43 \pm 2$ & $64 \pm 2$ & $32,5 \pm 0,6$ & $75 \pm 3$ & $256 \pm 29$ & $189 \pm 24$ & $111 \pm 4$ \\
\hline $\begin{array}{l}\text { L.edodes } \\
\text { (SJL) }^{\mathrm{b}}\end{array}$ & Juquitiba & $0,18 \pm 0,03$ & $22,2 \pm 1,9$ & $20674 \pm 994$ & $73 \pm 6$ & $160 \pm 12$ & $44 \pm 3$ & $85 \pm 6$ & $61 \pm 6$ & $530 \pm 49$ & $1179 \pm 46$ & $71 \pm 4$ \\
\hline $\begin{array}{l}\text { L.edodes } \\
\text { (CSD) }{ }^{\mathrm{d}}\end{array}$ & China & $0,21 \pm 0,02$ & $48,2 \pm 1,3$ & $20188 \pm 232$ & $51 \pm 5$ & $35 \pm 1$ & $68,9 \pm 0,3$ & $394 \pm 25$ & $48 \pm 6$ & $1034 \pm 142$ & $613 \pm 18$ & $148 \pm 1$ \\
\hline $\begin{array}{l}\text { L.edodes } \\
\text { (CJD) }{ }^{\mathrm{d}}\end{array}$ & Japão & $0,11 \pm 0,01$ & $34,4 \pm 3,1$ & $20483 \pm 1563$ & $44 \pm 3$ & $45 \pm 2$ & $68 \pm 2$ & $200 \pm 15$ & $39 \pm 1$ & $360 \pm 43$ & $183 \pm 11$ & $156 \pm 20$ \\
\hline $\begin{array}{l}\text { L.edodes } \\
\text { (SML) }^{\mathrm{b}}\end{array}$ & Mogi das Cruzes & $0,80 \pm 0,04$ & $46,1 \pm 3,0$ & $20496 \pm 1133$ & $74 \pm 4$ & $16 \pm 1$ & $44 \pm 2$ & nd & $29 \pm 1$ & nd & $611 \pm 29$ & nd \\
\hline
\end{tabular}

${ }^{\mathrm{a}}$ Valor da média e desvio padrão de 3 determinações

nd: não detectado

${ }^{\mathbf{b}}$ lavado ${ }^{\mathbf{c}}$ não lavado ${ }^{\mathbf{d}}$ desidratado 
Alguns aspectos serão considerados a seguir antes da discussão dos teores dos elementos obtidos em cogumelos analisados neste trabalho.

Um elemento é considerado essencial para um organismo, quando a redução de sua exposição menor que um certo limite resulta consistentemente em uma redução de uma função fisiologicamente importante, ou quando o elemento é uma parte integral de uma estrutura orgânica desempenhando uma função vital naquele organismo (WHO, 1996).

Os elementos essenciais podem ser classificados como macro e micronutrientes ou elementos traço. Os macronutrientes, como $\mathrm{C}, \mathrm{H}, \mathrm{Na}, \mathrm{K}, \mathrm{Cl}, \mathrm{Ca}$ entre outros, estão presentes na faixa de percentagens ou $\mathrm{mg} \mathrm{g}^{-1}$. Os micronutrientes ou elemento traço, como Fe, $\mathrm{Zn}$, Se, Co entre outros aparecem na faixa de $\mu \mathrm{g} \mathrm{g}^{-1}$ a $\mathrm{ng} \mathrm{g}^{-1}$. Existe um grupo de elementos que são considerados tóxicos mesmo presentes em concentrações extremamente baixas, como $\mathrm{Hg}, \mathrm{Pb}$ e $\mathrm{Cd}$. Porém todo elemento pode vir a ser considerado potencialmente tóxico se inalado ou ingerido em quantidades suficientemente altas.

A seguir, serão apresentadas as concentrações de cada elemento obtido em todas as amostras de cogumelos analisadas, a importância dos elementos para a saúde da população e a comparação com os valores encontrados na literatura para cogumelos comestíveis.

\subsection{Arsênio em cogumelos}

O elemento arsênio existe na natureza numa variedade de formas químicas, incluindo espécies orgânicas e inorgânicas. A flora e a fauna marinha contêm compostos de arsênio, pois nas vias metabólicas o nitrogênio e o fósforo podem ser facilmente trocados por ele. O efeito tóxico das espécies de arsênio depende, principalmente, de sua forma química. Compostos inorgânicos de arsênio são tóxicos, em especial na forma 
trivalente $\left(\mathrm{As}^{3+}\right)$, ao contrário dos compostos orgânicos, considerados pouco tóxicos. A arsenobetaína, cuja presença em alimentos de origem marinha constitui a maior fonte de arsênio na dieta, é essencialmente não tóxica e excretada na urina (ROSSIN, 2005)

Pequenas quantidades de compostos de arsênio podem estar presentes no ar e na água devido aos processos naturais como dissolução, desgaste ou erosão das rochas. Outras formas de contaminação ambiental são devidas às atividades realizadas pelo homem, tais como: uso de compostos à base de arsênio, na agricultura, pelos herbicidas e inseticidas, na preservação de madeira, ração para aves, refino de petróleo, microeletrônica, além do despejo de resíduos industriais (SAKUMA, 2004).

No ambiente terrestre, o arsênio é geralmente encontrado em baixas concentrações em plantas cultivadas, de acordo com o Danish Food Monitoring Programme, variando na faixa de $0-0,02 \mathrm{mg} \mathrm{kg}^{-1}$, com exceção do arroz, cuja concentração encontra-se entre 0,15 e $0,25 \mathrm{mg} \mathrm{kg}^{-1}$, e de certas espécies de cogumelos comestíveis, que contêm arsênio na faixa de vários $\mathrm{mg} \mathrm{kg}^{-1}$ proveniente do solo (COZZOLINO, 2005).

A concentração do arsênio nas diferentes espécies de cogumelos pertencentes aos três gêneros estudados encontra-se na Figura 4.2.

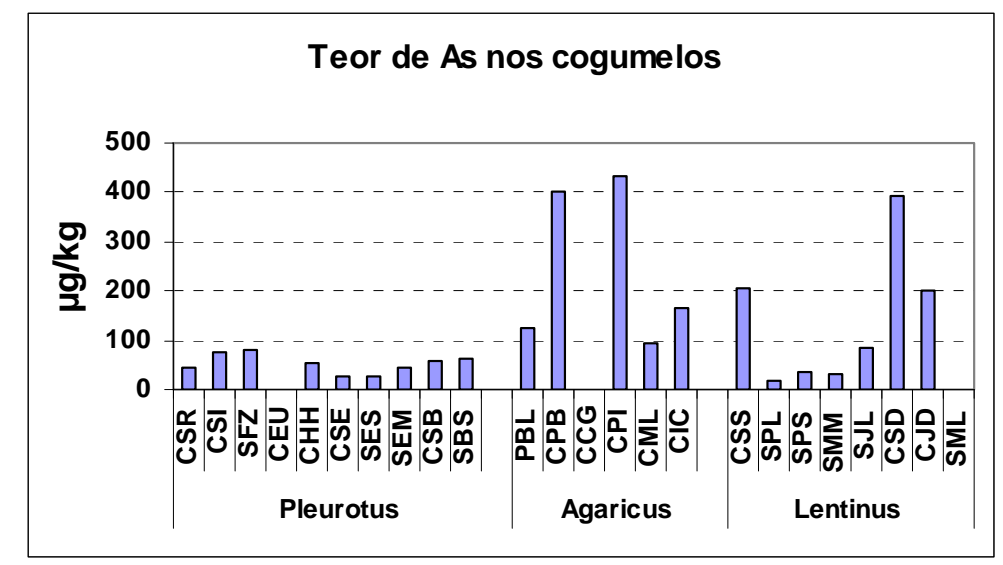

Figura 4.2- Distribuição dos teores de arsênio nas diferentes espécies de cogumelos 
A concentração de As após a lavagem diminuiu consideravelmente. VETTER (2004) analisou diferentes espécies de cogumelos coletados na região da Hungria, obtendo nas espécies do gênero Pleurotus valores menores que $50 \mu \mathrm{g} \mathrm{kg}^{-1} \mathrm{em}$ peso seco.

As concentrações de As obtidas foram mais elevadas no gênero Agaricus, de $402 \mu \mathrm{g} \mathrm{kg}^{-1}$ na amostra Porto Belo e $433 \mu \mathrm{g} \mathrm{kg}^{-1}$ na amostra champignon de Paris de São Paulo. A amostra do gênero Lentinus proveniente da China apresentou uma concentração também elevada em relação às outras analisadas $\left(394 \mu \mathrm{g} \mathrm{kg}^{-1}\right)$. Entretanto, os valores determinados no presente trabalho são inferiores aos obtidos por VETTER (2004), onde os cogumelos do gênero Agaricus apresentaram teores de 4600 a $14900 \mu \mathrm{g} \mathrm{kg}^{-1}$ em peso seco.

Segundo SLEJKOVEC e col. (1997), muitos cogumelos apresentam o As na forma de arsenobetaína. As espécies do gênero Agaricus, têm maior habilidade para acumular arsênio que o gênero Lentinus. VETTER (2004) determinou concentrações de As maiores que $10000 \mu \mathrm{g} \mathrm{kg}^{-1}$ em peso seco na espécie Agaricus spp e até maiores que 50000 $\mu \mathrm{g} \mathrm{kg}^{-1}$ na espécie Laccaria amethysthe, que correspondem de 1000 a $5000 \mu \mathrm{g} \mathrm{kg}^{-1}$ de As em cogumelo in natura, e segundo este autor o As não representa risco à saúde humana, uma vez que a maior parte deste elemnto está presente na forma não tóxica e o consumo de cogumelos pela população é baixo.

COCCHI e col. (2005) analisaram diferentes espécies de cogumelos comestíveis coletados na região da Itália, dentre eles Agaricus bisporus, cuja concentração média de As obtida foi de $210 \mu \mathrm{g} \mathrm{kg}^{-1}$; os valores obtidos neste trabalho para mesma espécie ficaram entre 94 a $433 \mu \mathrm{g} \mathrm{kg}^{-1}$. A concentração de As em uma espécie cultivada sugere uma possível contaminação pelo uso de pesticidas durante o processo de cultivo.

Durante o cultivo de cogumelos, pode ocorrer a presença de outros fungos competidores, podendo diminuir a produtividade. Desta forma os produtores utilizam fungicidas, estes devem ser cuidadosamente utilizados para que não deixem resíduos nos 
cogumelos cultivados e possível alteração na concentração de elementos como As. Desse modo a espécie Lentinus edodes, que normalmente é cultivada em toras de eucalipto, que sofrem tratamento para a conservação da madeira e eliminação de fungos competidores pode conter esse elemento em níveis elevados (BONONI, 1999).

As espécies Lentinus edodes desidratadas apresentam teores de arsênio próximos aos teores obtidos para o gênero Agaricus, porém superiores aos determinados nas amostras in natura.

\subsection{Bromo em cogumelos}

É um dos elementos traço mais abundante na biosfera (MAIHARA, 1996). Bromo é encontrado em níveis de traço em humanos. Entretanto ainda não se conhece exatamente a função que realiza nos seres humanos.

A Figura 4.3 mostra a distribuição do bromo nas espécies de cogumelos nos três gêneros analisados.

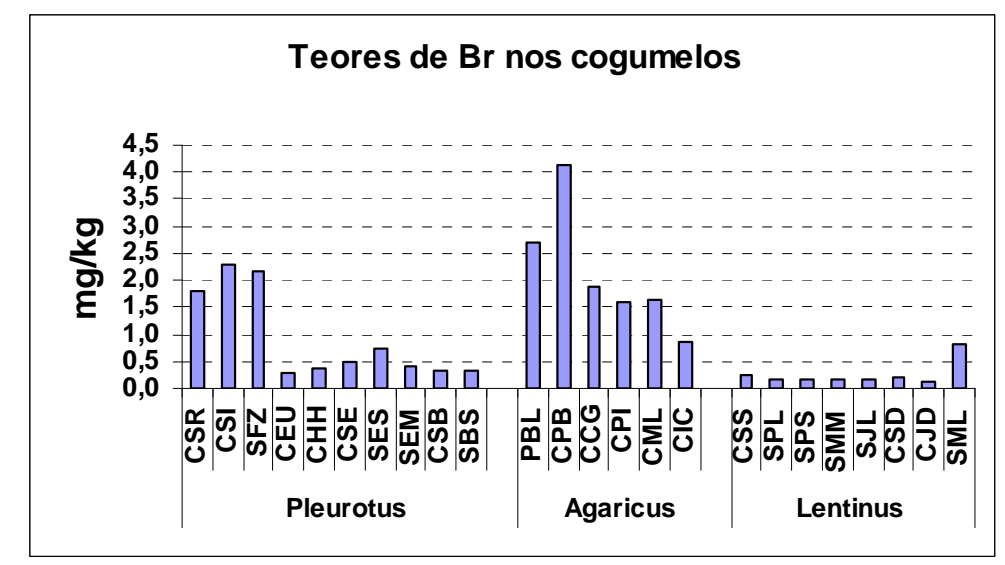

Figura 4.3- Distribuição dos teores de bromo nas diferentes espécies de cogumelos

Conforme pode ser observado na Figura 4.3 o elemento bromo esteve presente em todas as amostras de cogumelos, sendo as menores concentrações encontradas nas 
amostras do gênero Lentinus. A maior concentração de $\mathrm{Br}$ foi determinada na espécie Agaricus ssp (Porto belo), de 4,14 $\mathrm{mg} \mathrm{kg}^{-1}$.

RANDA e KUCERA (2003), na região da Republica Checa, determinaram a concentração de $\mathrm{Br} 4,20 \mathrm{mg} \mathrm{kg}^{-1}$ em uma espécie de cogumelo pertencente ao gênero Agaricus, sendo este valor próximo ao obtido neste trabalho em uma espécie do mesmo gênero.

No entanto, poucos são os trabalhos encontrados na literatura, relacionados à concentração de bromo em cogumelos, não permitindo fazer uma comparação com os valores da literatura.

\subsection{Césio em cogumelos}

O elemento césio não apresenta muito interesse nos estudos relacionados à sua concentração em alimentos, em especial aos cogumelos, portanto são raros os trabalhos que fazem sua determinação.

A Figura 4.4 apresenta os valores determinados no presente trabalho para o elemento césio nos cogumelos analisados.

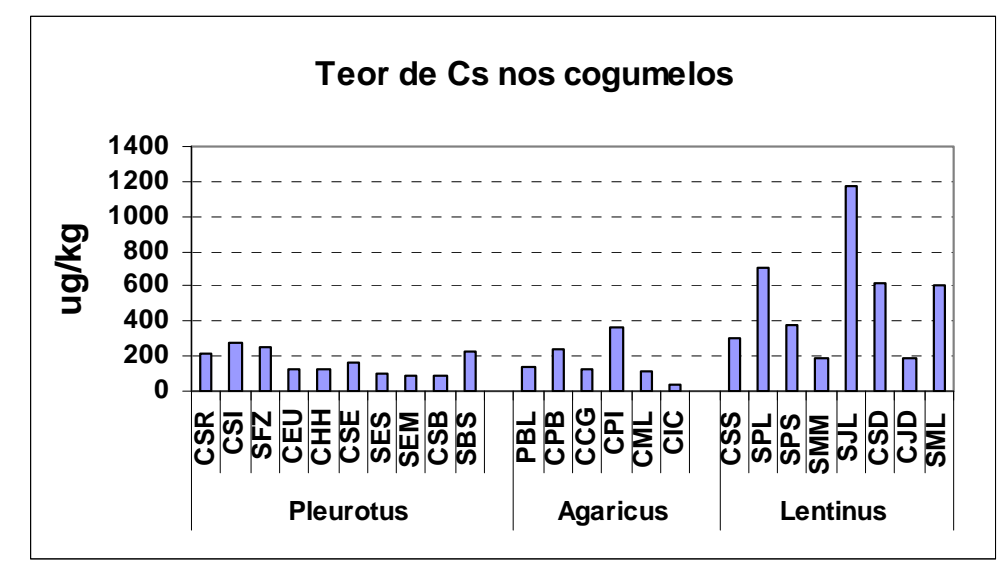

Figura 4.4- Distribuição dos teores de césio nas diferentes espécies de cogumelos 
Césio esteve presente nos cogumelos dos três gêneros analisados, sendo o maior valor na espécie Shitake adquirida diretamente do produtor em Juquitiba (1179 $\left.\mu \mathrm{g} \mathrm{kg}^{-1}\right)$ e o menor na espécie Champignon de Paris em conserva $\left(41 \mu \mathrm{g} \mathrm{kg}^{-1}\right)$.

Dados reunidos por KALAC e SVOBODA (1999), apontam que em algumas espécies de cogumelos o Cs pode estar presente em concentrações variando entre $3000 \mu \mathrm{g} \mathrm{kg}^{-1}$ e $12000 \mu \mathrm{g} \mathrm{kg}^{-1}$, sendo estes valores superiores aos determinados neste trabalho nos três gêneros de cogumelos.

\subsection{Cobalto em cogumelos}

Os seres humanos absorvem Co como cobalto inorgânico ou como cobalto da vitamina $B_{12}$. $O$ cobalto inorgânico não pode ser utilizado pelo organismo na síntese de vitamina $\mathrm{B}_{12}$. A única função orgânica associada ao cobalto até o momento é a sua função na vitamina $B_{12}$. Níveis baixos de cobalto nos cabelos podem significar uma diminuição de cobalto inorgânico, sem significado clínico até o momento, ou uma deficiência de vitamina $\mathrm{B}_{12}$.

Na Figura 4.5 encontra-se a distribuição do cobalto nos três gêneros de cogumelos estudados no presente trabalho.

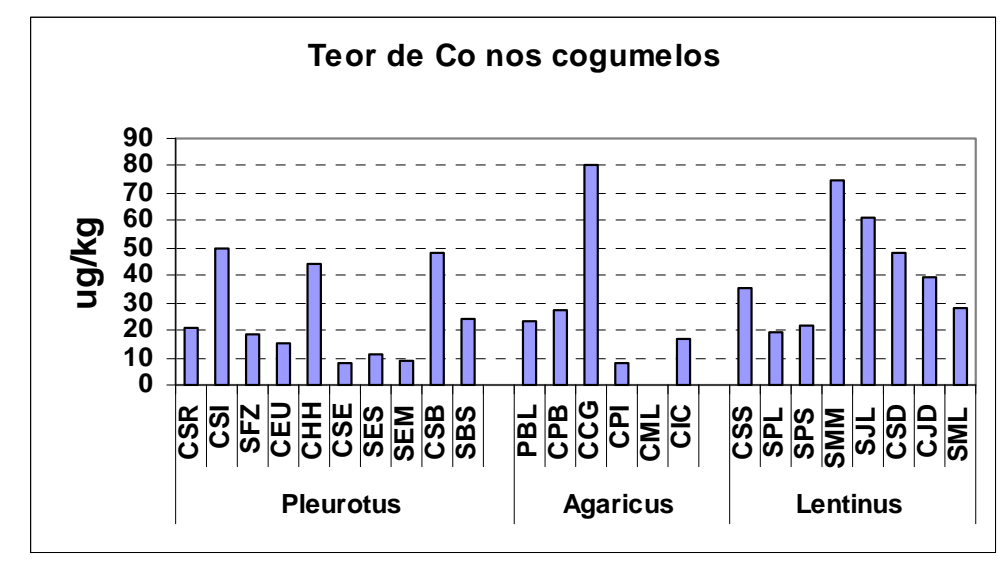

Figura 4.5- Distribuição dos teores de cobalto nas diferentes espécies de cogumelos 
Cobalto esteve presente em baixas concentrações em quase todas as amostras determinadas. A maior concentração foi encontrada nas amostras do gênero Agaricus na espécie Champignon de Paris de São Paulo $\left(81 \mu \mathrm{g} \mathrm{kg}^{-1}\right)$. Entretanto, amostras da mesma espécie produzidas na região de Mogi das Cruzes possuem concentração abaixo do LD. Sendo as amostras de lugares diferentes, o resultado condiz com a literatura, pois, mesmo sendo do mesmo gênero, a presença do elemento em uma amostra e abaixo do LD em outra, reforça que alguns elementos estão diretamente relacionados ao tipo de substrato onde o cogumelo foi cultivado (COCCHI e col., 2006).

Todos os valores obtidos nos três gêneros de cogumelos para o elemento Co estão abaixo dos reportados por KALAC e SVOBODA (1999). Em suas revisões as concentrações de Co em cogumelos de diferentes gêneros variaram de 100 a $3000 \mu \mathrm{g} \mathrm{kg}^{-1}$.

ISILOGLU e col. (2001) analisaram diferentes espécies de cogumelos selvagens comestíveis coletados na região Turquia e uma espécie de Agaricus bisporus, adquirida comercialmente. A média na concentração de Co na espécie Agaricus bisporus foi de $150 \mu \mathrm{g} \mathrm{kg}^{-1}$, sendo superior ao determinado no presente trabalho para a mesma espécie. Este resultado pode estar relacionado não somente ao tipo de substrato em que o cogumelo se desenvolveu, mas também a idade do corpo de frutificação (KALAK e SVOBODA, 1999).

\subsection{Crômio em cogumelos}

Crômio é um mineral amplamente distribuído no solo, em diversas formas, das quais a trivalente e hexavalente são as mais comuns. A forma hexavalente é reconhecida como tóxica, e a trivalente mais estável, encontrada nas plantas geralmente ligada a 
complexos orgânicos. O crômio está distribuído em diversos tipos de alimentos, sendo que muitos contribuem com menos de 1 a $2 \mu \mathrm{g}$ por porção (COZZOLINO, 2005).

O elemento crômio é um nutriente essencial que potencializa a ação da insulina e assim influencia o metabolismo de carboidratos, lipídeos e proteínas (OMS, 1998).

Em alimentos e em suplementos apenas a forma trivalente está presente. Quando ingerido, $\mathrm{o}^{3+}$ possui baixo grau de toxicidade, principalmente por sua baixa absorção (COZZOLINO, 2005).

A Figura 4.6 apresenta os resultados obtidos para o crômio nos três gêneros estudados.

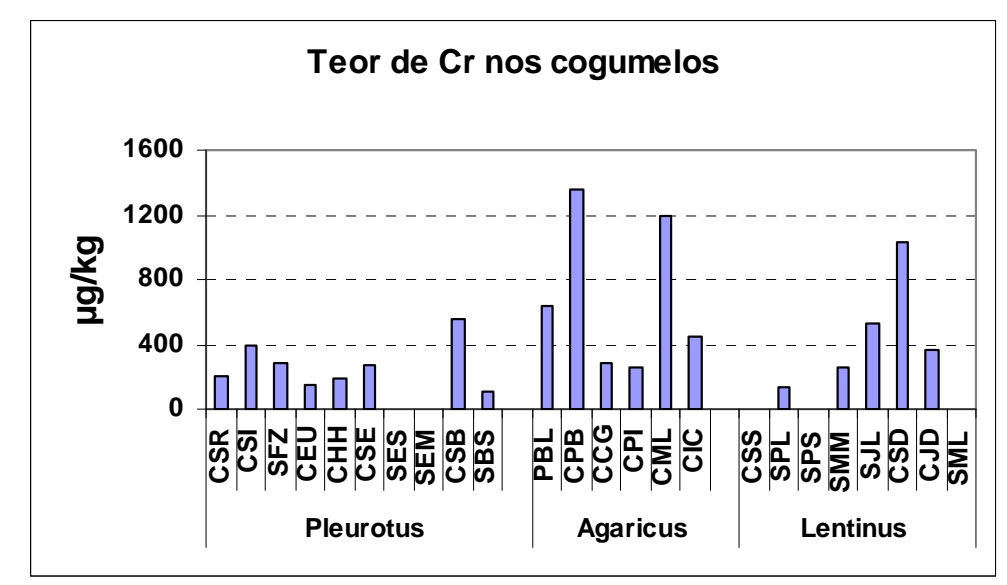

Figura 4.6- Distribuição dos teores de crômio nas diferentes espécies de cogumelos

Ocorreu variação considerável na concentração de crômio entre os três gêneros, sendo os maiores valores encontrados nas espécies de cogumelos do gênero Agaricus, na amostra (Porto Belo) de São Paulo, de $1362 \mu \mathrm{g} \mathrm{kg}^{-1}$.

De acordo com dados reunidos por KALAC e SVOBODA (1999), a concentração de $\mathrm{Cr}$ nos cogumelos varia consideravelmente. Eles verificaram que pode variar de 100 a $2000 \mu \mathrm{g} \mathrm{kg}^{-1}$ em várias espécies, dentre elas a Agaricus spp. Segundo estes autores, algumas espécies podem acumular seletivamente os minerais, dentre eles o $\mathrm{Cr}$. 


\subsection{Ferro em cogumelos}

Ferro é um micronutriente essencial ao nosso organismo. Ele é encontrado naturalmente nos alimentos e compõem estruturas do nosso corpo, como os grupos heme das proteínas transportadoras de oxigênio (hemoglobina e mioglobina). Sua deficiência acarreta na anemia ferropriva, que é a carência nutricional mais freqüente no mundo (MAIHARA, 1996).

Uma dieta equilibrada é o suficiente para atender às nossas necessidades diárias de ferro, porém alguns pontos devem ser considerados para que isso de fato aconteça e não haja o desenvolvimento de doenças relacionadas à sua deficiência, como a anemia ferropriva (COZZOLINO, 2005).

Os resultados obtidos nas análises das amostras de cogumelos nos três gêneros, para o elemento ferro, estão apresentados na Figura 4.7.

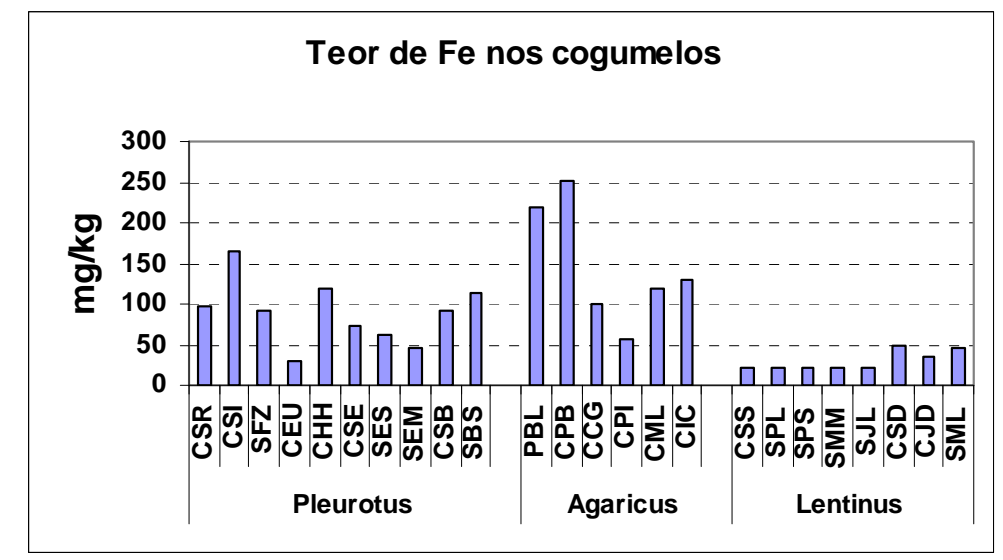

Figura 4.7- Distribuição dos teores de ferro nas diferentes espécies de cogumelos

No gênero Pleurotus os valores obtidos para o elemento Fe, variaram de 31 a $164 \mathrm{mg} \mathrm{kg}^{-1}$, onde a grande maioria esteve maior que o determinado por MATTILA e 
col. (2001) na região da Finlândia, em cogumelos da espécie Pleurotus ostreatus $\left(54 \mathrm{mg} \mathrm{kg}^{-1}\right)$.

MATTILA e col. (2001), obtiveram média de $33 \mathrm{mg} \mathrm{kg}^{-1}$ na espécie Lentinus edodes pertencente ao gênero Lentinus, sendo próximos aos valores obtidos neste trabalho, para o mesmo gênero.

A maior concentração de ferro ocorreu nas amostras do gênero Agaricus Porto Belo sem lavagem $\left(251 \mathrm{mg} \mathrm{kg}^{-1}\right)$ e Porto Belo lavado $\left(220 \mathrm{mg} \mathrm{kg}^{-1}\right)$. Estes valores estão dentro dos valores determinados por OUZONI e col. (2007) na região da Grécia em cogumelos comestíveis selvagens (de 46,3 a $317 \mathrm{mg} \mathrm{kg}^{-1}$ ).

SESLI e TUZEN (2006) analisaram cogumelos comestíveis selvagens coletados na região da Turquia. Eles obtiveram valores entre $152 \mathrm{mg} \mathrm{kg}^{-1}$ a $820 \mathrm{mg} \mathrm{kg}^{-1}$ nas diferentes espécies por eles analisadas, sendo alguns concordantes com os valores apresentados neste trabalho.

ISIDAK e col. (2007) analisaram cogumelos da espécie Agaricus bisporus, e determinaram teores de 454,85 $\mathrm{mg} \mathrm{kg}^{-1}$, sendo este valor superior aos determinados neste trabalho na mesma espécie. Este tipo de cogumelo é cultivado em diferentes tipos de substratos, conforme foi discutido no item 2.3.3, o que pode contribuir para essa diferença.

Algumas espécies de cogumelo pertencentes aos gêneros Pleurotus e Agaricus apresentaram teores de Fe comparáveis aos teores apresentados por alimentos considerados fontes desse elemento, como espinafre(270 $\left.\mathrm{mg} \quad \mathrm{kg}^{-1}\right)$ e ervilha(212 $\mathrm{mg} \mathrm{kg}^{-1}$ ) (COZZOLINO, 2005; TACO, 2006). 


\subsection{Potássio em cogumelos}

Potássio é um mineral essencial em nosso organismo. Faz bem ao coração, pois é essencial para controlar os batimentos cardíacos e para manter a integridade das células em geral. Protege contra o aumento da pressão sangüínea, além de manter o equilíbrio de água no corpo.

Geralmente, não há deficiência de potássio devido à ingestão inadequada em indivíduos saudáveis, uma vez que o elemento encontra-se amplamente distribuído nos alimentos (MAIHARA, 1996).

A Figura 4.8 apresenta a distribuição do potássio nas amostras dos três gêneros estudados.

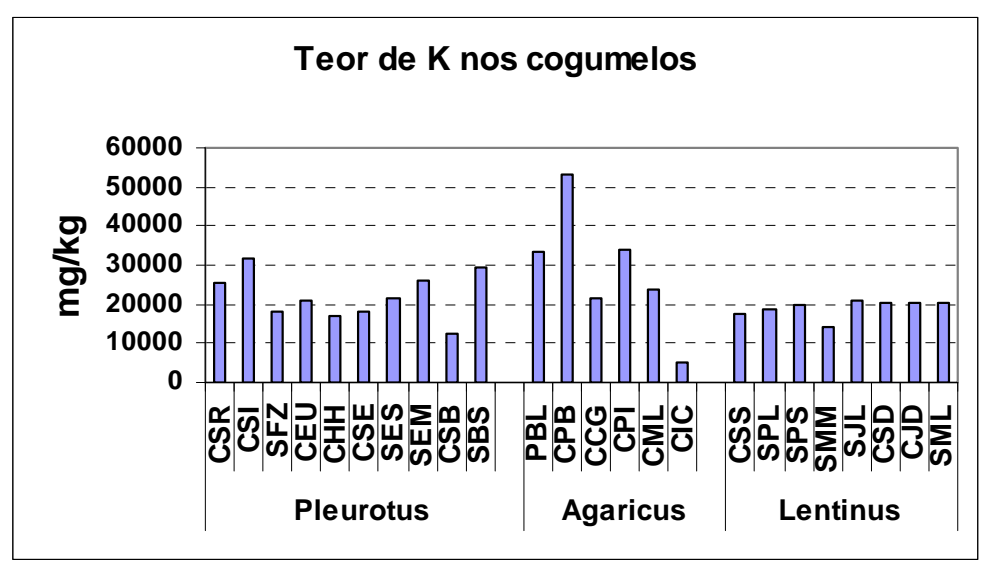

Figura 4.8- Distribuição dos teores de potássio nas diferentes espécies de cogumelos

Nas amostras de cogumelos do gênero Pleurotus, o elemento encontrado em maior concentração foi o potássio, cujos valores foram de 12470 a $31559 \mathrm{mg} \mathrm{kg}^{-1}$, estando de acordo com os resultados encontrados na literatura. MANZI e col. (1998) determinaram valores entre 21846 a $40543 \mathrm{mg} \mathrm{kg}^{-1}$ em espécies de cogumelos do gênero Pleurotus da 
região da Itália. SESLI (2006) encontrou valores entre 22875 a 50475 mg kg-1 em diferentes espécies de cogumelos comestíveis coletados na região da Turquia.

Potássio foi o elemento em maior concentração em relação aos outros elementos determinados, também nos gênero Agaricus e Lentinus, apresentando uma menor concentração no cogumelo em conserva champignon de Paris (5194 mg kg-1) e maior na amostra in natura (33908 $\mathrm{mg} \mathrm{kg}^{-1}$ ), do gênero Agaricus adquirida em São Paulo.

SANMEE e col. (2002) obtiveram valores entre $12800 \mathrm{mg} \mathrm{kg}$ e $45200 \mathrm{mg} \mathrm{kg}^{-1}$ do elemento potássio, em diferentes espécies de cogumelos comestíveis selvagens adquiridos na Tailândia. Todos os valores obtidos para potássio neste trabalho estiveram dentro ou acima destes valores, com exceção da amostra em conserva.

\subsection{Rubídio em cogumelos}

O interesse biológico pelo rubídio é estimulado por sua relação com o elemento potássio e por sua presença em concentrações altas nos tecidos humanos. O teor de rubídio no corpo humano é em torno de 0,32 g (MAIHARA, 1996).

A Figura 4.9 apresenta as concentrações do rubídio nos cogumelos analisados.

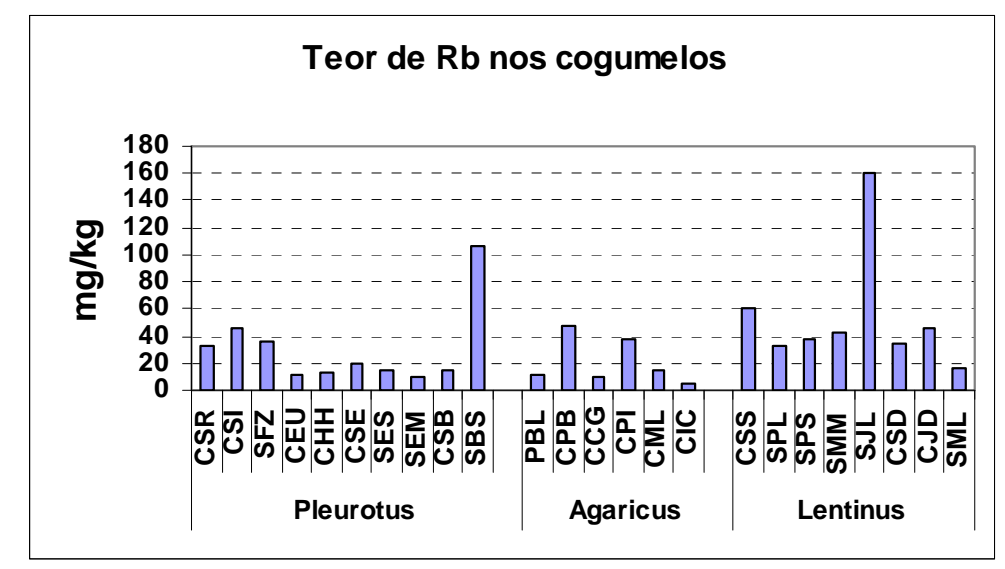

Figura 4.9- Distribuição dos teores de rubídio nas diferentes espécies de cogumelos 
Rubídio esteve presente em todas as amostras, sendo o maior valor encontrado na amostra de shitake adquirida diretamente do produtor na região de Juquitiba (160 $\left.\mathrm{mg} \mathrm{kg}^{-1}\right)$, e o menor na amostra champignon de Paris em conserva $\left(5,2 \mathrm{mg} \mathrm{kg}^{-1}\right)$.

Valores de concentração para $\mathrm{Rb}$ em cogumelos não são normalmente encontrados na literatura.

\subsection{Selênio em cogumelos}

De acordo com SILVA e col. (2007), foram Schwarz e Foltz em 1957 que descobriram a importância do selênio na nutrição animal a partir da observação de que a adição de selênio na dieta de ratos com deficiência de vitamina $\mathrm{E}$, evitava a necrose do fígado. A vitamina $\mathrm{E}$ age minimizando o dano na membrana provocado pelos radicais livres; o selênio por meio da glutationa peroxidase age prevenindo o acúmulo de peróxidos $(\mathrm{HOOH})$, que é fonte de radicais livres. Os Radicais hidroxilas podem causar danos às membranas celulares. Dessa forma, a necessidade de vitamina E é diminuída na presença de selênio.

A função mais conhecida do selênio é a de antioxidante, devido à associação desse elemento com a enzima glutationa peroxidase, uma enzima que contém um átomo de selênio ligado covalentemente na forma de selenocisteína. A atividade antioxidante é devida ao selênio ser essencial para a atividade dessa enzima, que tem um papel importante na prevenção de danos às membranas celulares, causados por peróxidos de lipídeos e radicais livres (YOSHIZAWA e col., 2003).

A principal fonte de selênio para o homem é o alimento, que pode apresentar em concentrações variadas desse elemento dependendo dos teores presentes no solo onde o alimento foi cultivado (BRATAKOS e col., 1990). 
O selênio pode ser essencial ou tóxico para homens e animais, dependendo da concentração na qual é administrado. Sua deficiência pode provocar cardiomiopatias, distrofia muscular e desordem na reprodução de várias espécies animais.

A castanha do Pará é o alimento mais rico em selênio. Outras fontes de selênio são: frutos do mar, rim, fígado, carne bovina e aves (MAIHARA e col., 2004).

Na Figura 4.10 encontram-se os valores de selênio determinados nas amostras de cogumelos.

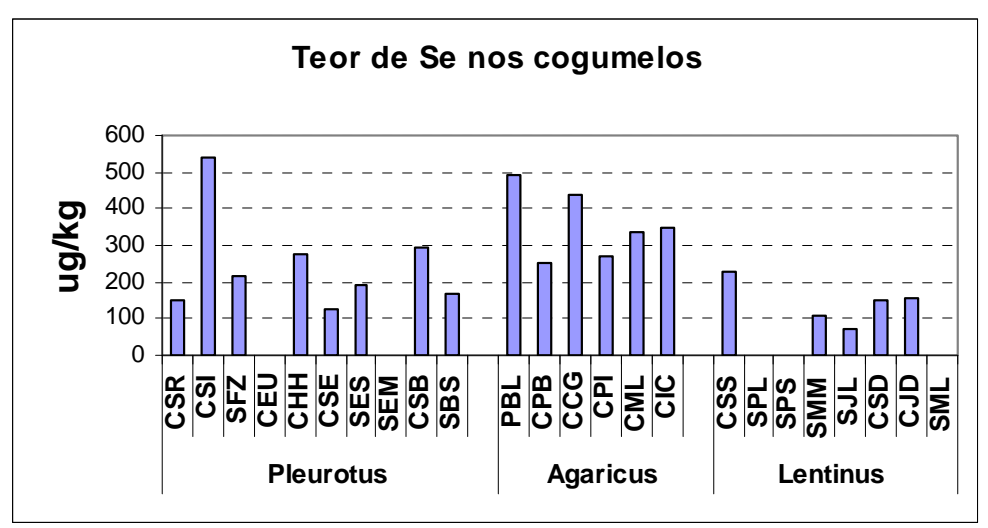

Figura 4.10- Distribuição dos teores de selênio nas diferentes espécies de cogumelos

De todos os elementos estudados neste trabalho, o selênio foi encontrado abaixo do limite de detecção deste elemento para a maioria das amostras.

A mais alta concentração de selênio foi verificada na amostra pertencente ao gênero Pleurotus na espécie P.ostreatoroseus $\left(539 \mu \mathrm{g} \mathrm{kg}^{-1}\right)$.

MANZI e col. (2001) analisaram amostras de cogumelos comestíveis Agaricus bisporus, Lentinus edodes e Pleurotus ostreatus na região da Finlândia e também verificaram uma variação de selênio entre as espécies analisadas. A concentração do elemento Se na amostra de Pleurotus ostreatus obtida por estes pesquisadores foi de $150 \mu \mathrm{g}$ $\mathrm{kg}^{-1}$, próximo ao determinado neste trabalho no mesmo tipo de cogumelo $\left(190 \mu \mathrm{g} \mathrm{kg}^{-1}\right)$. 
Dados obtidos por JANSSON e KUTTI (2004) demonstram que o elemento selênio pode ser encontrado na espécie Lentinus edodes na concentração de $330 \mu \mathrm{g} \mathrm{kg}^{-1}$, sendo este valor superior ao determinado neste trabalho para mesma espécie. A diferença da concentração de um mesmo elemento entre amostras da mesma espécie pode ocorrer por vários fatores, dentre eles, a idade do corpo de frutificação do cogumelo, a região de cultivo, o tipo de substrato em que se desenvolveu e a parte do cogumelo que foi analisada, uma vez que existe uma diferença na concentração de alguns elementos nas diferentes partes do cogumelo (estipe ou píleo) (KALAC e SVOBODA, 1999).

\subsection{Sódio em cogumelos}

Sódio é o principal componente do fluido extracelular e exerce uma função osmótica (BELITZ e col., 2004)

Dados reportados por MARCONDELLI e col. (2004) relatam que altos níveis de sódio na alimentação, aumentam a excreção de cálcio pela urina, causando alteração no balanço desse mineral.

Um grande problema relacionado com a ingestão excessiva de sódio é a hipertensão arterial ou pressão alta. A hipertensão arterial é um aumento da pressão interna dos vasos sanguíneos podendo levar à ruptura dos mesmos, em especial, de capilares. 


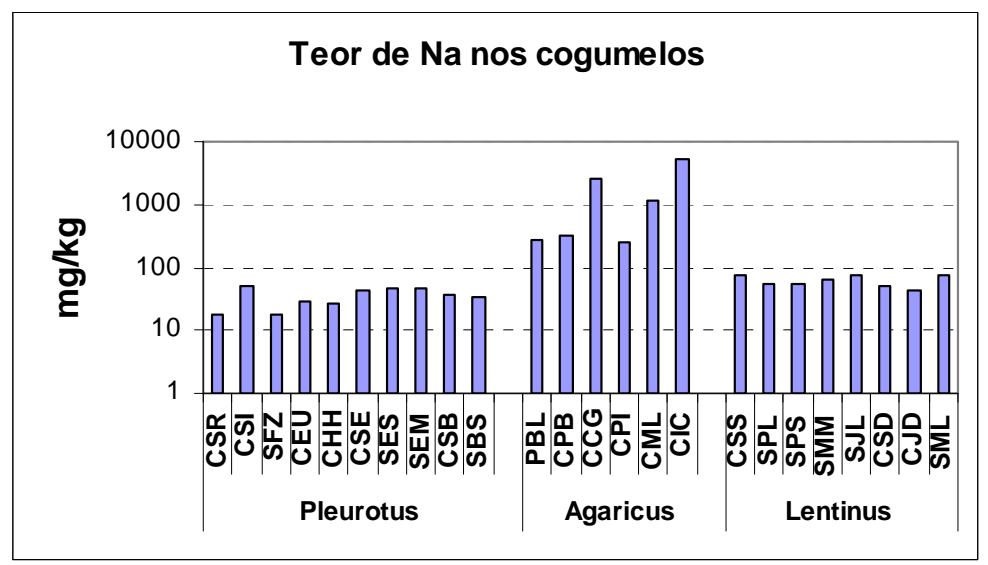

Figura 4.11- Distribuição dos teores de sódio nas diferentes espécies de cogumelos

Segundo STURION e RANZANI (2000) os cogumelos do gênero Pleurotus, em especial as espécies hiratake e shimeji podem ser classificados como alimentos ou condimentos no realce do sabor para pacientes com hipertensão ou outras doenças cardíacas, onde há restrição de sódio, pois os mesmos apresentam valores muitos baixos deste mineral. Os resultados do presente trabalho comprovaram esta afirmação, como pode ser observado na Figura 4.11, onde as espécies do gênero Pleurotus apresentaram valores de sódio inferiores em relação à espécie dos outros gêneros analisados.

Espécies de cogumelos Pleurotus ostreatus, Pleurotus eringui e Lentinus edodes coletadas na Itália foram analisadas por MANZI e col..(1998), onde puderam verificar que os níveis de $\mathrm{Na}$ variam muito entre as espécies, e sua concentração é também baixa.

No gênero Agaricus ocorreu a maior concentração de sódio em relação aos outros, principalmente na amostra champignon de Paris em conserva $\left(5476 \mathrm{mg} \mathrm{kg}^{-1}\right)$. A amostra champignon de Paris in natura de São Paulo também apresentou um valor elevado em relação as outras $\left(2498 \mathrm{mg} \mathrm{kg}^{-1}\right)$, este resultado pode estar relacionado ao tratamento desta amostra pelo produtor, pois de acordo com BONONI (1999), alguns agricultores conservam champignon de Paris em uma mistura de "salmoura" contendo cloreto de sódio. 


\subsection{Zinco em cogumelos}

Zinco é o segundo elemento traço mais abundante no corpo humano. É um componente essencial para a atividade de mais de 300 enzimas e estabilizador de estruturas moleculares de constituintes citoplasmáticos. Participa da síntese e da degradação de carboidratos, lipídios, proteínas e ácidos nucléicos (COZZOLINO, 2005).

Como componente estrutural e/ou funcional de várias metaloenzimas e metaloproteínas, o zinco participa de muitas reações do metabolismo celular, incluindo processos fisiológicos, tais como função imune, defesa antioxidante, crescimento e desenvolvimento (COZZOLINO, 2005).

A alimentação é a principal fonte de zinco no organismo humano. Zinco é encontrado em diversos alimentos como nas ostras, carnes vermelhas, aves, alguns pescados, mariscos, favas e nozes (SEMMLER, 2007).

Atualmente, inúmeras pesquisas têm sido realizadas na determinação de zinco nos cogumelos (OUZOUNI e col., 2007; YAMAÇ e col., 2006 e TÜZEN e col., 2003).

A Figura 4.12 apresenta os valores encontrados nos três gêneros de cogumelos estudados

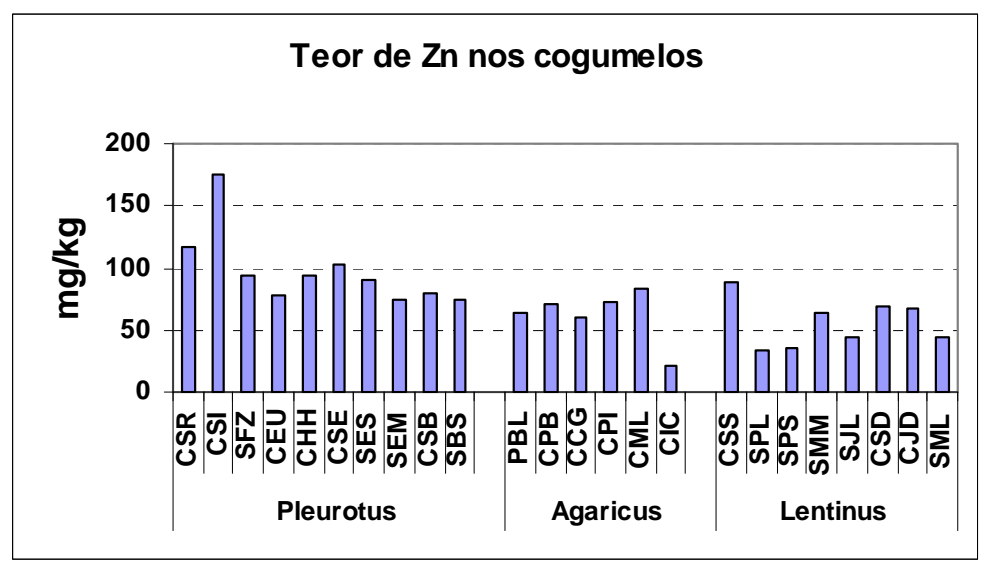

Figura 4.12- Distribuição dos teores de zinco nas diferentes espécies de cogumelos 
Os maiores valores encontrados para o elemento zinco foram nas amostras do gênero Pleurotus. A concentração do elemento $\mathrm{Zn}$ nos cogumelos do gênero Pleurotus variou de 75 a $175 \mathrm{mg} \mathrm{kg}^{-1}$, sendo a maior concentração encontrada na espécie Pleurotus ostreatoroseus. YAMAÇA e col. (2007) analisaram cogumelos comestíveis coletados em florestas na Turquia, obtendo valores entre 45,20 e 173,80 $\mathrm{mg} \mathrm{kg}^{-1}$.

Este elemento é bastante estudado em cogumelos, havendo inúmeros relatos na literatura (MARZANO e col., 2001; RANDA e KUCERA 2003). SANMEE e col.(2002) determinaram $\mathrm{Zn}$ em amostras de cogumelos comestíveis selvagens na região da Tailândia obtendo valores entre 37,8 a $253 \mathrm{mg} \mathrm{kg}^{-1}$.

A menor concentração de Zn esteve presente no gênero Agaricus na amostra de Agaricus bisporus em conserva $\left(22 \mathrm{mg} \mathrm{kg}^{-1}\right)$.

DIAS e col. (2003) estudaram a espécie $P$. ostreatus cultivada em diferentes substratos (casca de café; palha de milho; palha de feijão; farelo de trigo). Os resultados variaram de 9,19 $\mathrm{mg} \mathrm{kg}^{-1}$ a $110,1 \mathrm{mg} \mathrm{kg}^{-1}$, de acordo com o substrato em que se desenvolveu. Portanto, mesmo em amostras da mesma espécie, alguns minerais diferem na concentração quando cultivados em substratos diferentes.

OUZOUNI e RIGANAKOS (2006) obtiveram em cogumelos da espécie Pleurotus ostreatus coletados na região da Grécia, a concentração de $62,4 \mathrm{mg} \mathrm{kg}^{-1}$, sendo este valor inferior ao determinado neste trabalho na mesma espécie de cogumelo.

Os cogumelos podem contribuir significativamente com a ingestão de zinco, uma vez que os níveis encontrados nas amostras analisadas foram de 22 a $175 \mathrm{mg} \mathrm{kg}^{-1}$, valores próximos aos encontrados em alimentos ricos em $\mathrm{Zn}$, como nozes $\left(28 \mathrm{mg} \mathrm{kg}^{-1}\right)$, aves $\left(87 \mathrm{mg} \mathrm{kg}^{-1}\right)$ e carne vermelha (148 $\left.\mathrm{mg} \mathrm{kg}^{-1}\right)$ (COZZOLINO, 2005, TACO, 2006) 


\subsection{Considerações Finais}

Para resumir todos os dados obtidos neste trabalho e facilitar a visualização, a Tabela 4.9 apresenta os valores médios e desvio padrão, com o intervalo de concentração para todos os elementos determinados nos três gêneros de cogumelos comestíveis. Os valores médios, desvio-padrão, erro-padrão da estimativa e os outliers (valores discrepantes) estão representados nas Figuras Box Plot a seguir (Figuras 4.13 e 4.14).

O Box-Plot trata-se de um tipo de gráfico que tem como característica principal a visualização de várias informações simultaneamente, sendo especialmente útil para mostrar a dispersão de um grupo de dados e as diferenças que existem entre estes grupos. 
Tabela 4.9: Média e Desvio Padrão dos elementos determinados nos 3 gêneros de cogumelos comestíveis

\begin{tabular}{|c|c|c|c|}
\hline \multirow{2}{*}{ Elemento } & \multicolumn{3}{|c|}{ Gêneros } \\
\hline & Pleurotus & Agaricus & Lentinus \\
\hline $\operatorname{Br}\left(\mathrm{mg} \mathrm{kg}^{-1}\right)$ & $\begin{array}{c}0,93 \pm 0,82 \\
(0,30-2,31)^{\mathrm{a}} \\
\end{array}$ & $\begin{array}{c}2,14 \pm 1,15 \\
(0,85-4,14) \\
\end{array}$ & $\begin{array}{c}0,26 \pm 0,22 \\
(0,11-0,80) \\
\end{array}$ \\
\hline $\mathrm{Fe}\left(\mathrm{mg} \mathrm{kg}^{-1}\right)$ & $\begin{array}{r}89 \pm 38 \\
(31-164) \\
\end{array}$ & $\begin{array}{l}146 \pm 75 \\
(56-251) \\
\end{array}$ & $\begin{array}{l}29,7 \pm 11,4 \\
(21,7-48)\end{array}$ \\
\hline$K\left(\mathrm{mg} \mathrm{kg}^{-1}\right)$ & $\begin{array}{r}22130 \pm 5941 \\
(12470-31559 \\
\end{array}$ & $\begin{array}{l}28573 \pm 15951 \\
(5194-53120) \\
\end{array}$ & $\begin{array}{c}18978 \pm 2224 \\
(14215-20674)\end{array}$ \\
\hline $\mathrm{Na}\left(\mathrm{mg} \mathrm{kg}^{-1}\right)$ & $\begin{array}{c}35 \pm 12 \\
(18-51,5) \\
\end{array}$ & $\begin{array}{l}1668 \pm 2059 \\
(243-5476) \\
\end{array}$ & $\begin{array}{l}61 \pm 12 \\
(44-76) \\
\end{array}$ \\
\hline Rb( $\left.\mathrm{mg} \mathrm{kg}^{-1}\right)$ & $\begin{array}{c}31 \pm 29 \\
(10,5-107) \\
\end{array}$ & $\begin{array}{c}20,9 \pm 17,5 \\
(5,2-48)\end{array}$ & $\begin{array}{c}54 \pm 45 \\
(15,7-160)\end{array}$ \\
\hline $\mathrm{Zn}\left(\mathrm{mg} \mathrm{kg}^{-1}\right)$ & $\begin{array}{r}98 \pm 30 \\
(75-175) \\
\end{array}$ & $\begin{array}{c}62 \pm 21 \\
(22-84) \\
\end{array}$ & $\begin{array}{l}56 \pm 19 \\
(34-88) \\
\end{array}$ \\
\hline $\operatorname{As}\left(\mu g k^{-1}\right)$ & $\begin{array}{l}53 \pm 19 \\
(26-80) \\
\end{array}$ & $\begin{array}{l}244 \pm 161 \\
(94-433) \\
\end{array}$ & $\begin{array}{l}139 \pm 137 \\
(20-394) \\
\end{array}$ \\
\hline Co $\left(\mu g k^{-1}\right)$ & $\begin{array}{l}25 \pm 16 \\
(8-50)\end{array}$ & $\begin{array}{c}31 \pm 29 \\
(7,7-80,7)\end{array}$ & $\begin{array}{l}41 \pm 19 \\
(19-75)\end{array}$ \\
\hline $\operatorname{Cr}\left(\mu g k^{-1}\right)$ & $\begin{array}{l}233 \pm 148 \\
(91-552) \\
\end{array}$ & $\begin{array}{c}695 \pm 474 \\
(255-1362) \\
\end{array}$ & $\begin{array}{r}323 \pm 328 \\
(91-1034) \\
\end{array}$ \\
\hline $\mathrm{Cs}\left(\mu \mathrm{g} \mathrm{kg} \mathrm{g}^{-1}\right)$ & $\begin{array}{l}166 \pm 69 \\
(91-276) \\
\end{array}$ & $\begin{array}{l}171 \pm 114 \\
(41-365) \\
\end{array}$ & $\begin{array}{c}521 \pm 332 \\
(183-1179)\end{array}$ \\
\hline $\operatorname{Se}\left(\mu g \mathrm{~kg}^{-1}\right)$ & $\begin{array}{l}246 \pm 133 \\
(128-539)\end{array}$ & $\begin{array}{c}357 \pm 95 \\
(250-495)\end{array}$ & $\begin{array}{c}143 \pm 59 \\
(71-229)\end{array}$ \\
\hline
\end{tabular}

a (faixa de concentração) 

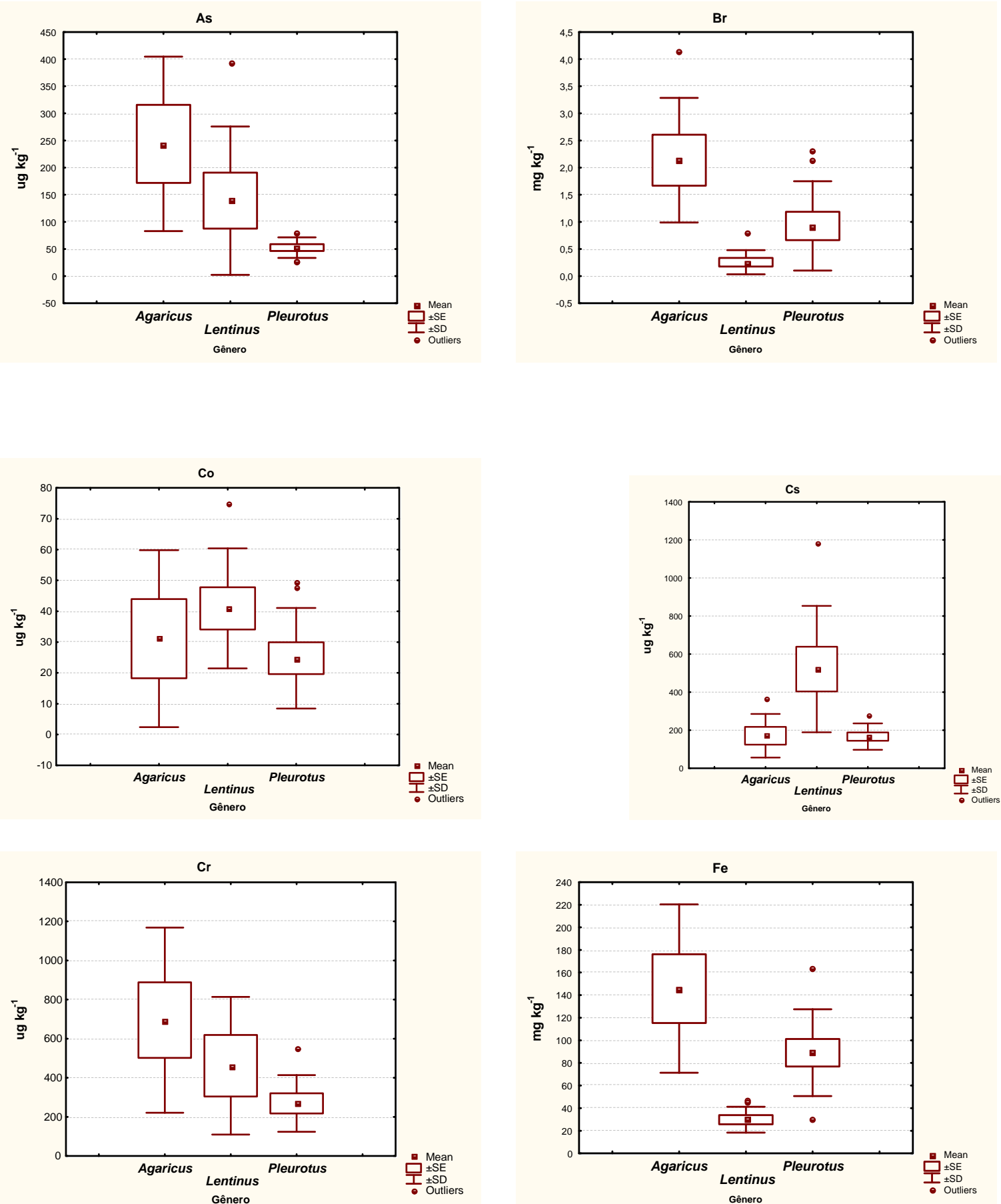

Figura 4.13- Concentração de As, $\mathrm{Br}, \mathrm{Co}, \mathrm{Cs}, \mathrm{Cr}$ e Fe para diferentes gêneros de cogumelos 

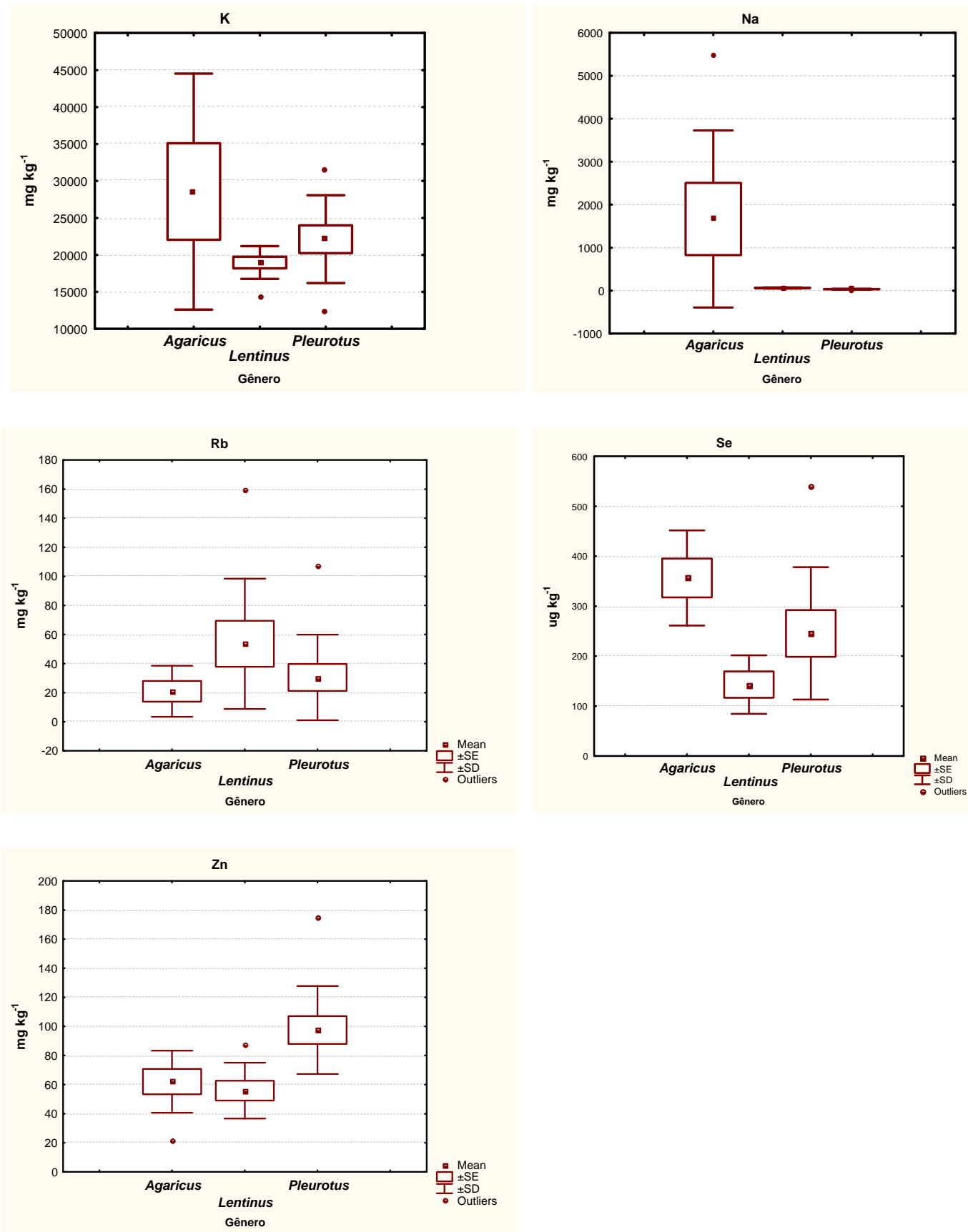

Figura 4.14-Concentrações de K, Na, Rb, Se e Zn

para diferentes gêneros de cogumelos

Nos três gêneros de cogumelos comestíveis estudados neste trabalho, houve variações nas concentrações dos elementos determinados. As diferenças ocorreram tanto dentro de amostras da mesma espécie, como também em espécies diferentes do mesmo gênero. Este resultado pode estar relacionado ao fato de que as amostras analisadas eram 
provenientes de marcas e/ou procedências diferentes, portanto as cepas ou linhagens podem ter contribuído para essa diferença. Cabe ressaltar que em alguns casos as empresas apenas comercializam os cogumelos, comprando-os de vários produtores e apenas embalando-os e distribuindo-os, sendo assim, uma mesma espécie pode ter sido cultivada em diferentes substratos. Os diferentes substratos utilizados para o cultivo de cogumelos podem alterar a composição dos elementos nos cogumelos (STURION e OETTERER,1995).

Inúmeros são os trabalhos realizados na investigação do melhor substrato (composto), para o desenvolvimento dos cogumelos comestíveis. As pesquisas buscam um substrato que aumente a produtividade dos cogumelos, sem a diminuição na concentração das proteínas, fibras, vitaminas e minerais (ROSSI e col., 2002; MODA e col., 2005; PHILIPPOUSSIS, 2006).

A utilização dos diversos tipos de substratos pelos cogumelos depende de sua capacidade de secretar as enzimas celulase, hemicelulase e ligninase, liberando nutrientes para seu crescimento (ROSSI e col., 2001).

Conforme pode ser observado nos gráficos Box-Plot, a espécie Pleurotus ostreatoroseus, do gênero Pleurotus, apresentou uma maior quantidade de outliers (valores discrepantes), em relação a todas as amostras estudadas. Os elementos que apresentaram valores discrepantes foram: As $\left(80 \mu \mathrm{g} \mathrm{kg}{ }^{-1}\right)$, Co $\left(50 \mu \mathrm{g} \mathrm{kg}^{-1}\right), \mathrm{Zn}\left(175 \mathrm{mg} \mathrm{kg} \mathrm{kg}^{-1}\right)$, Cs $\left(276 \mu \mathrm{g} \mathrm{kg}^{-1}\right), \mathrm{Fe}\left(164 \mathrm{mg} \mathrm{kg}^{-1}\right)$ e $\left(31 \mathrm{mg} \mathrm{kg}^{-1}\right)$, Se $\left(539 \mu \mathrm{g} \mathrm{kg}^{-1}\right), \mathrm{Br}\left(2,31 \mathrm{mg} \mathrm{kg}^{-1}\right)$ e $\mathrm{K}\left(31559 \mathrm{mg} \mathrm{kg}^{-1}\right)$ e $\left(12470 \mathrm{mg} \mathrm{kg}^{-1}\right)$.

MODA e col. (2005) analisaram o rendimento de cogumelos do gênero Pleurotus em substrato produzido com bagaço de cana de açúcar lavado e sem suplementação, obtendo em suas amostras $163 \mathrm{mg} \mathrm{kg}^{-1}$ de $\mathrm{Fe}, 192 \mathrm{mg} \mathrm{kg}^{-1}$ de $\mathrm{Zn}$ e $43200 \mathrm{mg} \mathrm{kg}^{-1}$ de $\mathrm{K}$, sendo estes valores próximos ao encontrados na espécie Pleurotus 
ostreatoroseus, indicando uma possível influência na concentração destes elementos pelo substrato onde o cogumelo é cultivado.

O substrato utilizado pelos produtores da região de Mogi das Cruzes segundo BONONI e col. (1999) é um composto preparado à base de cana de açúcar enriquecido com cerca de $1 \%$ de farelo de soja ou farelo de arroz e $18 \%$ de esterco. Os cogumelos do gênero Agaricus necessitam para o seu desenvolvimento, principalmente, fonte de nitrogênio e carbono, a partir dos quais fabricam substâncias necessárias à sua estrutura. As principais fontes fornecedoras destes elementos ao cogumelo são a palha de arroz como fonte de carbono e o esterco como fonte de nitrogênio. As maiores médias obtida na concentração dos elementos: $\operatorname{Br}\left(2,14 \mathrm{mg} \mathrm{kg}^{-1}\right), \mathrm{Cr}\left(695 \mu \mathrm{g} \mathrm{kg}^{-1}\right)$, Fe $\left(146 \mathrm{mg} \mathrm{kg}{ }^{-1}\right)$, $\mathrm{K}\left(28573 \mathrm{mg} \mathrm{kg}^{-1}\right)$, Se $\left(357 \mu \mathrm{g} \mathrm{kg}^{-1}\right)$, nos três gêneros estudados, encontram-se no gênero Agaricus. Este resultado pode estar relacionado ao tipo de substrato (composto) utilizado pelos produtores.

A variação encontrada na concentração dos elementos nos três gêneros está de acordo com os resultados reportados na literatura, para amostras de cogumelos comestíveis cultivados ou selvagens (JANSSON e KUTTI, 2004; OUZOUNI e RIGANAKOS, 2006; STURION e RANZANI, 2000; YAMAÇ e col., 2006). 


\section{CAPÍTULO 5}

\section{CONCLUSÃO}

O método de análise por ativação com nêutrons instrumental utilizado no presente estudo, demonstrou-se eficaz para determinar as concentrações dos elementos As, Br, Co, Cr, Cs , Fe, K, Na, Rb, Se e Zn, nas amostras de cogumelos comestíveis com exatidão e precisão adequada, como pôde ser confirmado pela análise dos materiais de referência analisados.

As amostras de cogumelos comestíveis apresentaram diferenças nas concentrações dos elementos, entre os gêneros Agaricus, Lentinus e Pleurotus. Essa diferença pode estar relacionada às características de absorção de nutrientes, ao tipo de substrato utilizado no cultivo, ao grau de maturação, a maneira de preservação para cada gênero ou ainda a forma de tratamento para o consumo, com ou sem lavagem.

Nos três gêneros de cogumelos, o elemento determinado em alta concentração foi o potássio, apresentando concentrações em média de 22130 mg kg ${ }^{-1}$ no gênero Pleurotus, 28573 mg kg-1 no gênero Agaricus e $18978 \mathrm{mg} \mathrm{kg}^{-1}$ no gênero Lentinus. Portanto os cogumelos podem contribuir significativamente com a ingestão deste elemento.

Os cogumelos dos gêneros Pleurotus e Lentinus podem ser utilizados como alimento para pessoas com restrição ao elemento sódio, uma vez que a concentração obtida para este elemento foi baixa. 
O gênero Agaricus apresentou altas concentrações de sódio em relação aos outros, este fato pode estar relacionado ao tipo de tratamento sofrido por este cogumelo pós-colheita, pois os mesmos são lavados com solução branqueadora de bissulfito de sódio e em alguns casos conservados em salmoura até o momento de consumo.

Os cogumelos podem ser podem ser considerados como fontes de Fe e Zn, principalmente as espécies pertencentes ao gênero Pleurotus.

A presença de arsênio nas amostras não pode ser considerada como risco a saúde humana, uma vez que a concentração deste elemento nas amostras foi baixa e a média de consumo deste alimento para a população brasileira é relativamente pequena.

Embora os cogumelos não possam ser considerados como fonte de todos os elementos determinados, eles podem contribuir com o aporte dos mesmos na dieta da população brasileira

Uma vez que a metodologia foi eficaz na determinação dos elementos presentes nos cogumelos, estudos futuros relacionados ao substrato (composto) utilizados no cultivo dos mesmos contribuiriam para a complementação deste estudo. 


\section{REFERÊNCIAS BIBLIOGRÁFICAS}

ARORA, D. Mushrooms demystified: A comprehensive guide to the fleshy fungi. Ten Speed Press, California, 1986.

ARUGUETE, D.M.; ALDSTADT, J.H.; MUELLER, G.M. Accumulation of several heavy metals and lanthanides in mushrooms (Agaricalis) from the Chicago region.The Science of the Environment,v. 224, p 43-56, 1998.

BARROS, L.; BAPTISTA, P.; CORREIA, D.M.; CASAL, S.; OLIVEIRA, B.; FERREIRA, I. C. F. R. Fatty acid and sugar compositions, and nutritional value of five wild edible mushrooms from Northeast Portugal. Food Chemistry, v.105, p. 140-145, 2007.

BELITZ, H.D.; GROSCH, W.; SCHIEBERLE, P. Food Chemistry. Germany, Springer, 2004. cap. 7 Minerals. p.427-428.

BODEK, P.; GALBAVY, S. Hypercholesterolemic and ant-artherogenic of oyster mushroom (Pleurotus ostreatus) in rabbit. Nahrung, v. 43, p. 339-342, 1999.

BONONI, V.L.; CAPELARI, M.; MAZIERO, R.; TRUFEN, S.F.B. Cultivo de cogumelos comestíveis. Íconi .São Paulo, S.P, 1999.

BONONI, V. L. R. O cultivo de Agaricus bisporus no Brasil. Anais do $1^{\text {o }}$. Simpósio Internacional sobre cogumelos, alimentação, saúde, tecnologia e meio ambiente no Brasil. Brasília: Ed. Urben, A. F.;Santos, J. K. P.;Oliveira, H. C. B.: Embrapa, agosto 2003. p. 24-31.

BRATAKOS, M.S.; KANAK, H.C.; VASILIOV, W.A.; IOANNAOU, P.V. The nutritional selenium status of healthy Greeks. Science of the Total Environment. v.91. p.161-176

CHANG, S.T.; MILLES, P.G. Edible Mushrooms and their cultivation. CRC Press, inc Boca Raton, Florida, 1989. 
CHANG, S.T.; MILES, P.G. Mushrooms Cultivation.Nutritional Value Medicinal Effect and Envioramental Impact CRC Press, inc Boca Raton, 2004.

COCCHI, L. ; VESCOVI,L. ; PETRINI,L.E. ; PETRINI, O. Heavy metals in edible mushrooms in Italy. Food Chemistry, v.98, p. 277-284, 2006.

COLAUTO, N. B.; EIRA, A. F. Avaliação quantitativa da comunidade bacteriana na camada de cobertura de Agaricus bisporus. Energia na Agricultura, Botucatu, v. 13, n. 2, p. 15-26, 1998.

COUTINHO, L.N. Cultivo de Espécies de Cogumelo Comestíveis.

Disponível em: http://www.geocities.com/esabio.geo/cogumelo/agaricus.htm Acesso em: 13 maio 2004.

COZZOLINO, S.M.F. Biodisponibilidade de nutrientes. Manole, Barueri,São Paulo, 2005.

CURRIE, L. A., Nomenclature in evaluation of analytical methods including detection and quantification capabilities (IUPAC recommendations 1995). Pure and Applied Chemistry, v.67, p.1669-1723, 1995.

CVE- Centro de Vigilância Epidemiológica. Manual das doenças transmitidas por alimentos, Toxinas dos cogumelos. Secretaria de Estado de Saúde de São Paulo, 2003.

Disponível em http://www.cve.saude.sp.gov.br/htm/hidrica/cogumelos.htm Acesso em: 9 jan. 2008

DIAS, E. S.; KOSHIKUMO, E.M.S.; SCHWAN, R. F.; SILVA, R. Cultivo do cogumelo Pleurotus sajor caju em diferentes resíduos agrícolas. Ciência e Agrotécnica., Lavras v.27, n. 6, p. 1363-1369, 2003.

EIRA, A.F.; BRAGA, G.C., Manual do cultivo teórico e pratico do cultivo de cogumelos comestíveis, Fundação de Estudos e Pesquisas Agrícolas Florestais. p.34-36, 1997. 
EIRA, A.F. Cultivo do “cogumelo-do-sol” (Agaricus blazei (Murrill) Heinemann.: Ed. Aprenda Fácil, Viçosa, 203p, 2003.

EKANEM, E. O.; UBENGAMA, V. S. Chemical composition, anti-nutritional factors and shelf-life of oyster mushroom (Pleurotus ostreatus). Journal of Food Science Technology, v. 39, n. 6, p. 635-338, 2002.

EMBRAPA Empresa Brasileira de Pesquisa Agropecuária- Boletim de pesquisa e desenvolvimento n 48 Análise da comercialização e do consumo de cogumelos comestíveis no mercado do Distrito Federal e entorno. Brasília, 2003.

EMBRAPA- Empresa Brasileira de Pesquisa Agropecuária.- Exposição de Cogumelos Comestíveis e Medicinais, em feira de Botânica. Brasília, 2005.

Disponível em:http://www.portaldoagronegocio.com.br/index.php?p=noticia\&\&edN=4895 Acesso em: 20 dez. 2007.

EMBRAPA Recursos Genéticos e Biotecnologia - III Simpósio Internacional sobre cogumelos no Brasil e II Simpósio nacional sobre cogumelos comestíveis. de 14 a 16 Set em São Paulo SP, 2006.

FORTES, R.C.; NOVAIS, M.R. C. G. Efeitos da suplementação dietética com cogumelos Agaricales e outros fungos medicinais na terapia contra o câncer. Revista Brasileira de Cancerologia, v.52, p. 363-371, 2006.

FURLANI, R. P. Z Valor nutricional de cogumelos comestíveis cultivados no Brasil. 2004. Tese (Doutorado) - Universidade Estadual de Campinas, Campinas.

FURLANI, R. P. Z. ; GODOY. H. T. Valor nutricional de cogumelos comestíveis. Revista do Instituto Adolfo Lutz. v. 64, n. 2,. p. 149-154, 2005.

FURLANI, R. P. Z. ; GODOY. H. T. Valor nutricional de cogumelos comestíveis. Revista Ciência e Tecnologia de Alimentos.v.27, n. 1,. p. 154-157, 2007. 
JANSSON, L. M.; KUTTI, L. Micronutrients in edible mushrooms. Human Nutrition.. v.5, p.1-8, 2004.

GUERREIRO, R. T Glossário Ilustrado de Fungos: Termos e Conceitos Aplicados a Micologia. Rio Grande do Sul. UFRGS 2 ${ }^{\text {a }}$ Edição,2003.

HERNÁNDEZ, D.; SANCHEZ, J. E.;YAMASAKI, K. A simple procedure for preparing substrate for Pleurotus ostreatus cultivation. Bioresource Technology, v.90, n.2, p.145-150, 2003.

HERRERA,O.M. Produção, economicidade e parâmetros energéticos do cogumelo Agaricus blazei:Um enfoque de cadeia produtiva 2001.Tese (doutorado) - Faculdade de Ciências Agronômicas da Unesp, São Paulo.

INSTITUTE OF NUCLEAR CHEMISTRY AND TECHNOLOGY (INCT) Certificate of analysis, Mixed Polish Herbs INCT-MPH2, Warszawa, Polônia, October 31, 2002

INSTITUTE OF NUCLEAR CHEMISTRY AND TECHNOLOGY (INCT) Certificate of analysis Tea Leaves INCT-TL-1, Warszawa, Polônia, October 31, 2002

INTERNATIONAL ORGANIZATION FOR STANDARDIZATION- ISO/DIS 13528 Statistical methods for use in proficiency testing by interlaboratory comparisons. 66p, 2002.

ISILDAK, O.; TURKEKUL, I.; ELMASTAS, M. TUZEN, M.A.,Analysis of heavy metals in some wild-grown edible mushrooms from the middle black sea region, Turkey. Food Chemistry, v.86, p. 547-552, 2004.

ISILDAK, O.; TURKEKUL, I. ; ELMASTAS, M. ; ABOUL-ENEIN, H. Y. Bioaccumulation of Heavy Metals in Some Wild- Grown Edible Mushrooms. Analytical Letters, v. 40, p. 1099-1116, 2007.

ISILOGLU, M.; YILMAZ, F.; MERDIVAN, M. , Concentrations of trace elements in wild edible mushrooms. Food Chemistry. v. 73, p.169-175, 2001. 
KALAC, P.; SVOBODA, L., A review of trace element concentrations in edible mushrooms. Food Chemistry. v.69, p. 273-281, 1999.

KEITH, L.H.; CRUMMETT, W.; JR DEEGAN, J.; LIBBY, R.A.; TAYLOR, J.K.; WENTLER, G. Principles of environmental analysis. Analytical Chemistry. v.55, p.22102218, 1983.

KELLER, C. Radioquímica. Recife: Universitária, 1981. Tradução de: Radiochemie.

KUROZAWA, L.M. Efeitos das condições de processo na cinética de secagem de cogumelo Agaricus blazei 2005. Dissertação (mestrado) Universidade Estadual de Campinas, Campinas.

LAURENCE, J. Biologia Nova Geração, São Paulo 2005, p. 272-280

MAIHARA, V.A., Avaliação do conteúdo de Elementos Essenciais e Tóxicos em Dietas de Crianças e Idosos pelo Método de Análise por Ativação com Nêutrons. 1996. Tese (Doutorado) -Universidade de São Paulo, São Paulo.

MAIHARA, V.A.; GONZAGA, I.B.; SILVA, V.L.;FÁVARO, D.I.T.; VASCONCELLOS, M.B.A.; COZZOLINO, S.M.F. Daily dietary selenium intake of selected Brazilian population groups. Journal of Radioanalytical and Nuclear Chimestry. v. 259, n.3, p. 465-468, 2004.

MAKI, C.S; TEIXEIRA, F.F.; PAIVA, E.; MEIRELLES, L. D. P., Analyses of genetic variability in Lentinula edodes through mycelia responses to different abiotic conditions and rapid molecular markers. Brazilian Journal of Microbiology.v.32, p. 170-175, 2001.

MANZI P.; GAMBELLI L.; MARCONI S.; VIVANT V.; PIZZOFERRATO L., Nutrients in edible mushrooms: an inter-species comparative study. Istituto Nazionale della Nutrizione- Rome Italy, 1998.

MANZI, P.; PIZZOFERRATO, L.; AGUZZI, A. Nutritional value of mushrooms widely consumed in Italy. Food Chemistry, Oxford, v. 73, n. 3, p. 321-325, mai. 2001. 
MARCONDELLI, P.; MARACON, A.F.; SCHMITZ, B.A.S. Revisão de literatura sobre alimentação e saúde Universidade. Ciência e Saúde, Brasília, v.2, n.1, p 1-151, 2004.

MARZANO, F.N. ; BRACCHI, P.G.; PIZZET, P.Radioactive and conventional pollutants accumulated by edible muschrooms (Boletus sp.) are useful indicators of species origin. Environmental Research A 85, p.260-264, 2001.

MATTILA, P.; KONKO, K.; EUROLA, M.; PIHLAVA,J.; ASTOLA, J.; VAHTERISTO, L.; HIETANIEMI, V.; KUMPULAINEN, J.; VALTONEN, M.; PIIRONEN, V., Contents of vitamins, mineral elements, and some phenolic compounds in cultivated mushrooms Journal of Agricultural Food Chemistry. v.49, p.2343-2348, 2001.

MIZUNO, T.; HAGIWARA, T.; NAKAMURA, T.; ITO, H.; SHIMURA, K..; SUMIYA, T.; ASAKURA, A. Antitumor activity and some properties of water-soluble polysaccharides from "Himematsutake", the fruiting body of Agaricus blazei murill. Agriculture and Biological Chemistry, v. 54, n. 11, p. 2889-2896, 1990.

MODA, E.M.; HORII, J.; SPOTO, M.H.F. Edible mushroom Pleurotus sajor caju production on washed and supplemented sugarcane bagasse. Science Agriculture.v.62, n. 2,p. 127-132, 2005.

MOLENA, O. O Moderno Cultivo de Cogumelos. São Paulo: Nobel, 1996. 170p.

NATIONAL INSTITUTE OF STANDARDS AND TECNOLOGY (NIST) Certificate of analysis:Bovine Liver SRM 1577B, Gaithersburg, MD, August 27, 1991

NOBEL- Guia Prático de Cogumelos, São Paulo,Brasil,1999, 64p.

OBODAI, M.; CLELAND-OKINE, J.; VOWOTOR, K.A. Comparative study on the growth and yield of Pleurotus ostreatus mushroom on different lignocellulosic by-products. Journal of Industrial Microbiology and Biotechnology, V.30, P.146-149, 2003. 
OLIVEIRA, E. C. M.; OLIVEIRA, E. R.; LIMA, L.C.O.; BOAS, E. V. B. V. Composição Centesimal do Cogumelo do Sol (Agaricus blazei). III Simpósio Latino Americano de Ciências dos Alimentos- Campinas - SP,1999.

OUZOUNI, P. K.; VELTSISTAS, P. G.; PALEOLOGOS, E. K. ; RIGANAKOS, K. A. Determination of metal content in wild edible mushroom species from regions of Greece. Journal of Food Composition and Analysis. v.20, p.480-486, 2007.

PARRY, S.J. Handbook of Neutron Activation Analysis.Viridian Publishing, 2003, 243p.

PICCOT, D. Comunicação pessoal.

POLKOWSKA, M. H.; ROSSBACH, M. Preparation and characterization of a proficiency test material Polish mushroom supported by the International Atomic Energy Atomic (IAEA), Viena .Accreditation. Quality Assurance, v.12, p. 343-350, 2007.

PHILIPPOUSSIS, A.; DIAMANTOPOULOU, P.; ISRAILIDES, C. International Biodeterioration \& Biodegration, v. 59, p.216-219, 2007.

RAGUNATHAN, R.; GURUSAMY, R.; PALANISWAMY M.; SWAMINATHAN, K. Cultivation of Pleurotus spp. on various agro-residues. Food Chemistry, v. 55, n. 2, p. 139-144, 1996.

RAGUNATHAN, R..; SWAMINATHAB, K. Nutritional status of Pleurotus spp. grown on various agro-wastes. Food Chemistry v.80, p. 371-375, 2003.

RANDA,Z; KUCERA J., Trace elements in higher fungi (mushrooms) determined by activation analysis. Journal of Radionalytical and Nuclear Chemistry, v. 259, p. 99107,. 2004.

RANZANI, M. R. T. C.; STURION, G. L. Avaliação da composição em aminoácidos de Pleurotus spp. cultivados em folha de bananeira. Archivos Latinoamericanos de Nutricion. v. 48, n. 4, p. 339-348, 1998. 
ROSSI, I. H.; MONTEIRO, A. C.; MACHADO, J. O. Desenvolvimento micelial de Lentinula edodes como efeito da profundidade e suplementação do substrato. Pesquisa Agropecuária Brasileira, v.36, n.6, p.887-891, 2001.

ROSSIN, R. Especiação de arsênio inorgânico em águas por espectrometria de absorção atômica acoplada com gerador de hidratos. 2005. Dissertação (Mestrado) Universidade Estadual de Campinas, São Paulo.

SAKUMA, A. M. Avaliação da exposição humana ao arsênio no alto Vale do Ribeira, Brasil 2004 Tese (Doutorado) Universidade Estadual de Campinas, São Paulo.

SAGIR, A. ; YLLDIZ, A. Growth of mycelium of Pleurotus spp. on different grains and determination of their competition with some contaminant fungi. Acta Alimentaria, v.33, n.2, p.249-257, 2004.

SANMEE. R.; DELL. B.; LUMYONG. P.; IZUMORI. K.; LUMYONG S., Nutritive value of popular wild edible mushrooms from northern Thailand. Food Chemistry. v.82, p. 527-532, 2002.

SCHMIDT, P.; WECHSLER, F.S.; JUNIOR, F.M.V.; ROSSI, P. Valor nutritivo do feno de braquiária amonizado com uréia ou inoculado com Pleurotus ostreatus Revista Brasileira de Zootecnia. v.32, n.6, p.1866-1871, 2003.

SLEJKOVEC,.Z.;BYRNE, A.R.; STIJE, T.; GOESSLER, W.; IRGOLIC.K. Arsenic compounds in higher fungi. Applied. Organometallic. Chemistry, 11 (1997) 673.

SEMMLER, M.G.M.C. Biomonitoração de Hg, Cd, Pb e outros elementos em áreas costeiras do estado de São Paulo por meio do mexilhão transplantado Perna perna (Linnaeus, 1758) 2007- Tese (Doutorado) Universidade de São Paulo, São Paulo. 
SESLI, E., TUZEN, M., Micro and macroelement contents of edible wild growing Mushrooms in Artvin Province of Turkey. Journal of Chemistry. v.18, n.2, p.1423-1429, 2006.

SHIBATA, C.K.; DEMIATE, I.M. Cultivo e análise da composição química do cogumelo do Sol (Agaricus blazei Murril). UEPG Ciências Biológicas Saúde, Ponta Grossa. v.9, p.21-32, 2003.

SILVA , E.G.; DIAS, E.S.; SIQUEIRA, F.G.; SCHWAN, R.F. Análise química de corpos de frutificação de Pleurotus sajor caju cultivado em diferentes concentrações de nitrogênio. Ciência e Tecnologia de Alimentos. v. 27, n.1, 2007.

STURION, G. L.; OETTERER, M. Composição Química de Cogumelos Comestíveis (Pleurotus spp.) Originados de Cultivos em Diferentes Substratos. Ciência e Tecnologia de Alimentos, v. 15, n. 2, p. 189-193, 1995.

STURION, G. L.; RANZANI, M. R. T. C., Composição em minerais de cogumelos comestíveis no Brasil - Pleurotus ssp e outras espécies desidratadas. Archivos Latinoamericanos de Nutrición. v.50, n.1, p. 102-108, 2000.

SUGUI, M. M.; ALVES de LIMA, P. L.; DELMANTO, R. D.; EIRA, A. F.; SALVADORI, D. M. F.; Ribeiro, L. R. Antimutagenic effect of Lentinula edodes (BERK.) Pegler mushroomand possible variation among lineages. Food and Chemical Toxicology; v. 41, n. 4, p.447-602, 2003.

SVOBODA, L.; KALAC, P., Concentrations of mercury, cadmium, lead and copper in fruiting bodies of edible mushrooms in an emission area of a copper smelter and mercury smelter. The Science of the Total Enrironment. v. 246, p. 61-67, 2000.

SVOBODA, L.; HAVLICKOVA, B.; KALAC, P. Contents of cadmium, mercury and lead in edible mushrooms growing in a historical silver-mining area. Food Chemistry. v.96, p. 580-585, 2006. 
TACO-Tabela Brasileira de Composição de alimentos

Disponível em: http://www.unicamp.br/nepa/taco/contar/taco_versao2.pdf Acesso:15 de maio 2008

TÜZEN, M.; TURKEKUL, I.; HASDEMIR, E.; MENDIL, D.; SARI, H. Atomic absorption spectrometric determination of trace metal contents of mushroom samples from Tokat, Turkey. Analytical Letters. v. 36, n. 7, p. 1401-1410, 2003.

URBEN, A. F., OLIVEIRA, H. C. B., VIEIRA, W., CORREIA, M. J., URIARTT, A. H., Mushrooms production by means of modified Chinese technology.Brasília: EMBRAPA, 2001, 151p.

URBEN, A.F.; SIQUEIRA, P. Cogumelos e suas Delicias. Brasília, D.F., EMBRAPA Informação Tecnológica ,2003.

VETTER, J., Data on sodium content of common edible mushrooms. Food Chemistry. v.81, p.589-513, 2003.

VETTER, J., Arsenic content of some edible muschroom species.European Food Research and Technology A. v.219, p.71-74, 2004.

WORLD HEALTH ORGANIZATION (WHO), Trace Elements in Human Nutrition and Health, World Health Organization, Geneva, 1996.

YAMAÇ, M., YILDIZ, D., SARIKURKCU,C., CELIKKOLLU, SOLAK,M.H, Heavy metals in some edible mushrooms from the Central Analolia, Turkey. Food Chemistry. v.103, p. 263- 267, 2007.

YOSHIZAWA, K.; ASCHERIO, A.; MORRIS, J.S.; STAMPFER, M.J.; GIOVANNUCCI, E.; BASKETT, C.K.; WILLETT, W.C.; RIMM, E.B., Prospective Study of Selenium Levels in Toenails and Risk of Coronary Heart Disease in Men. American Journal of Epidemiology. v. 158, p. 852-860, 2003 